\title{
NP-MHTGR Fuel Development Program Results
}

\author{
J. T. Maki \\ D. A. Petti \\ R. R. Hobbins \\ R. K. McCardell \\ E. L. Shaber \\ F. H. Southworth
}

October 2002

Idaho National Engineering and Environmental Laboratory Bechtel BWXT Idaho, LLC 


\title{
NP-MHTGR Fuel Development Program Results
}

J. T. Maki

D. A. Petti

R. R. Hobbins

R. K. McCardell

E. L. Shaber

F. H. Southworth

October 2002

Idaho National Engineering and Environmental Laboratory Idaho Falls, Idaho 83415

\author{
Prepared for the \\ U.S. Department of Energy \\ Under DOE Idaho Operations Office \\ Contract DE-AC07-99ID13727
}







\section{EXECUTIVE SUMMARY}

In August 1988, the Secretary of Energy announced a strategy to acquire New Production Reactor capacity for producing tritium. The strategy involved construction of a New Production Modular High Temperature Gas-Cooled Reactor (NP-MHTGR) where the Idaho National Engineering and Environmental Laboratory (INEEL) was selected as the Management and Operations contractor for the project. Immediately after the announcement in August 1988, tritium target particle development began with the INEEL selected as the lead laboratory. Fuel particle development was initially not considered to be on a critical path for the project, therefore, the fuel development program was to run concurrently with the design effort of the NP-MHTGR.

During 1989, a fuel technology working group was formed which comprised members of the Department of Energy (DOE), Oak Ridge National Laboratory (ORNL), General Atomics (GA), and the INEEL. The working group identified technical uncertainties concerning the fuel that might jeopardize a favorable Record of Decision for the NP-MHTGR. Based upon these concerns, the NP-MHTGR Fuel Development Program was initiated in January 1990. The program had the following objectives:

- develop fuel fabrication processes that meet product and process specifications

- demonstrate and qualify the fuel irradiation behavior under normal and accident conditions

- develop and refine predictive fuel performance and fission product behavior capabilities.

Proof test fuel was manufactured by General Atomics and its subcontractor, Babcock \& Wilcox on laboratory scale equipment. The fuel particle configuration included four major changes from previous U.S. gas reactor fuel designs. These changes were:

- the fuel kernel was $\mathrm{UCO}$ rather than $\mathrm{UC}_{2}$ or $\mathrm{UO}_{2}$

- a protective pyrolytic carbon (PPyC) layer was added to reduce mechanical damage of the fuel particles during compacting 
- the inner pyrolytic carbon (IPyC) layer was made thicker to protect the kernel from chemical attack during $\mathrm{SiC}$ application

- seal coats were added to both sides of the PPyC layer and between the buffer and IPyC layers to prevent coating interactions.

This fuel met the fuel product specifications and had the best as-manufactured particle quality ever produced in the U.S.

Three irradiation tests were conducted to demonstrate that the proof test fuel would meet the performance goals for the NP-MHTGR. One test, designated NPR-1, was to demonstrate maximum service life conditions for temperature, burnup, and fast neutron fluence. The second test, designated NPR-2, was conducted at a lower temperature which was to be more representative of the core average temperature. These two tests were performed in the High Flux Isotope Reactor (HFIR) at ORNL. The third test, designated NPR-1A, was conducted as a backup test to NPR-1 and would increase the assurance that a bounding demonstration would be completed. This test was performed in the Advanced Test Reactor (ATR) at the INEEL.

Fuel performance models predicted no particle failures in each of the tests. However, after reaching a burnup of $48 \%$ FIMA, NPR-1A experienced its first particle failure. Continued monitoring indicated about two additional particle failures each day until the irradiation was terminated after reaching $64 \%$ FIMA, instead of its original goal of $75 \%$ FIMA. It was decided to remove NPR-1A early to allow for the earliest possible assessment of the particle failures. It was estimated that a total of 48 particles had failed. NPR-1 experienced its first particle failure at a burnup of $72 \%$ FIMA and NPR-2 at $75 \%$ FIMA. About 526 particles were estimated to have failed in NPR-1 and about 135 particles in NPR-2 after the fuel reached a burnup of $79 \%$ FIMA in each test. In total, about 700 out of the 230,000 fuel particles contained in the three tests had failed.

Shortly after the completion of the irradiation tests, DOE announced in September 1992 the closeout of the NP-MHTGR program. Work continued through to September 1993 in areas of exploratory process development of NP-MHTGR fuel, characterization of the as-manufactured proof test fuel, and postirradiation examination of the irradiated proof test fuel. 
Evidence from the as-manufactured characterization, irradiation, and postirradiation examination data indicated that irradiation-induced changes in the pyrocarbons played a dominant role in the failure of the fuel particles. It was expected that the PPyC layers would shrink and fail early in the irradation. Shrinkage was also expected in the OPyC, however, the extent of the OPyC failure was unexpected and was most likely caused by crack propagation from the $\mathrm{PPyC}$, facilitated by the seal coat. The observed widespread IPyC layer failures were most likely a result of irradiation-induced shrinkage. These failures placed large concentrations of tensile stress in the $\mathrm{SiC}$ layer adjacent to the IPyC crack tips. Crack propagation through the $\mathrm{SiC}$ layer was then the most probable cause for total particle failure.

The NP-MHTGR program demonstrated that fuel could be designed and fabricated to meet asmanufactured quality levels more stringent than previously achieved in the U.S. However, the irradiation performance of this fuel did not change appreciably from that of previous U.S. tests. These results indicate that future particle fuel designs would benefit by considering the performance of the entire system of coating layers with respect to particle integrity under irradiation. 


\section{FOREWORD}

This report documents the results of the NP-MHTGR fuel development program. It was written in the early 1990's, but never published. With the recent renewed interest in gas reactors worldwide, the authors felt it was important to publish the report for the benefit of future gas reactor programs. 


\title{
ACKNOWLEDGMENTS
}

The authors wish to acknowledge all who contributed to the NP-MHTGR fuel development program but are too numerous to mention. Instead, their affiliations will be noted:

\author{
Babcock \& Wilcox \\ Department of Energy \\ General Atomics \\ Idaho National Engineering and Environmental Laboratory \\ Oak Ridge National Laboratory
}




\section{CONTENTS}

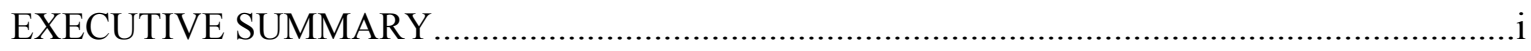

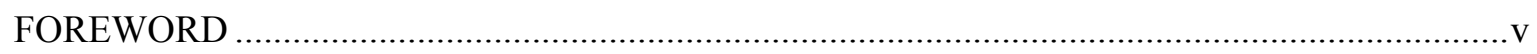

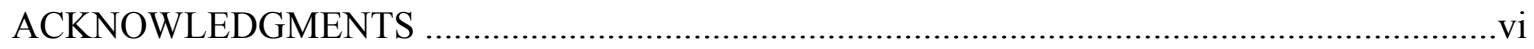

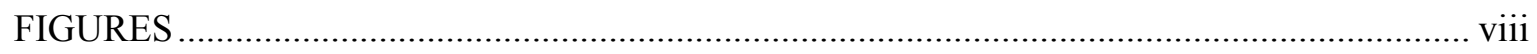

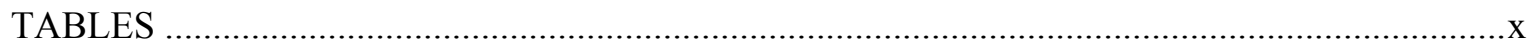

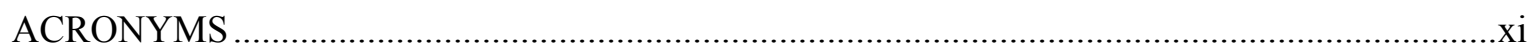

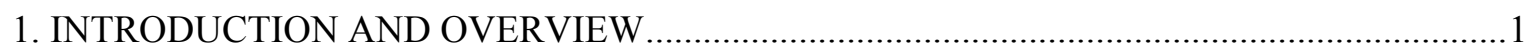

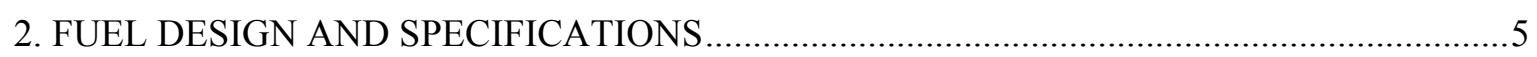

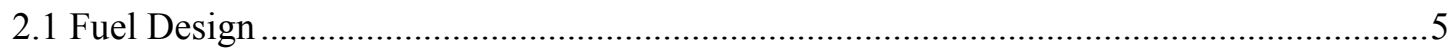

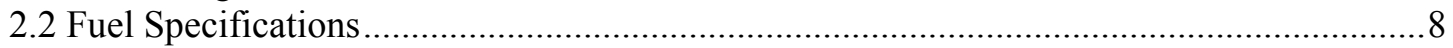

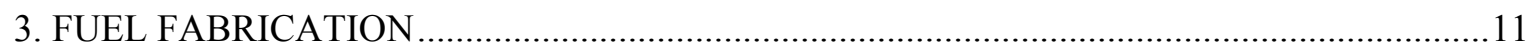

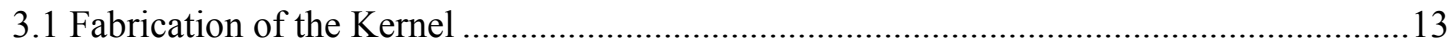

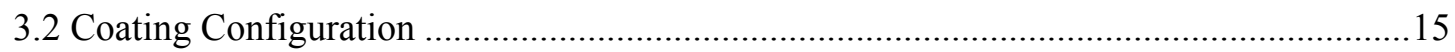

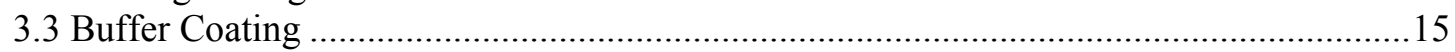

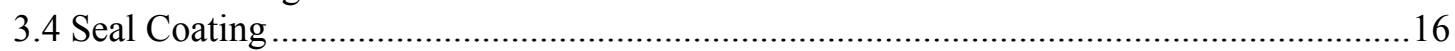

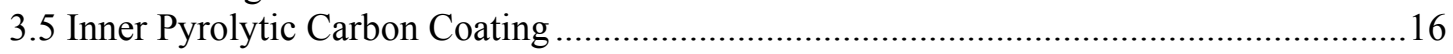

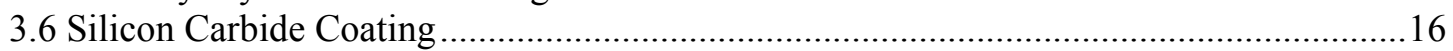

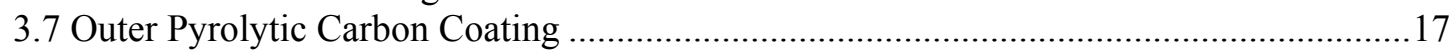

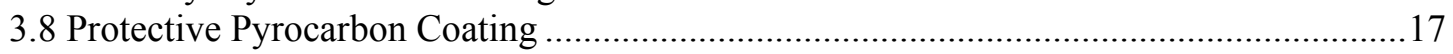

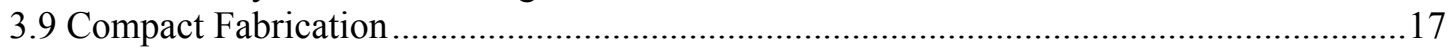

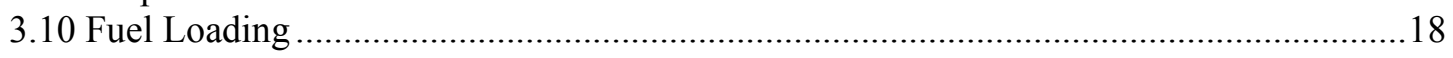

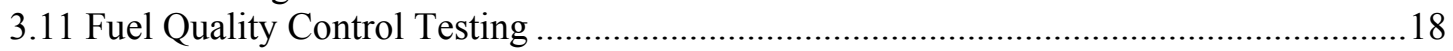

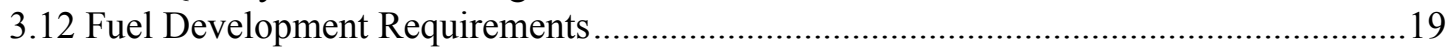

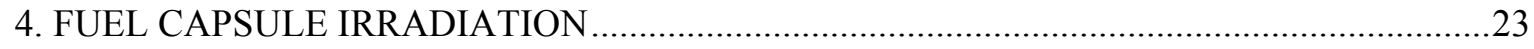

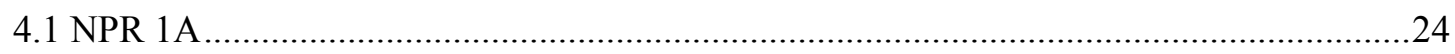

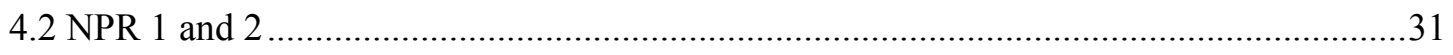

4.3 Comparison with Previous Gas Reactor Irradiations .................................................. 41

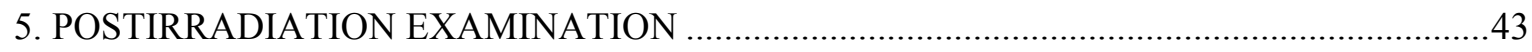

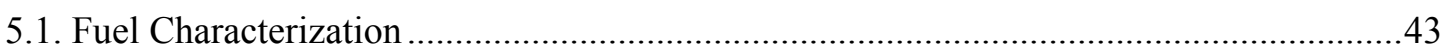

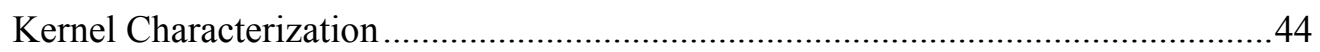

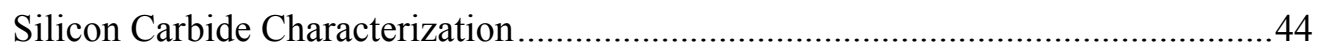

Fission Product Release Prediction ................................................................45

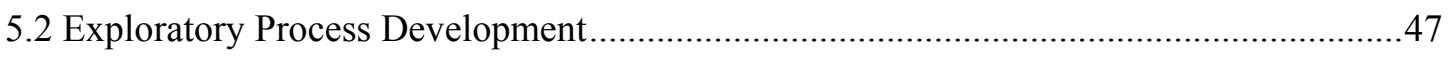

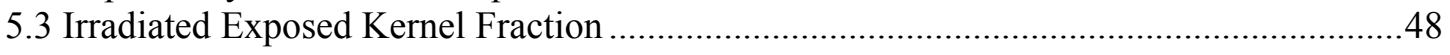

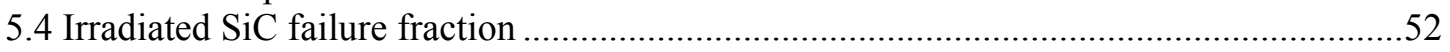

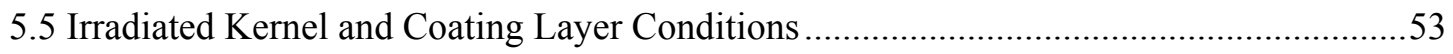

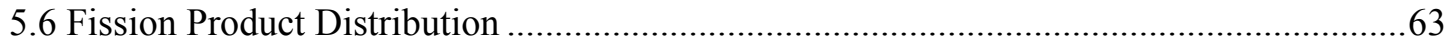

6. MOST PROBABLE CAUSES OF FUEL PARTICLE FAILURE .........................................67

7. RECOMMENDATIONS FOR FUTURE MHTGR FUEL DEVELOPMENT ..........................71

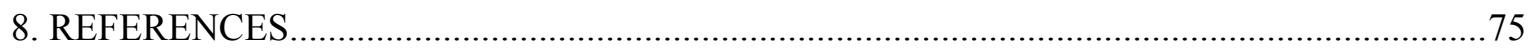




\section{FIGURES}

Figure 2-1. The as-fabricated NP-MHTGR fuel particle. ..........................................................5

Figure 2-2. Cross section of as-fabricated performance test fuel particle....................................6

Figure 3-1. Material flow for the NP-MHTGR test fuel fabrication process............................... 12

Figure 3-2. Comparison of Kernel Fabrication Processes.......................................................... 14

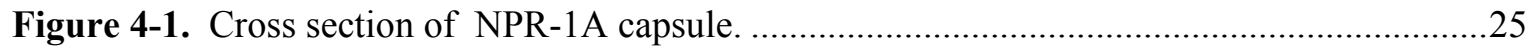

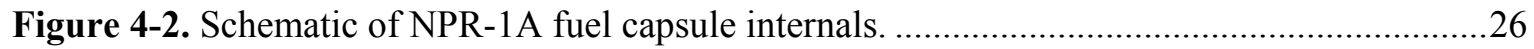

Figure 4-3. Compact centerline temperatures for Test NPR-1A.............................................28

Figure 4-4. Average fuel burnup for NPR-1A compacts. ......................................................28

Figure 4-5. Average fast fluence for NPR-1A compacts. ........................................................29

Figure 4-6. NPR-1A release-to-birth ratio for ${ }^{85 \mathrm{~m}} \mathrm{Kr}$ before and after first particle failure. .............30

Figure 4-7. A schematic cross section of the NPR-1/2 irradiation capsule, showing the fuel compacts, thermocouple bundles, flux monitors and encapsulated specimen cavities and the sweep gas feed. The gas returns through the gap between the graphite and the Inconel-718 primary containment. The HFIR colling water is in contact with the outer wall of the secondary containment.

Figure 4-8. NPR-1 Fuel compact loading scheme.

Figure 4-9. NPR-1 capsule averaged fuel compact temperature and the maximum local fuel compact temperature as a function of irradiation time.

Figure 4-10. Calculated fast fluence as a function of irradiation time for the NPR-1 test. .35

Figure 4-11. NPR 1 capsule fast neutron fluence versus burnup (\%FIMA).

Figure 4-12. a. NPR-1 calculated R/B ratios as a function of full power days for ${ }^{85 \mathrm{~m}} \mathrm{Kr}$ and ${ }^{88} \mathrm{Kr}$. b. NPR-1 calculated R/B ratios as a function of full power days for ${ }^{133} \mathrm{Xe}$ and ${ }^{138} \mathrm{Xe}$.

Figure 4-13. NPR-2 capsule averaged fuel compact temperature and the maximum local fuel compact temperature as a function of irradiation time.

Figure 4-14. Calculated fast fluence as a function of irradiation time for the NPR-2 test. .38

Figure 4-15. NPR 2 capsule fast neutron fluence versus burnup (\%FIMA)

Figure 4-16. a. NPR-2 calculated R/B ratios as a function of full power days for ${ }^{85 \mathrm{~m}} \mathrm{Kr}$ and ${ }^{88} \mathrm{Kr}$. b. NPR-2 calculated R/B ratios as a function of full power days for ${ }^{133} \mathrm{Xe}$ and ${ }^{138} \mathrm{Xe}$.

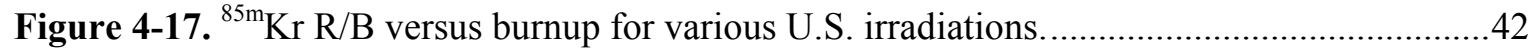

Figure 4-18. ${ }^{85 \mathrm{~m}} \mathrm{Kr} \mathrm{R} / \mathrm{B}$ versus fast fluence for various U.S. irradiations.....................................42

Figure 5-1. Exposed kernel fraction (from normalized TRIGA R/B) versus fast fluence, temperature and burnup. 
Figure 5-2. Irradiation-induced shrinkage of buffer caused a gap between the IPyC and buffer. Fission gas bubbles in the kernel indicate kernel swelling took place. (3.7 $\mathrm{x} 10^{25} \mathrm{n} / \mathrm{m}^{2}, 79 \%$ FIMA, $\left.746^{\circ} \mathrm{C}\right)$.

Figure 5-3. Kernel swelling through a radial crack in the buffer was effectively retained by IPyC. $\left(3.7 \times 10^{25} \mathrm{n} / \mathrm{m}^{2}, 79 \%\right.$ FIMA, $\left.987^{\circ} \mathrm{C}\right)$.

Figure 5-4. Radial cracks in the $\mathrm{SiC}$ were usually near a crack in the IPyC. The IPyC was generally in contact with the $\mathrm{SiC}$ except at the location of the crack in the IPyC. $\left(3.7 \times 10^{25} \mathrm{n} / \mathrm{m}^{2}, 79 \%\right.$ FIMA, $\left.746^{\circ} \mathrm{C}\right)$.

Figure 5-5. Small circumferential cracks on the inside surface of the $\mathrm{SiC}$ layer. $(3.7 \mathrm{x}$ $10^{25} \mathrm{n} / \mathrm{m}^{2}, 79 \%$ FIMA, $746^{\circ} \mathrm{C}$.) 58

Figure 5-6. Large circumferential cracks in SiC. $\left(2.3 \times 10^{25} \mathrm{n} / \mathrm{m}^{2}, 73 \%\right.$ FIMA, $845^{\circ} \mathrm{C}$.).

Figure 5-7. Porosity in SiC. $\left(3.7 \times 10^{25} \mathrm{n} / \mathrm{m}^{2}, 79 \% \mathrm{FIMA}, 806^{\circ} \mathrm{C}\right.$.)

Figure 5-8. Lenticular flaws (gold spots) in SiC. $\left(3.7 \times 10^{25} \mathrm{n} / \mathrm{m}^{2}, 79 \%\right.$ FIMA, $987^{\circ} \mathrm{C}$.).

Figure 5-9. a. Secondary electron image of a non retentive particle containing a portion of the fuel kernel $\left(3.7 \times 10^{25} \mathrm{n} / \mathrm{m}^{2}, 79 \%\right.$ FIMA, $\left.987^{\circ} \mathrm{C}\right)$. b. Cesium distribution in the kernel, buffer, IPyC, and SiC. c. Cerium distribution in the kernel, buffer, $\mathrm{IPyC}$, and SiC. d. Barium distribution in the kernel, buffer, IPyC, and SiC.

Figure 5-10. a. Secondary electron image of a retentive particle without kernel and buffer $\left(3.7 \times 10^{25} \mathrm{n} / \mathrm{m}^{2}, 79 \%\right.$ FIMA, $\left.987^{\circ} \mathrm{C}\right)$. b. Palladium accumulation at the $\mathrm{IPyC} / \mathrm{SiC}$ interface. 


\section{TABLES}

Table 2-1. Normal and accident conditions for the NP-MHTGR. ........................................

Table 2-2. As-fabricated quality requirements for NP-MHTGR fuel. ........................................9

Table 2-3. NP-MHTGR end-of-life fuel performance requirements............................................9

Table 3-1. Performance test fuel dimensions and densities............................................................11

Table 4-1. Values of key experiment parameters in NPR capsules...........................................24

Table 5-1. Comparison of exposed kernel fraction derived from TRIGA R/B, EOL R/B,

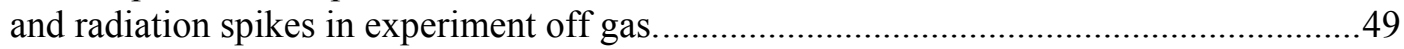

Table 5-2. Particle Failure in NP-MHTGR fuel compacts. IMGA Met LBL*LBL** .................51

Table 5-3. Coating layer failures measured by metallography of compact cross sections............62 


\section{ACRONYMS}

\section{ACRONYM DEFINITION}

ATR

BAF

BOL

$\mathrm{B} \& \mathrm{~W}$

CGR

DOE

EOL

EPD

FIMA

GA

GM

HEU

HFIR

HMTA

HRB

HTGR

IMGA

INEEL

IPyC

LBL

MET

MTS

na

NE-MHTGR

NP-MHTGR
Advanced Test Reactor at INEEL

Bacon Anisotropy Factor

Beginning of Life

Babcock \& Wilcox

Coating Gas to Total Gas Ratio

Department Of Energy

End of Life

Exploratory Process Development

Fissions of Initial Metal Atoms

General Atomics

Geiger-Müller

High-Enrichment Uranium

High Flux Isotope Reactor

Hexamethylene Tetramine

HFIR Removable Beryllium

High Temperature Gas Reactor

Irradiated Microsphere Gamma Analyses

Idaho National Engineering and Environmental Laboratory

Inner Pyrocarbon

Leach-Burn-Leach Procedure

Metallography

Methyltrichlorosilane

Not Available or Not Applicable

Commercial version of Modular High Temperature Gas Reactor

New Production Modular High Temperature Gas Reactor 


\section{ACRONYM DEFINITION}

\begin{tabular}{ll} 
NPR & New Production Reactor \\
NPR-1A & Backup Fuel Irradiation Test \\
OPyC & Outer Pyrocarbon \\
ORNL & Oak Ridge National Laboratory \\
PIE & Post-irradiation Examination \\
PPyC & Protective Pyrocarbon \\
PTF & Performance Test Fuel \\
PyC & Pyrocarbon \\
QC & Quality Control \\
R/B & Release-to-Birth Ratio \\
SiC & Silicon Carbide \\
TRIGA & Testing Research Isotopes General Atomics \\
TRISO & TRI ISOtropic: 3-layer coated particle with buffer, IPyC and \\
TRISO-P & OPyC coating \\
UCO & TRISO Protective \\
U.S. & Uranium oxycarbide \\
\hline
\end{tabular}




\section{INTRODUCTION AND OVERVIEW}

In August 1988, the Secretary of Energy announced a strategy to acquire New Production Reactor capacity of producing tritium. The strategy involved construction of a New Production Modular High Temperature Gas-Cooled Reactor (NP-MHTGR), and the Idaho National Engineering and Environmental Laboratory (INEEL) was selected as the Management and Operations contractor of the NP-MHTGR project. The INEEL was also selected as the lead laboratory to develop the target technology for the NP-MHTGR. Target particle development began immediately after the announcement in August 1988.

The fuel technology development program, however, was not considered to be on the critical path for the NP-MHTGR project. Therefore, the fuel development program was initially expected to run concurrently with design of the NP-MHTGR with little risk to schedule.

A Fuel Technology Working Group comprising members of the Department of Energy (DOE), Oak Ridge National Laboratory (ORNL), General Atomics, and the INEEL was formed in 1989. The Working Group identified technical questions about the NP-MHTGR fuel configuration and fuel manufacturing processes (last quarter FY-89) that might jeopardize a favorable Record of Decision for the NP-MHTGR in December 1991. Based on these results, the NP-MHTGR Fuel Development Program was initiated in January 1990 with the following objectives:

- Develop fuel fabrication processes, quality control techniques, and test systems to ensure acceptable material usage and to produce fuel compacts on a full scale process line that meet product and process specifications.

- Demonstrate and qualify the irradiation behavior of UCO fuel compacts and fission product transport behavior in a prototypical NP-MHTGR operating environment under normal and accident conditions.

- Develop and refine material property correlations and physical models, and independently validate computerized design methods to predict fuel performance and fission product behavior to specified predictive accuracies. These methods, models, and codes were to be used to demonstrate that fuel design met the DOE requirements related to normal operation and postulated accident conditions in the NP-MHTGR.

The Working Group also designated the basic NP-MHTGR fuel configuration. The NP-MHTGR fuel particle configuration selected in 1989 was derived from the NE-MHTGR (the commercial 
version of the MHTGR) fuel configuration. The eight-layer TRISO (TRISO is the name for the 3layer coated particle with buffer, IPyC and OPyC) coating for the NP-MHTGR fuel particle included concentric layers (beginning at the fuel kernel surface) of low density pyrolytic carbon (buffer), high density pyrolytic carbon (IPyC), silicon carbide (SiC), high density pyrolytic carbon (OPyC), and low density pyrolytic carbon (PPyC) with thin layers of extra-high density pyrolytic carbon (seal coats) between the buffer and the IPyC and between the OPyC and PPyC. The NE-MHTGR fuel kernel was $350 \mu \mathrm{m}$ in diameter and was composed of low-enriched UCO. The NP-MHTGR fuel particle used the same coating thicknesses as the TRISO coated NEMHTGR fuel to encapsulate a $200 \mathrm{~m} \mu \mathrm{m}$ diameter highly enriched UCO kernel. An additional seal coat was added to the outside of the PPyC to reduce any possible interaction between the fuel compact material and the fuel particle surface. The NE-MHTGR fuel particle configuration had not been verified, either by mechanistic structural analysis, or by irradiation testing.

The NP-MHTGR and NE-MHTGR fuel particle configurations included four major changes from the previous evolution (Fort St. Vrain) fuel particle:

(1) Fuel kernel was UCO rather than $\mathrm{UC}_{2}$

(2) The PPyC layer was added to reduce mechanical damage of the fuel particles during compacting ${ }^{\text {a }}$

(3) The IPyC layer was made thicker for added protection of the fuel kernel from $\mathrm{HCl}$ attack during $\mathrm{SiC}$ application

(4) Seal coats were added to both sides of the PPyC (for the NP-MHTGR and the inside only for the NE-MHTGR), and between the buffer and the IPyC.

The Fuel Development Program Plan (McCardell, 1990) was finalized in December 1990. Subsequent revisions were issued December 1991, (Rev. B), and September 1992, (Rev. C). Appendix A of the Fuel Development Program Plan is a comprehensive summary of gas-cooled reactor fuel and fission product behavior data available in the open literature.

Design of two capsules (designated NPR-1 and NPR-2) to irradiate NP-MHTGR test fuel specimens was initiated in January 1990. One capsule was to demonstrate maximum service life conditions of temperature, burnup, and high-energy neutron fluence. The second capsule was to

\footnotetext{
${ }^{a}$ The fuel particles together with graphite pitch and graphite shim particles are hot pressed into $12.5 \mathrm{~mm}$ diameter by $49.33 \mathrm{~mm}$ long cylinders designated compacts and sealed at the top. The hot pressing and sealing process is called compacting.
} 
be more representative of core peak average fuel temperatures. These irradiations were subsequently performed in the High Flux Isotope Reactor (HFIR) at ORNL.

In January 1990, a requisition was issued for a two-phased acquisition of initial Performance Test Fuel (PTF) that could be produced after construction of full-scale modular equipment, and subsequent proof test fuel that would be produced after construction of a full scale modular fuel process line. The PTF was manufactured by General Atomics and their subcontractor, Babcock and Wilcox.

Program participants concluded that it was necessary to have a backup fuel irradiation test, NPR1A, for the NPR-1 test, conducted in the Advanced Test Reactor (ATR) at the INEEL. This increased the assurance that a bounding demonstration test would be completed even if the HFIR continued its operational uncertainty. Design of the NPR-1A capsule began in January 1991. The capsule was completed in September 1991 with PTF compacts loaded and an on-line stateof-the-art fission product detection system in place.

Although the PTF fuel fabrication campaign met with difficulties, the PTF was shipped to INEEL and ORNL on May 21, 1991, before it was needed for loading in the test capsules. The PTF met the fuel product specifications and had the best "as manufactured" particle fuel quality ever produced in the United States.

The NPR-1, NPR-2, and NPR-1A Capsule irradiations began on July 25, August 28, and October 2, 1991, respectively. On December 12, 1991, with a peak burnup of 48\% fissions per initial metal atom (FIMA), the on-line monitoring system detected a single particle failure in NPR 1-A. Continued monitoring indicated about 2 additional particle failures each day until the irradiation was terminated on January 2, 1992. A total of 48 particles was estimated to have failed at that time. Although NPR-1A had reached a burnup of $64 \%$ rather than its original goal of $75 \%$, it was decided to remove NPR-1A to allow the earliest possible assessment of the particle failures. The NPR-1 and NPR-2 tests continued to operate with no particle failures. There was high confidence that these two HFIR tests would be able to be irradiated to their maximum desired burnup and fluence levels. However, in January 1992, NPR-1 had its first particle failure at a burnup of $72 \%$ FIMA. In February 1992, NPR-2, operating at a lower temperature than NPR-1 had its first particle failure at a burnup of 75\%FIMA. About 135 particles were estimated (by observed fission gas spikes) to have failed in NPR-2 and about 526 in NPR-1. About 700 out of 230,000 
particles contained in the three tests failed in contrast with the General Atomics model, which predicted no failures.

When the NPR-1A fuel particles failed, fuel experts from all program participants convened in a workshop at the INEL in January 1992. As a result of this workshop, the Fuel Development Program was reissued in September 1992 outlining a course of action to recover from the unexpected fuel failures. However, closeout of the NP-MHTGR program was also announced in September 1992. Work continued on the determination of the cause of the unexpected failure of the fuel particles through September 1993, when the NP-MHTGR Program was finally closed out. During FY 93, work continued in the areas of exploratory process development of the NPMHTGR fuel, characterization of the as-manufactured PTF, and postirradiation examination of the irradiated fuel from Capsules NPR-1, NPR-2, and NPR-1A.

This report describes fuel design and specification, fuel fabrication, including PTF characterization and exploratory process development, capsule irradiations and results, postirradiation examinations and results, probable causes of fuel particle failure during the irradiations, and recommendations for future MHTGR fuel development. 


\section{FUEL DESIGN AND SPECIFICATIONS}

\subsection{Fuel Design}

Similar to previous U.S. gas reactor designs, the NP-MHTGR fuel element consists of a stack of cylindrical fuel compacts containing the fuel particles inserted into a graphite block. As shown in Figure 2-1, the reference NP-MHTGR fuel particle consists of a highly enriched uranium oxycarbide fuel kernel surrounded by an eight-layer TRISO coating.

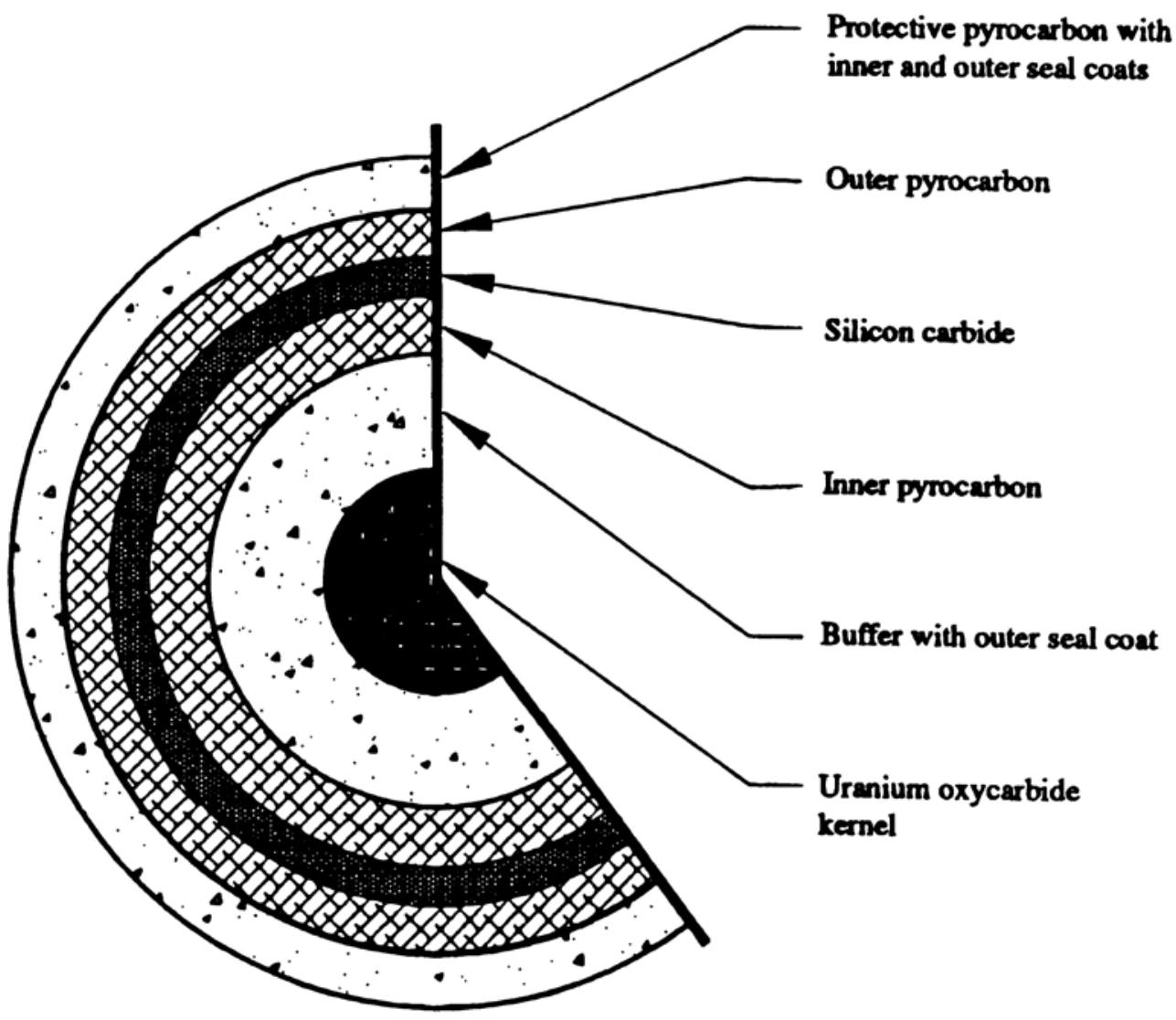

Figure 2-1. The as-fabricated NP-MHTGR fuel particle. 


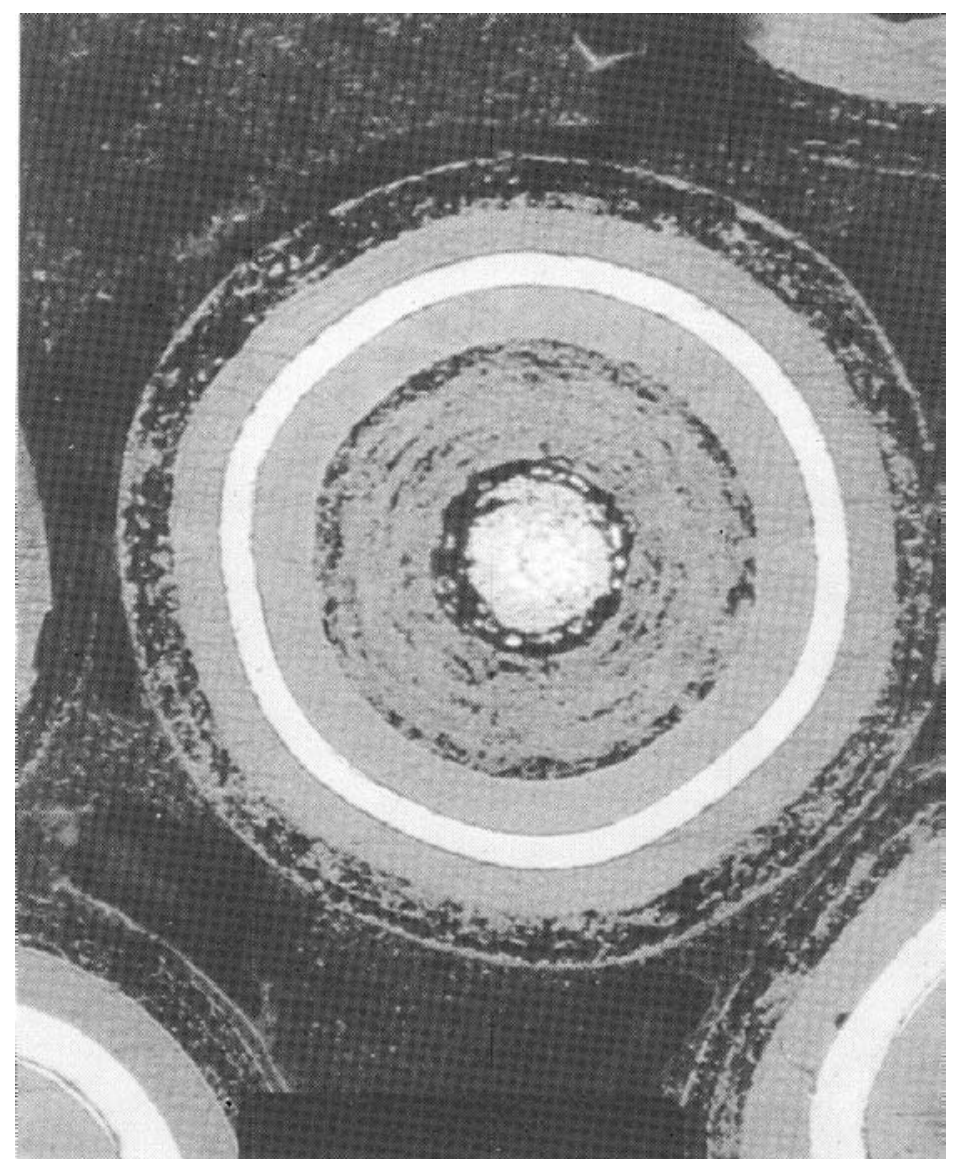

Figure 2-2. Cross section of as-fabricated performance test fuel particle.

Uranium oxycarbide (UCO) was selected as the reference kernel fuel material based on its potential for superior performance over $\mathrm{UO}_{2}$ and $\mathrm{UC}_{2}$ (McCardell 1992). The design of the NPMHTGR core required that the fuel kernel contain highly enriched uranium (HEU).

The first layer of the TRISO coating is the buffer, a porous coating of low-density carbon, $100 \mu \mathrm{m}$ thick, with a density of 0.8 to $1.1 \mathrm{~g} / \mathrm{cm}^{3}$. The purpose of the buffer is (a) to attenuate fission product recoils, thereby protecting the outer layers of the TRISO coating from damage, (b) to provide a void volume into which fission product and reaction gases produced during irradiation can expand, (c) accommodate dimensional changes from kernel swelling or coating shrinkage, and (d) act as a sacrificial layer to minimize mass transfer reaction effects caused by the temperature gradient across the kernel. The second layer is a seal coating, a dense anisotropic PyC about five $\mu \mathrm{m}$ thick. This layer separates the buffer and IPyC to facilitate measurement of the IPyC coating density. The third layer of the TRISO coating is high density IPyC. The primary purpose of the IPyC layer during fabrication is to protect the buffer and kernel from chlorine intrusion during SiC coating. The IPyC layer is $\sim 50 \mu \mathrm{m}$ thick, with a density between 
1.85 and $2 \mathrm{~g} / \mathrm{cm}^{3}$. The fourth layer is $\mathrm{SiC}$, which is the primary barrier to the release of fission products and the primary pressure boundary of the fuel system. The $\mathrm{SiC}$ is cubic crystalline in structure, approximately $30 \mu \mathrm{m}$ thick, with a density in excess of $3.18 \mathrm{~g} / \mathrm{cm}^{3}$. The fifth layer is OPyC deposited on the $\mathrm{SiC}$; it is $\sim 30 \mu \mathrm{m}$ thick with a density between 1.8 and $1.95 \mathrm{~g} / \mathrm{cm}^{3}$. The sixth layer is a seal coat applied between the $\mathrm{OPyC}$ and $\mathrm{PPyC}$ to protect the $\mathrm{OPyC}$ from failure induced by radiation shrinkage of the PPyC. The PPyC is applied over the OPyC to prevent particle damage during compact fabrication. This seventh layer is low-density carbon $\sim 50 \mu \mathrm{m}$ thick with a density of $1 \mathrm{~g} / \mathrm{cm}^{3}$. The eighth layer is a final seal coat applied over the PPyC to facilitate the flow of particles through the metering and blending equipment used during compact formation and to impede matrix impregnation of the PPyC.

The IPyC, the $\mathrm{SiC}$, and the $\mathrm{OPyC}$ are designed to retain fission products and other reaction gases produced during irradiation. The OPyC and IPyC will shrink during irradiation. The OPyC induces compressive stresses that partially offset the tensile stresses generated in the SiC layer, as will the IPyC if it remains bonded to the SiC.

The fuel compact was composed of the coated fuel particles, a carbon matrix, and graphite shim. The compact had a nominal finished diameter of $\sim 12.5 \mathrm{~mm}$. Mixing the fuel particles with the shim before compacting provided a uniform method for obtaining different heavy metal loadings required by the core design while maintaining uniform dispersion of fuel throughout the compact. Table 2-1 lists the normal operating and accident conditions selected by the designer for the NPMHTGR fuel. 
Table 2-1. Normal and accident conditions for the NP-MHTGR.

\begin{tabular}{|l|l|}
\hline \multicolumn{2}{|c|}{ Normal Operating Conditions } \\
\hline Fuel temperature & 700 to $1400^{\circ} \mathrm{C}$ \\
\hline Burnup & $<75 \% \mathrm{FIMA}$ \\
\hline Fast fluence & $<5 \times 10^{25} \mathrm{n} / \mathrm{m}^{2}$ \\
\hline Environment & Helium \\
\hline Pressure & 0.1 to $6.3 \mathrm{MPa}$ \\
\hline \multicolumn{2}{|c|}{ Accident Conditions- Conduction Cooldown } \\
\hline $\begin{array}{l}\text { Fuel temperature } \\
\text { - Pressurized } \\
\text { - Depressurized }\end{array}$ & 900 to $1200^{\circ} \mathrm{C}$ \\
& 1200 to $2000^{\circ} \mathrm{C}$ \\
\hline Environment & \\
\hline Pressure (Depressurized) & Helium \\
\hline
\end{tabular}

\subsection{Fuel Specifications}

The radiological source term from a gas reactor during normal operation and during accidents depends on the levels of as-manufactured defects and the number of fuel failures that occur during irradiation. Therefore, the reactor designer sets requirements for the fuel quality levels of fuel compacts as-fabricated and at the end of life. These quality requirements were derived by the designer from top-level radionuclide control requirements for the NP-MHTGR, such as the allowable doses at the site boundary and to workers at the plant. The quality requirements specify limits for the as-manufactured heavy metal contamination and the fraction of defective particles at both the particle and compact level in terms of a mean and an upper $95 \%$ confidence level for the entire compact lot. For end-of-life specifications, both 50 and $95 \%$ confidence limits are placed on the allowable fuel failure during normal operation and during design basis accidents. These values minimize radiological doses to workers and to the public, with a safety margin. These quality specifications parallel those specified by the commercial MHTGR program and thus did not take into account the role of the containment in the NP-MHTGR in reducing radiological doses to the environment. These fuel quality requirements are shown in Tables 2-2 and 2-3. 
Table 2-2. As-fabricated quality requirements for NP-MHTGR fuel.

\begin{tabular}{|l|c|c|}
\hline & \multicolumn{2}{|c|}{ Fraction of particles } \\
\hline Quality requirements & Mean & $95 \%$ Confidence \\
\hline \multicolumn{3}{|c|}{ Fuel Particles } \\
\hline Missing buffer fraction & $\leq 5.0 \times 10^{-5(\mathrm{a})}$ & $\leq 1.0 \times 10^{-4(\mathrm{~b})}$ \\
\hline Missing OPyC fraction & $\leq 1.0 \times 10^{-4(\mathrm{a})}$ & $\leq 1.0 \times 10^{-3(\mathrm{~b})}$ \\
\hline \multicolumn{3}{|c|}{ Fuel Compacts } \\
\hline Defective SiC fraction & $\leq 5.0 \times 10^{-5(\mathrm{c})}$ & $\leq 2.0 \times 10^{-5(\mathrm{~d})}$ \\
\hline $\begin{array}{l}\text { Heavy metal contamination } \\
\text { fraction (g U/g U in compact) }\end{array}$ & $\leq 1.0 \times 10^{-5(\mathrm{c})}$ & $\leq 1.2 \times 10^{-4}$ \\
\hline Total free uranium fraction & $\mathrm{e})$ \\
\hline Defective IPyC fraction & $\leq 6.0 \times 10^{-5}$ & $\leq 1.0 \times 10^{-4(\mathrm{~d})}$ \\
\hline
\end{tabular}
a. Particle composite mean.
b. $95 \%$ confidence that each particle composite mean is $\leq$ the specified limit.
c. Fuel compact composite lot mean.
d. $95 \%$ confidence that $\leq 5 \%$ of the compact lot mean exceeds the limit.
e. Determined as the sum of the defective $\mathrm{SiC}$ fraction and heavy metal contamination fraction.

Table 2-3. NP-MHTGR end-of-life fuel performance requirements.

\begin{tabular}{|l|c|c|}
\hline & NP-MHTGR driver fuel allowable fraction (core fraction) \\
\hline Parameter & $>50 \%$ Confidence & $>95 \%$ Confidence \\
\hline $\begin{array}{l}\text { Fuel failure during normal } \\
\text { operation }\end{array}$ & $\leq 1.0 \times 10^{-4}$ & $\leq 4.0 \times 10^{-4}$ \\
\hline $\begin{array}{l}\text { Incremental fuel failure } \\
\text { during design basis } \\
\text { accidents }\end{array}$ & $\leq 3.0 \times 10^{-4}$ & $\leq 1.2 \times 10^{-3}$ \\
\hline
\end{tabular}




\section{FUEL FABRICATION}

Fission products are contained within the NP-MHTGR fuel particles by SiC and carbon coatings. Specified fuel particle dimensions and densities together with as-fabricated values for the PTF are presented in Table 3-1. Fuel particles are cast into carbon matrix compacts $12.5 \mathrm{~mm}$ in diameter by $49.5 \mathrm{~mm}$ long to provide appropriate reactor core fuel density and to allow manual loading of hexagonal carbon fuel element blocks.

Table 3-1. Performance test fuel dimensions and densities.

\begin{tabular}{|l|c|c|c|c|}
\hline \multirow{2}{*}{ Particle Thickness } & \multicolumn{2}{|c|}{ Thickness } & \multicolumn{2}{c|}{ Density } \\
\cline { 2 - 5 } & $\begin{array}{c}\text { Spec. Mean } \\
(\mu \mathrm{m})\end{array}$ & $\begin{array}{c}\text { As fabricated } \\
(\mu \mathrm{m})\end{array}$ & $\begin{array}{c}\text { Spec. Mean } \\
\left(\mathrm{g} / \mathrm{cm}^{3}\right)\end{array}$ & $\begin{array}{c}\text { As fabricated } \\
\left(\mathrm{g} / \mathrm{cm}^{3}\right)\end{array}$ \\
\hline UCO kernel & $145-205$ & 200 & $>10.3$ & 10.51 \\
\hline Buffer carbon coating & $90-100$ & 102 & $0.8-1.10$ & 0.96 \\
\hline $\begin{array}{l}\text { IPyC + seal carbon } \\
\text { coats }\end{array}$ & $40-60$ & 53 & $1.85-1.95$ & 1.92 \\
\hline Silicon carbide & $30-40$ & 35 & $\geq 3.18$ & 3.23 \\
\hline $\begin{array}{l}\text { OPyC + seal carbon } \\
\text { coats }\end{array}$ & $30-50$ & 39 & $1.80-1.95$ & 1.86 \\
\hline $\begin{array}{l}\text { PPyC + seal carbon } \\
\text { coats }\end{array}$ & $40-60$ & 47 & $0.80-1.10$ & 1.06 \\
\hline
\end{tabular}

NP-MHTGR dependence on retaining the fission products within the fuel particle results in classification of the fuel as a safety system of the reactor. Fuel product specification must provide the fuel product requirements for the fuel to meet reactor fission product retention goals. The quality attributes and properties necessary for certifying the particles to the specification are verified at various steps during the fabrication sequence. Because of the large number of fuel particles involved, fuel quality is tested using statistically sized samples. Both average properties and population distributions of required characteristics are controlled to manage the product.

A diagram of material flow for the NP-MHTGR test fuel fabrication process is presented in Figure 3-1. The individual fabrication processes are discussed in subsequent sections followed by discussions of fuel development requirements, quality control testing, fuel characterization and exploratory process development. 


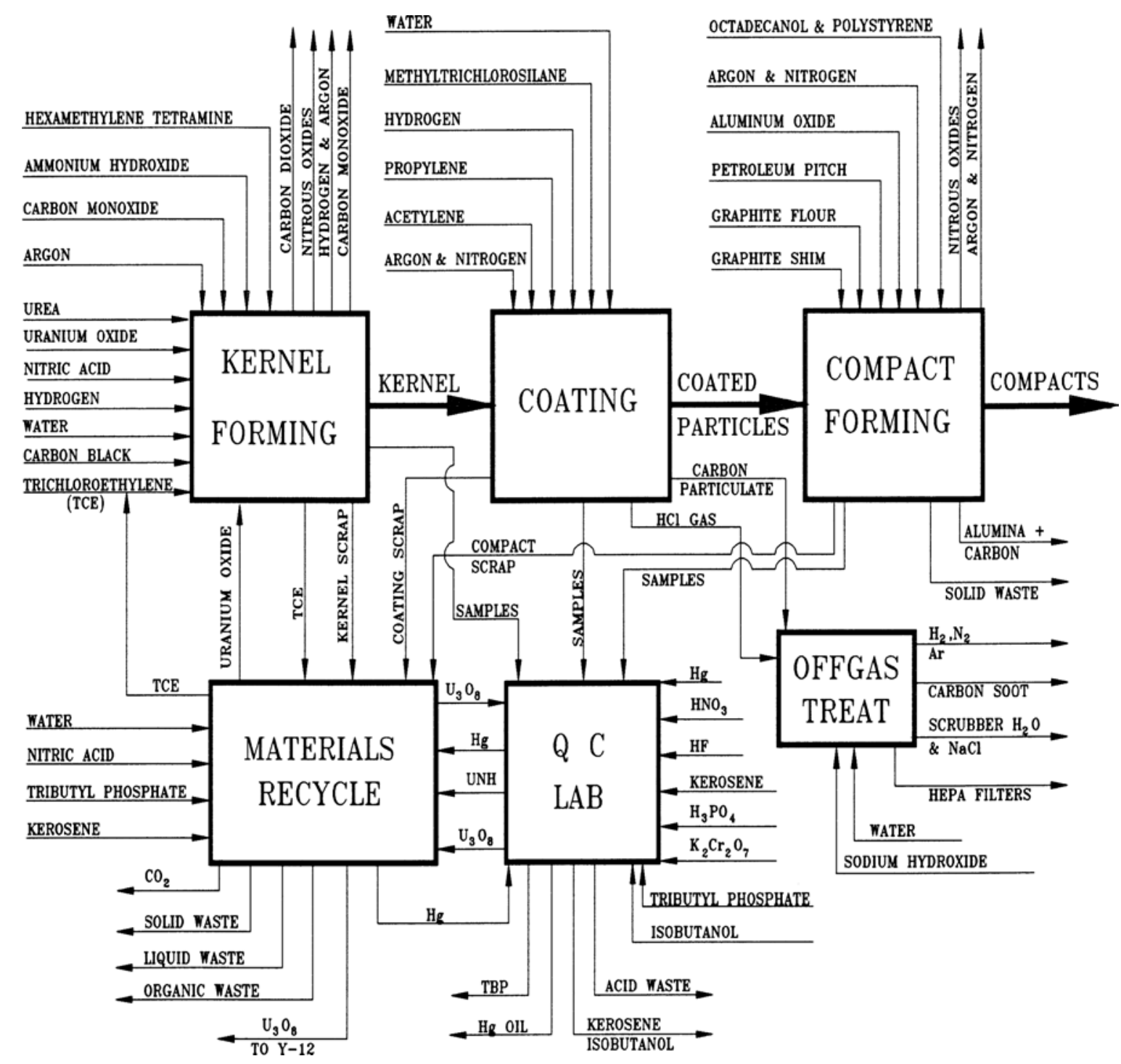

Figure 3-1. Material flow for the NP-MHTGR test fuel fabrication process. 


\subsection{Fabrication of the Kernel}

Spherical ceramic UCO kernels can be manufactured using chemical precipitation or tower melting processes. After testing and evaluating internal and external gel precipitation, the NPMHTGR program decided to use the internal gel precipitation process. Similarities and differences between these two processes are shown in Figure 3-2. Uranium oxide was obtained in the form of finely divided high surface area precipitated $\mathrm{UO}_{3}$. The material was digested in nitric acid to form an acid-deficient uranyl nitrate solution. In the internal gelation process, carbon black with a dispersant was added to the solution to provide carbon for the final oxycarbide form, and broth-forming urea $\left(\mathrm{H}_{2} \mathrm{NCONH}_{2}\right)$ was added. After slow chilling of the solution to below $0^{\circ} \mathrm{C}$, hexamethylene tetramine (HMTA, $\mathrm{C}_{6} \mathrm{H}_{12} \mathrm{~N}_{4}$ ) was added. The HMTA is unstable above $0^{\circ} \mathrm{C}$ and decomposes on heating to release ammonia which precipitates the uranyl nitrate. The broth was pulsed through needle orifices to form liquid droplets. The droplets formed spheres and were heated as they dropped through a column of $60^{\circ} \mathrm{C}$ trichloroethylene $\left(\mathrm{CH}_{3} \mathrm{CCl}_{3}\right)$ to form solid spherical fuel particles. Ammonium hydroxide $\left(\mathrm{NH}_{4} \mathrm{OH}\right)$ washing was then used for stabilizing the spheres before water washing and air-drying.

The particles were calcined to remove all volatile materials and water of hydration, leaving a product of pure $\mathrm{UO}_{3}+$ C. Finally, the kernels were sintered in a two-step cycle, initially using hydrogen near $1600^{\circ} \mathrm{C}$ to reduce the $\mathrm{UO}_{3}+\mathrm{C}$ to $\mathrm{UO}_{2}+\mathrm{UC}_{2}$, and then using argon and carbon monoxide near $1800^{\circ} \mathrm{C}$ to increase kernel density and adjust the carbon content in the kernel. A fluidized bed sintering furnace was required to provide the extreme temperatures and obtain a chemically uniform product. Particle adhesion to furnace surfaces and to other particles during sintering still resulted in some non-uniform distribution of oxide and carbide phases in the kernels.

Liquid waste from the internal gel process included $\mathrm{NH}_{4} \mathrm{OH}$, water, and trichloroethylene. The $\mathrm{NH}_{4} \mathrm{OH}$ was neutralized and sent to the wastewater treatment system with contaminated water. Trichloroethylene was recycled by distillation. Future production operations, however, should use a non-hazardous replacement heating fluid. 


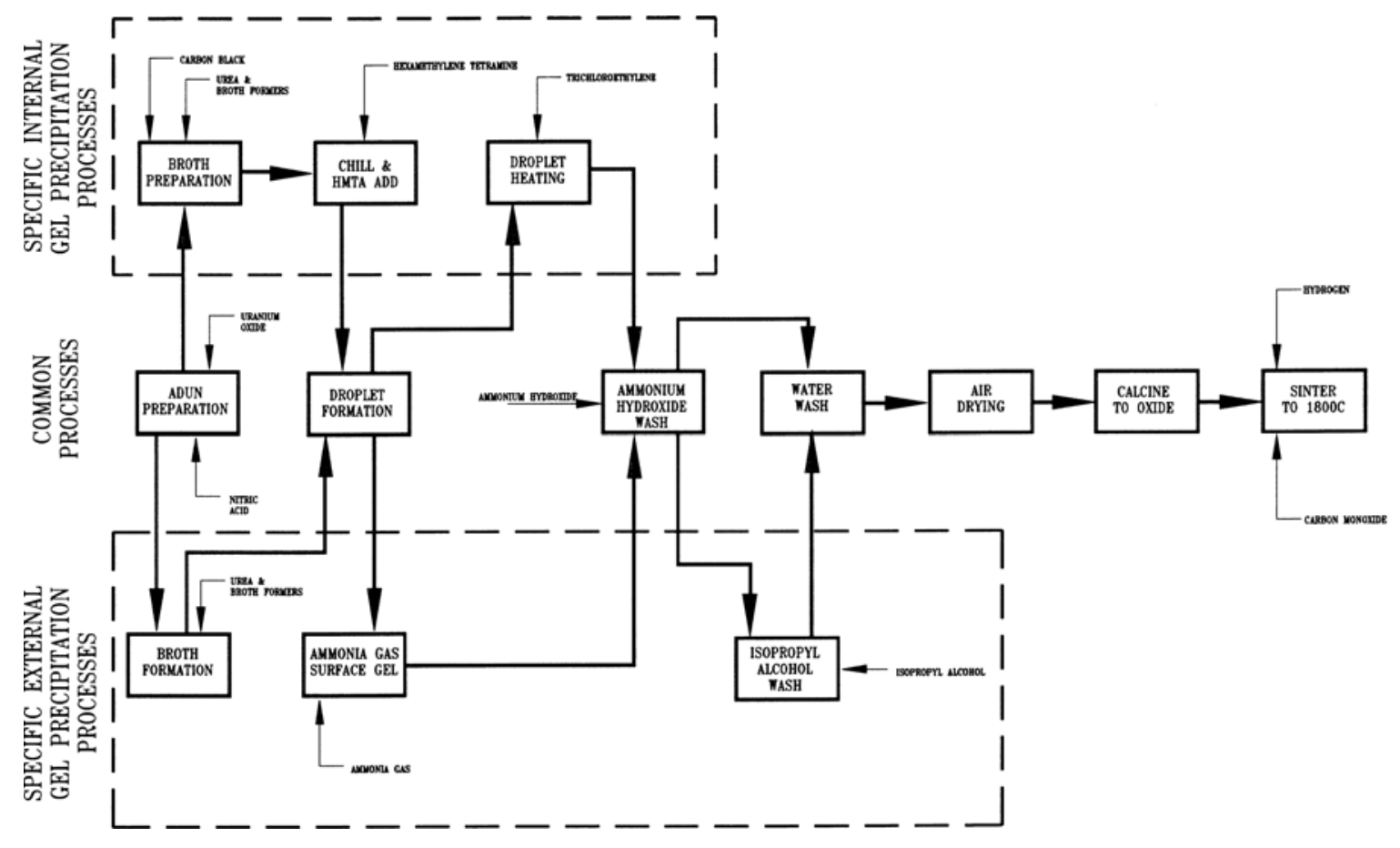

Figure 3-2. Comparison of Kernel Fabrication Processes. 
External gel precipitation, attempted early in the program, used a broth without an ammoniaforming chemical. The uranyl nitrate broth droplets fall through an ammonia gas to gel the external surface of the sphere. The particle then falls through a countercurrent $\mathrm{NH}_{4} \mathrm{OH}$ bath to slowly precipitate the broth in the center of the sphere. After precipitation, an isopropyl alcohol wash is used to add carbon and remove $\mathrm{NH}_{4} \mathrm{OH}$. The particles are then water washed and dried. External gel precipitation was abandoned primarily because of difficulties obtaining adequate density and consistent sphericity without large voids. Process analysis also revealed that the mixed ammonia-alcohol liquid waste from the external process exhibited hazardous characteristics, causing a waste disposal problem. Fuel kernels manufactured for the program met all fuel specification requirements.

\subsection{Coating Configuration}

Application of $\mathrm{PyC}$ and $\mathrm{SiC}$ coatings was performed using chemical vapor deposition in a fluidized bed-coating furnace. The furnace consisted of a conical bottom graphite cylinder with a two-inch inside diameter. The tube was induction heated with temperature measured optically. Coating and diluent gases were valved from a controlled manifold into the bottom of the graphite cone. Characteristics of the deposited materials depended on reaction rate, temperature, and the chemical reaction involved. The reaction rate was further determined by bed surface area and configuration, particle size, gas flow rate, laminar flow characteristics, and gas velocity through the reaction zone. The designs of the fluidization system and reaction zone of the furnace were found to be critical in obtaining a consistent quality coating. Fuel coating fluidization systems delivered a constant flow of coating gases to the reaction zone at a consistent pressure to preclude premature or delayed chemical reaction. The furnace internal components were designed to keep the particles in the reaction zone where the temperature is well controlled and where the chemical vapors can react with the fuel particles before they nucleate to form an ash. Fluid bed coating technology has been under development for many years and continues to be improved.

\subsection{Buffer Coating}

The low-density porous carbon buffer was applied through the exothermic cracking of acetylene gas near $1300^{\circ} \mathrm{C}$. Acetylene was metered into the coater using argon as a diluent and as a 
fluidizing gas. Coating process parameters were adjusted to obtain an optimum level of porosity in the coating to maximize the void space for fission product collection.

\subsection{Seal Coating}

A very thin $(1-5 \mu \mathrm{m})$ laminar seal coat was applied over the buffer to allow QC dimensional inspectors to distinguish between coating layers and to prevent coating interactions. The seal coat was applied using pyrolysis of propylene at a low coating rate. Similar seal coatings were applied after OPyC coating and on the exterior of the PPyC layer.

\subsection{Inner Pyrolytic Carbon Coating}

The inner pyrocarbon coating was added over the buffer and its seal coat to provide a high density, isotropic graphite boundary layer to seal the kernel from the $\mathrm{SiC}$ coating environment. The IPyC also provided secondary protection for the $\mathrm{SiC}$ from fission recoils during irradiation. Acetylene and propylene were pyrolized at about $1300^{\circ} \mathrm{C}$ to make the coating. Propylene provided the higher density coating, but acetylene was added to minimize the endothermic nature of propylene pyrolysis and stabilize the bed temperature. The highest coating density was obtained by reducing coating temperature. The IPyC coating process for the NP-MHTGR was managed to optimize coating density.

\subsection{Silicon Carbide Coating}

As the primary load bearing and fission product diffusion barrier in the fuel system, the SiC properties were critical. High strength, isotropy, and near theoretical density were obtained by depositing columnar beta-phase $\mathrm{SiC}$ from methyltrichlorosilane (MTS) at low coating rates (0.2$0.4 \mu \mathrm{m} / \mathrm{min}$ ) between 1500 and $1650^{\circ} \mathrm{C}$. Hydrogen was used as the diluent gas, and in the reaction to form $\mathrm{SiC}$. Hydrogen was passed over heated MTS to carry the silane vapor into the high temperature reaction zone of the fluidized bed. The chemical reaction involved was

$$
\mathrm{CH}_{3} \mathrm{SiCl}_{3}+\mathrm{H}_{2}=\mathrm{SiC}+3 \mathrm{HCl}+\mathrm{H}_{2}
$$


Density was optimized in the coating by using a high temperature $\left(1650^{\circ} \mathrm{C}\right)$ at low coating rates with an excess of hydrogen. Strength and grain size, however, could have been optimized near $1500^{\circ} \mathrm{C}$. Test fuel for the NP-MHTGR was coated to achieve the highest density, which was considered the most important parameter.

\subsection{Outer Pyrolytic Carbon Coating}

The OPyC provided a secondary barrier to the release of fission gases, protected the $\mathrm{SiC}$ from external corrosive environments, and pre-stressed the $\mathrm{SiC}$ layer to reduce its overall stress state during irradiation. Although similar to the IPyC, the outer pyrocarbon deposition temperature and coating rate were increased to optimize the isotropic response of the coating and minimize large microporosity. Very small, closed micropores, however, were used in this coating to entrap fission gases and delay their diffusion.

\subsection{Protective Pyrocarbon Coating}

An outer buffer layer of protective pyrocarbon was applied to the NP-MHTGR fuel as a new design feature to minimize the potential for particle damage in handling and to prevent fuel particle fracture during compacting operations. The PPyC layer was applied with the same process as for buffer coating.

\subsection{Compact Fabrication}

The fuel compact was a cylindrical rod containing fuel particles in a carbon matrix with the correct fuel loading for insertion into graphite fuel elements. Compacts were fabricated by injecting a hot liquid carbon base matrix into a mold cavity containing fuel particles and enough graphite shim material to provide the desired fuel loading. A number of different fuel loadings would typically be used in the reactor core to control power distribution.

The carbon-based matrix used for this program was a mixture of petroleum pitch, graphite filler, octadecanol, and polystyrene. The matrix was injected at a maximum of $1000 \mathrm{psi}$ at $160^{\circ} \mathrm{C}$. The conditions allowed filling of the compact mold but were below the pressures required for the angular graphite shim to cause fuel particle damage from edge contact. After the mold was 
cooled to solidify the matrix, the green compact was removed and packed in alumina power $\left(\mathrm{Al}_{2} \mathrm{O}_{3}\right)$ for carbonization at $900^{\circ} \mathrm{C}$. Carbonization decomposed all organic compounds in the matrix to leave a solid carbon compact. Control of the alumina was critical to ensure adequate packing of the compact for dimensional stability and still allow for the escape of volatile organics.

A petroleum pitch based matrix was used for the test fuel because the pitch came from an existing batch, successfully used previously for test fuel. Future production processes would require use of a synthetic thermosetting resin based system that would allow tight control of chemistry and allow carbonization without using alumina packing. Petroleum pitch would be difficult to use in production because it lacks a tightly controlled chemical composition. Both the chemistry and properties depended on the specific batch of crude oil from which it was processed. The NPMHTGR fuel was $\mathrm{HCl}$ gas leached after carbonization to remove iron contamination from the pitch, and to remove any uranium exposed during compacting from broken or failed particles. The final step in manufacture of the compacts was a controlled heat treatment at $1650^{\circ} \mathrm{C}$ to stabilize the carbon matrix and drive off any remaining volatiles or hydrogen.

\subsection{Fuel Loading}

Fuel compacts used in an NP-MHTGR core would be loaded and sealed with graphite cement in predrilled hexagonal graphite fuel blocks (approximately 100 compacts/block) using a specific loading pattern. The Fuel Development program, however, used irradiation test capsules consisting of fuel compacts loaded directly into tubular instrumented test assembles for accelerated irradiation tests.

\subsection{Fuel Quality Control Testing}

Fuel manufactured for the NP-MHTGR program was manufactured to full ASME-NQA-1, 1989, standards and achieved a higher quality level than had been produced previously in the United States. Fuel quality variables and attributes were measured extensively between fabrication steps to ensure conformance to fuel specification requirements. A total of 54 property and impurity spectra were analyzed and controlled during fuel processing. 
After completion of compacting, an additional series of tests were performed to verify the asmanufactured quality of the fuel and predict how the fuel would perform during reactor operation.

The test included the following:

- Defective IPyC Coating. This test located any dispersion of uranium from the kernel into the buffer by using radiography of burned back fuel particles (particles with outer pyrocarbon coatings burned off). Such dispersion indicates an inadequate IPyC coating, allowing $\mathrm{HCl}$ gas to reach and partially dissolve the fuel kernel.

- Heavy Metal Contamination. This test determined the presence of fuel outside completely coated particles by using high-temperature $\left(1550^{\circ} \mathrm{C}\right) \mathrm{HCl}$ gas leaching the compacts.

- Burn Leach Test. This test involved destructive analysis achieved by burning the compact and outer layer carbon away from fuel particles to expose $\mathrm{SiC}$ coatings, followed by leaching of the particles in a mixture of acids to dissolve any uranium not fully protected by the $\mathrm{SiC}$. The test identified any defective $\mathrm{SiC}$ and $\mathrm{SiC}$ damaged from compacting. By subtracting the heavy metal contamination values from the values obtained in this test, a value for defective $\mathrm{SiC}$ coatings was obtained.

- Krypton release-to-birth ratio (R/B). As a final verification of as-manufactured quality, this test irradiated finished compacts in a TRIGA reactor at $1000^{\circ} \mathrm{C}$ to establish an inventory of the ${ }^{85 \mathrm{~m}} \mathrm{Kr}$, which was subsequently measured to establish the relative retentiveness of the fuel coatings. Although an exact relationship between R/B and reactor performance did not exist, the very low values obtained verified that the as-manufactured quality was orders of magnitude better than previously manufactured test fuels.

The successful results from the above tests indicate that the NP-MHTGR test fuel should perform with exceptionally low fission product release in reactor service. The irradiation test experience, however, did not correspond to the as-manufactured fuel quality test results.

\subsection{Fuel Development Requirements}

The NP-MHTGR program has shown that fuel particles and compacts could be manufactured with very high statistical quality levels in test equipment. Irradiation performance of that same fuel, however, demonstrated that the fuel was only as good as the product and design specifications it was built to meet. Putting particle fuel into production for full reactor loading, however, would require several technically and environmentally driven process adjustments, equipment scale-up development, and process limits testing. 
Kernel fabrication was successful as a laboratory scale process. Scale-up to production would require development of better control of and measurement of kernel chemical stoichiometry ( $\mathrm{UO}_{2}$ and $\mathrm{UC}_{2}$ distribution), while switching to non-hazardous or treatable chemical compounds for forming kernels. Stoichiometry control would require improving calcining and fluidized bed sintering; furnace linings would need to be developed that do not hold particles or react with them during processing. A production method would also be needed to measure kernel stoichiometry and verify the adequacy of processing. Trichloroethylene would need to be replaced for production kernel fabrication in favor of a non-hazardous material, and production facilities would need to have built-in liquid waste treatment systems capable of handling ammonium hydroxide and other waste liquids.

Fluid bed particle coating depends on coating temperatures, pressure, gas composition, gas velocity, gas concentration, and coater fluidization characteristics. Because of the variety of variables involved, considerable development work remains to be done in this field to optimize the various coatings. Processing methodology and tooling also require development work to eliminate potential coating contamination from trace metals associated with gas supplies, tooling and furnace components. Pyrocarbon coating processes were relatively well characterized in terms of the temperatures and gas relationships that would provide a specific coating density and isotropy. Testing would still be needed, however, to characterize the variations in carbon structure and gas permeability resulting from process variables. Initial development testing in the exploratory development program (see Section 5.2) for example, shows that significant variability in coating quality was obtained using processes that produced almost identical density and isotropy.

Silicon carbide coating was perhaps the best-developed coating used in HTGR fuel, but additional studies would be needed to determine the optimum processing conditions and the methods to eliminate contamination and defects. The most notable defect observed in this program was a characteristic circumferential blister or gap within the coating, referred to as gold spot because of its characteristic color. The spots were apparently caused by particle movement outside the normal coating zone caused by pressure fluxuations in the fluidized bed. Although not determined to directly cause fuel failures, the defect indicates less than adequate process control and a potential need for coater configuration changes to ensure that particle coating occurs over a welldefined and tightly controlled portion of the coater. 
Compacting operations and full automation during scale-up were expected to require the most development, because of the high integrity required and the volume of compacts that would need to be manufactured, handled, and inspected. Initial development efforts would need to identify the thermosetting resin material, shim graphite, and basic process parameters needed to obtain the required fuel particle densities without particle breakage or dimensional nonconformity. In a parallel effort, improved methods to verify compact quality and the integrity of fuel particles within the compact would need to be refined. Using the basic process parameters and developed QC methods, high quality automated equipment would then need to be designed, built, and tested to ensure that production processing would not degrade compact quality.

Particle fuel would be batch processed owing to the variety of QC tests required during fabrication. Scale-up was primarily a throughput question rather than one of size because much of the equipment was already limited by considerations of nuclear criticality.

Statistically designed process tests would be needed to explore process limits. The major process variables and the effects and interrelationships between the variables must be known to ensure specification of statistical process controls within which the product specification can be met with a high degree of reliability. Such testing would also identify the processes that cannot be adequately controlled within the current product requirements. As such, the tests would reveal where further process development was required. 


\section{FUEL CAPSULE IRRADIATION}

Three irradiation tests were performed to demonstrate that the PTF would meet the performance goals set for the NP-MHTGR. Two tests, designated NPR-1 and NPR-2, were conducted in the HFIR at ORNL (Baldwin 1993). The remaining test, designated as NPR-1A, was conducted in the ATR at INEEL (Martinson 1993). These three capsule irradiations were part of a larger demonstration and qualification program for HEU-UCO fuel under normal and accident conditions for the NP-MHTGR. A large population of fuel particles had to be tested to establish, with high statistical confidence, normal operation fuel performance as required by the fuel specification. Furthermore, these demonstration experiments had to cover the normal operating temperature range and extend to full burnup and full fluence. The ATR and HFIR both have the capabilities to perform the required irradiations. Both have large enough test cavities and the requisite instrumentation to perform the irradiations. However, the unperturbed thermal and fast fluxes in these facilities are so high that the irradiations resulted in the accumulation of burnup and fluence about six times faster than that expected in the NP-MHTGR.

The experiments were designed such that fuel compacts could be irradiated at or near the NPMHTGR design service conditions for temperature, burnup, and fast fluence. (NPR-2 was at a slightly lower temperature than NPR-1 and NPR-1A). Each experiment consisted of approximately 75,000 fuel particles in 16 to 20 compacts. This population was sufficient to demonstrate a fuel defect level of $\sim \leq 1.8 \times 10^{-4}$ at the $95 \%$ confidence level if $\sim 7$ or less fuel particles failed. The primary objective of the experiments was to provide data related to fuel performance by measuring fission gases released during irradiation (e.g. ${ }^{85 \mathrm{~m}} \mathrm{Kr}$ ). The release-tobirth ratio $(\mathrm{R} / \mathrm{B})$, which is the measured fission gas release rate divided by the calculated fission gas birth rate, provided this measurement of fuel performance. Increases in the R/B for a given fission gas isotope would indicate fuel failure. This approach has been used historically in in-pile fuel tests (Olander 1976). The design parameters for the three capsules were a peak volume average temperature between 1000 and $1250^{\circ} \mathrm{C}$, end-of-life burnups from 60 to $75 \% \mathrm{FIMA}$, and a fast neutron fluence range from $2.5 \times 10^{25}$ to $3.7 \times 10^{25} \mathrm{n} / \mathrm{m}^{2}(\mathrm{E}>0.18 \mathrm{MeV})^{1}$. Table 4-1 lists the peak values of the key experiment parameters attained in the NPR-1, 1A, and 2 capsules. Details of the three experiments are summarized in the following sections.

\footnotetext{
${ }^{1}$ All fast neutron fluences reported in this section are for $\mathrm{E}>0.18 \mathrm{MeV}$.
} 
Table 4-1. Values of key experiment parameters in NPR capsules.

\begin{tabular}{|c|c|c|c|c|c|}
\hline Test & $\begin{array}{c}\text { Capsule } \\
\text { average } \\
\text { temp.(K) }\end{array}$ & $\begin{array}{c}\text { Peak } \\
\text { temp.(K) }\end{array}$ & $\begin{array}{l}\text { Peak fluence } \\
\left(* 10^{25} \mathrm{n} / \mathrm{m}^{2}\right)\end{array}$ & $\begin{array}{c}\text { Peak burnup } \\
\text { (\%FIMA) }\end{array}$ & $\begin{array}{c}\text { Number of } \\
\text { particles }\end{array}$ \\
\hline NPR-1 & $974^{\circ} \mathrm{C}$ & $1246^{\circ} \mathrm{C}$ & 3.7 & $79 \%$ & 77,500 \\
\hline NPR-1A & $977^{\circ} \mathrm{C}$ & $1119^{\circ} \mathrm{C}$ & 2.0 & $64 \%$ & 75,360 \\
\hline NPR-2 & $753^{\circ} \mathrm{C}$ & $1024^{\circ} \mathrm{C}$ & 3.7 & $79 \%$ & 77,500 \\
\hline $\begin{array}{l}\text { NP-MHTGR } \\
\text { core }\end{array}$ & $600^{\circ} \mathrm{C}$ & $1250^{\circ} \mathrm{C}$ & 3.7 & $75 \%$ & $1.8 \times 10^{10}$ \\
\hline
\end{tabular}

\subsection{NPR 1A}

The NPR-1A experiment was irradiated in test position B-5 in the ATR. The NPR-1A capsule was instrumented to provide measurements of temperature, gas flow, neutron fluence, and fission gas release. Radial and axial schematics of the capsule internals are shown in Figures 4-1 and 4-2 respectively. The capsule contained 20 compacts, each with about 3770 particles. The fuel compact stack was approximately $1.22 \mathrm{~m}$ long, $0.017 \mathrm{~m}$ in diameter, and contained five neutron fluence monitoring packages, two insulator pellets (aluminum oxide), and four graphite spacers all equally spaced throughout the stack. The fuel compacts were positioned within an instrumented graphite sleeve housed in an outer stainless steel capsule. The graphite sleeve was grooved along the length of the outer surface to permit routing of the thermocouple leads and the gas inlet tubes. The thermocouple leads and the gas tubing lines were held in place by four Inconel 600 bands around the outer circumference of the bonded sleeve.

The neutron fluence monitors provided passive data on the thermal and fast fluence environment at five different axial elevations in the capsule. Nine thermocouples were used to measure temperatures at various axial and azimuthal locations on the graphite sleeve. Fuel temperatures during the experiment were calculated by thermal analysis. 


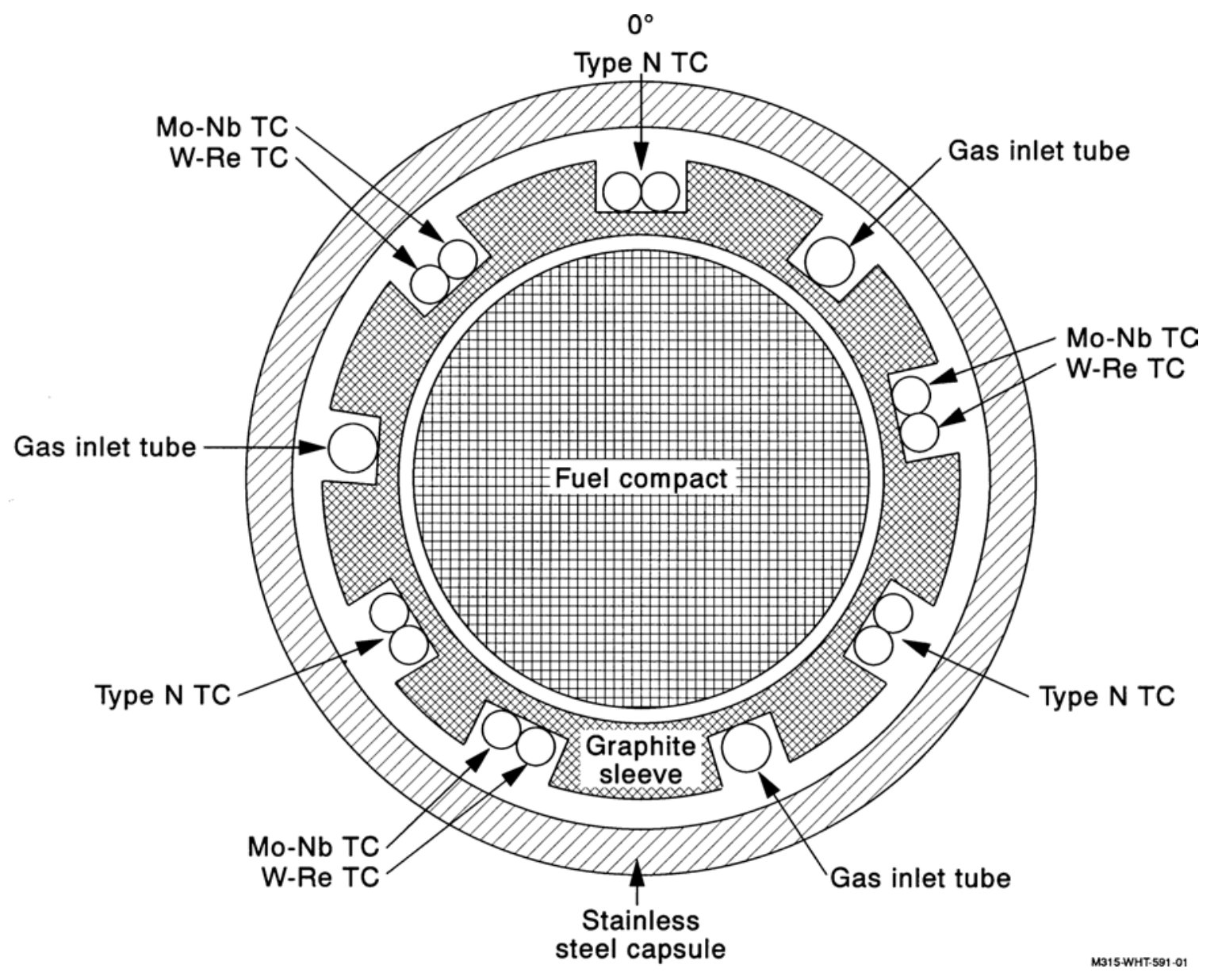

Figure 4-1. Cross section of NPR-1A capsule. 


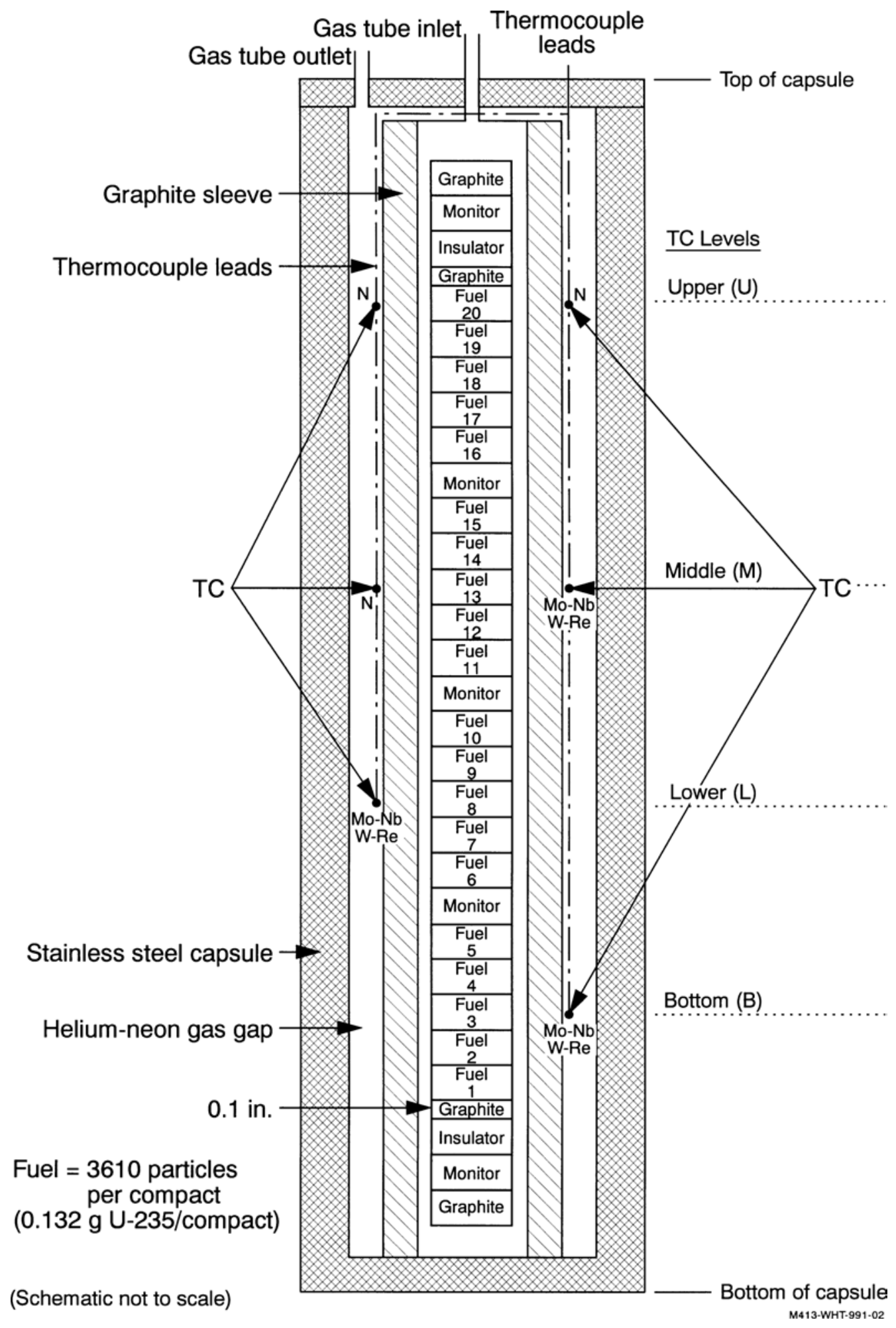

Figure 4-2. Schematic of NPR-1A fuel capsule internals. 
A gas supply was used to sweep and control the temperature of the fuel capsule during irradiation. The gas entered the top of the capsule, flowed down the outside of the compact stack, and then up around the compacts to sweep out any fission products released from the fuel. The gas was a mixture of helium and neon, the composition of which could be adjusted to maintain temperatures relatively constant as the uranium was depleted during the irradiation. Upon exiting the test capsule, the gas passed through a stainless steel particulate filter to trap any particles larger than 10 microns and into the fission product monitoring system.

The fission product monitoring system consisted of an on-line gamma-ray spectrometer and a sodium iodide detector that viewed a portion of the gas line. This on-line instrumentation provided almost instantaneous data on fission gas release during irradiation. Upon leaving the monitoring system, the gas passed through a grab sampling system (which did not work during most of the experiment) and into a delay tank to allow for decay of fission products.

Irradiation of the NPR-1A capsule began on October 2, 1991, and was terminated after 64.2 full power days. The calculated compact centerline temperatures, compact average burnup, and compact average fast neutron fluence during the experiment are plotted in Figures 4-3, 4-4, and 45. Calculated temperatures remained within a $100^{\circ} \mathrm{C}$ band in the upper and lower quadrants of the capsule. In the middle two quadrants, where the greatest uranium depletion (highest burnup) occurred, helium-neon gas control resulted in a slightly wider temperature variation $\left(\sim 200^{\circ} \mathrm{C}\right)$. Peak temperatures were about $1119^{\circ} \mathrm{C}$. The dips in the axial temperature distribution correspond to the locations of graphite spacers, insulators, or neutron monitors. The effect of axial cosine shaped neutron flux distribution in the ATR is apparent in the shape of the burnup and fast fluence curves in Figures 4-4 and 4-5. The peak compact average burnup was 64\%FIMA in the middle compacts, and the peak fluence was $2.0 \times 10^{25} \mathrm{n} / \mathrm{m}^{2}$. 


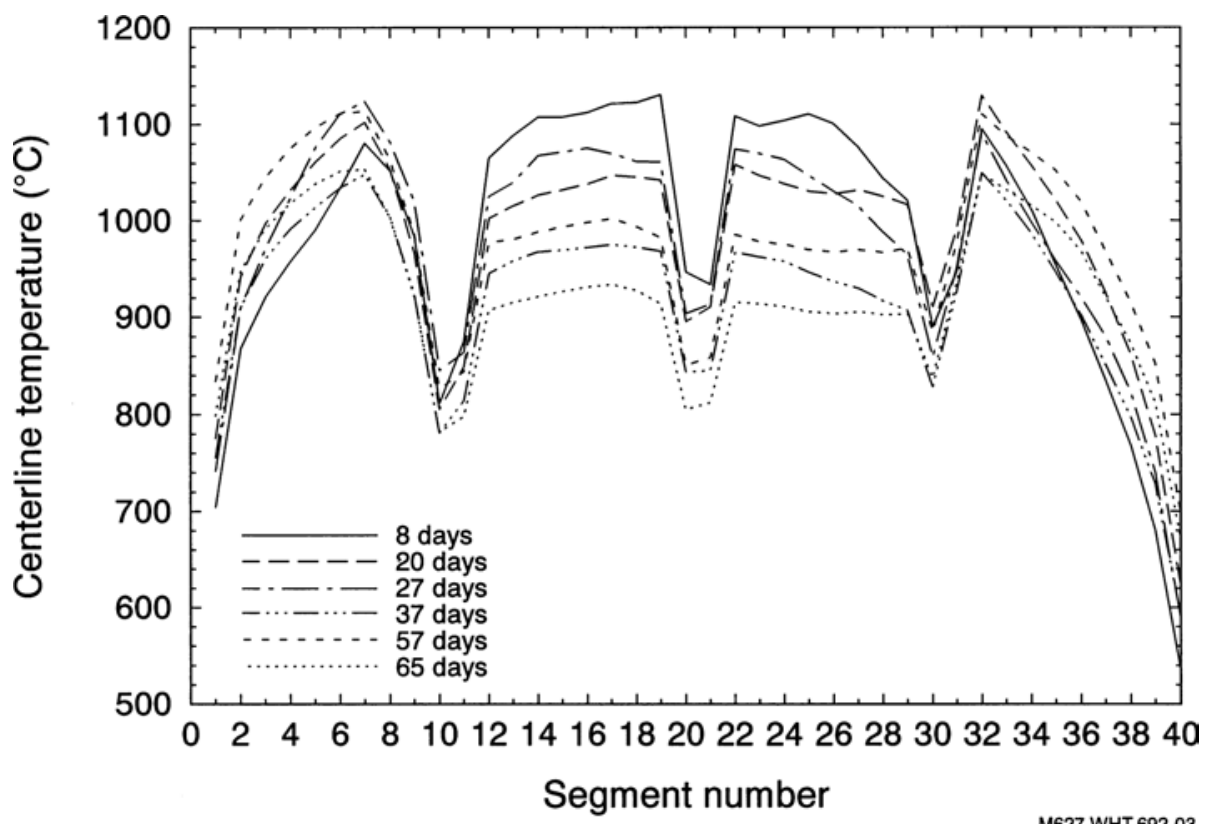

Figure 4-3. Compact centerline temperatures for Test NPR-1A.

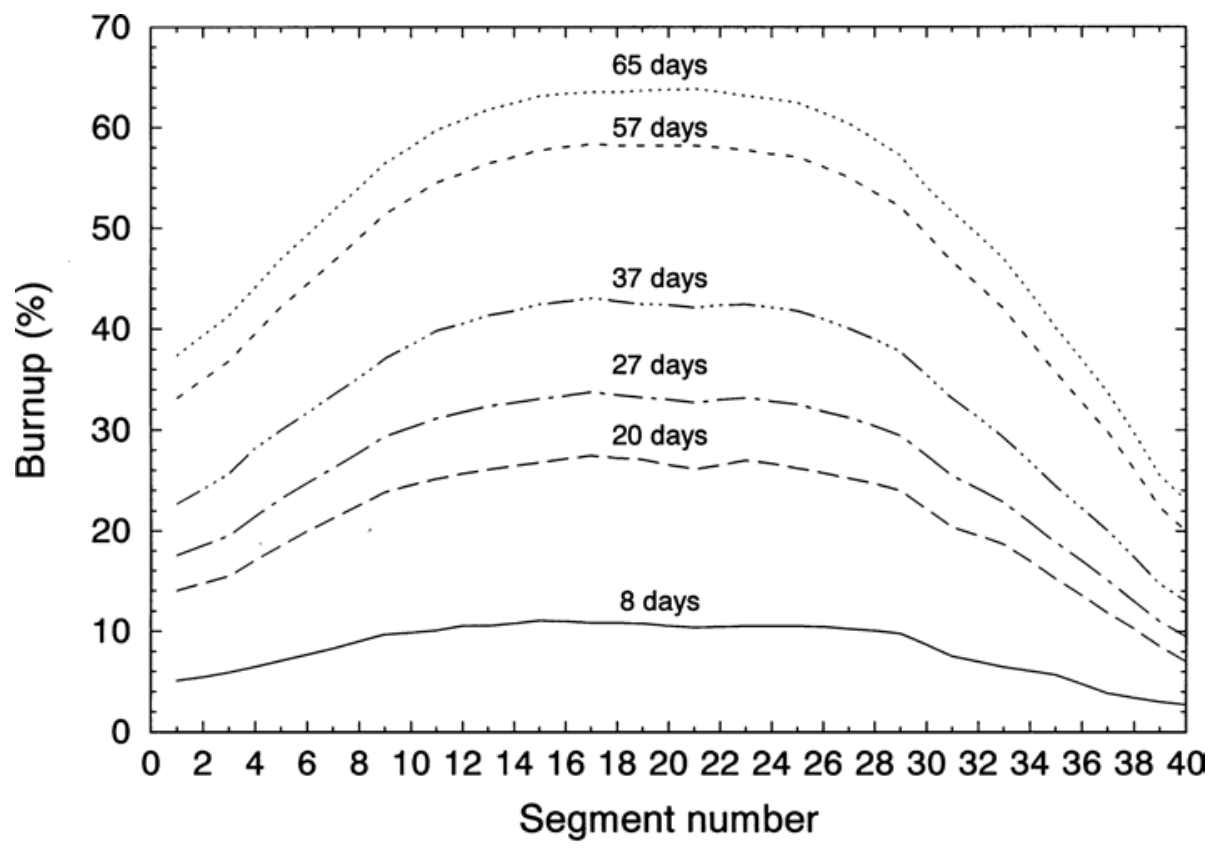

Figure 4-4. Average fuel burnup for NPR-1A compacts. 


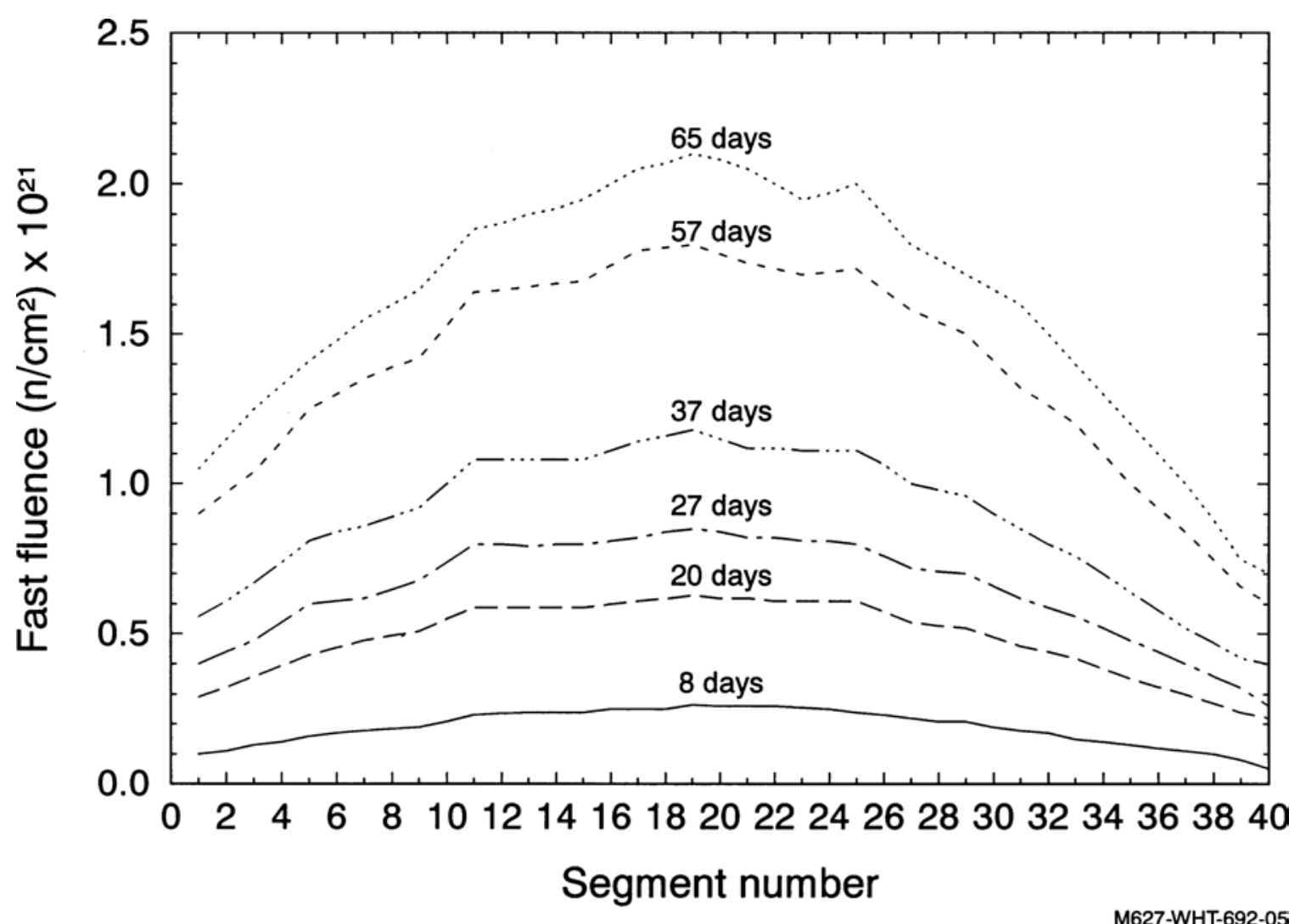

Figure 4-5. Average fast fluence for NPR-1A compacts.

Figure 4-6 is a plot of the ${ }^{85 \mathrm{~m}} \mathrm{Kr} \mathrm{R} / \mathrm{B}$ during the experiment. The $\mathrm{R} / \mathrm{B}$ remained low during the first 42 full power days of the experiment. However, on December 12, 1991 (71.4 elapsed days in Figure 4-6), the R/B increased from a value of $4 \times 10^{-9}$ to $3.8 \times 10^{-7}$, indicating particle failure. The initial particle failure occurred at a peak fluence of $1.27 \times 10^{25} \mathrm{n} / \mathrm{m}^{2}$, a peak burnup of $47 \%$ FIMA, and a peak temperature of $1133^{\circ} \mathrm{C}$. Based on this initial failure, an estimate of the $\mathrm{R} / \mathrm{B}$ for a failed particle can be made:

$(\mathrm{R} / \mathrm{B})_{\text {particle }}=\left[(\mathrm{R} / \mathrm{B})_{\text {after one failure }}-(\mathrm{R} / \mathrm{B})_{\text {before failure }}\right]^{*}$ Number of particles $=\left[3.8 \times 10^{-7}-4 \times 10^{-9}\right] * 75,360=0.028$

The ${ }^{85 \mathrm{~m}} \mathrm{Kr} \mathrm{R} / \mathrm{B}$ continued to increase over time to a peak value of $1.8 \times 10^{-5}$. Based on the peak $\mathrm{R} / \mathrm{B}$, the total number of particle failures in NPR-1A is estimated to be

Number of failures $=\left(1.8 \times 10^{-5}\right) * 75,360 / 0.028=\sim 48$ 


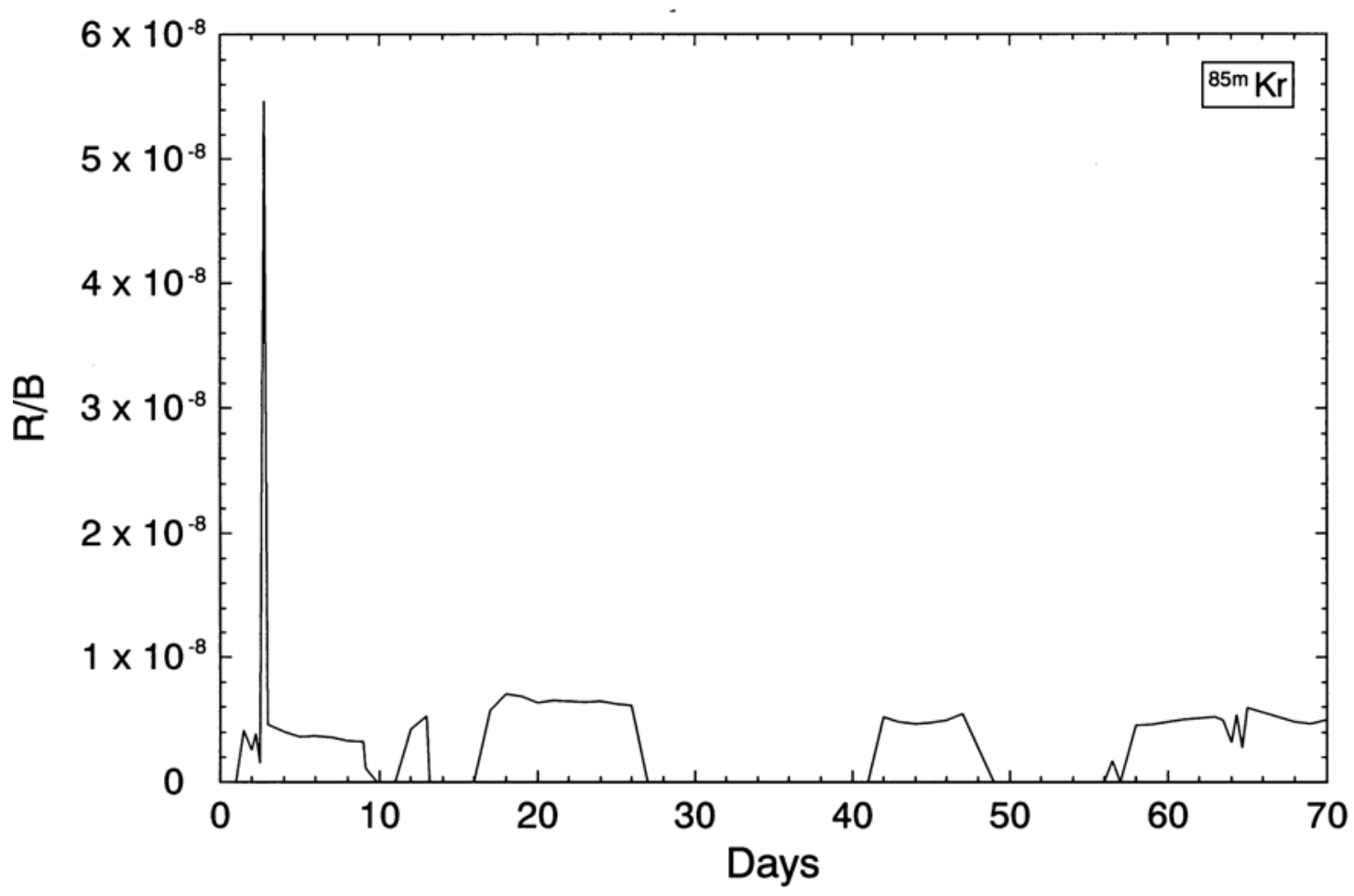

M645-WHT-692-02

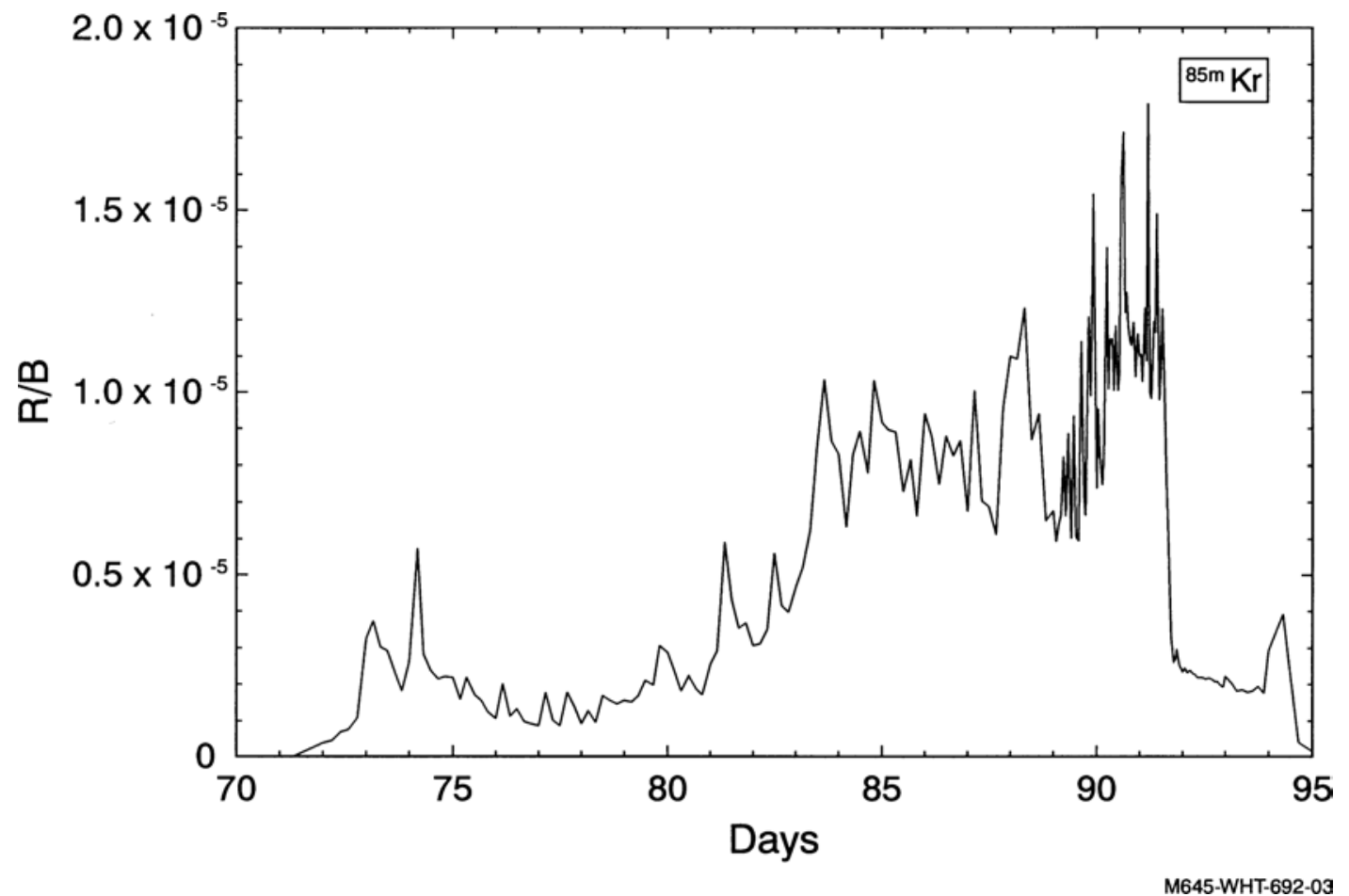

Figure 4-6. NPR-1A release-to-birth ratio for ${ }^{85 \mathrm{~m}} \mathrm{Kr}$ before and after first particle failure. 


\subsection{NPR 1 and 2}

The NPR 1 and 2 experiments were irradiated in the HFIR for a total of eight cycles. The capsules were instrumented to provide measurements of temperature, gas flow, neutron fluence, and fission gas release. Radial and axial schematics of the capsule are shown in Figures 4-7 and $4-8$, respectively. The irradiation capsule consists of a double contained, single, purged cell containing 16 fuel compacts surrounded by H-451 graphite fuel bodies. Pure helium gas sealed between the primary and secondary Inconel-718 containment vessels served as a containment integrity monitor during irradiation. The graphite holders contained the fuel compacts, flux monitors, thermocouples, and encapsulated, unbonded fuel particles known as piggyback samples. (The piggyback samples were designed to study key aspects of fission product behavior in the fuel particle.) The fuel particle loadings in each region were varied to compensate for the axial flux distribution in HFIR and allow for a somewhat more uniform heat generation rate along the capsule. The individual compact loadings varied between $\sim 3600$ and 6000 particles per compact. The total number of particles in each capsule was calculated to be 77, 500 .

The NPR 1 and 2 capsules each contained 27 thermocouples incorporated into four discrete thermocouple array tubes. These thermocouples were used to measure temperatures at various axial and azimuthal locations in the graphite holder. Fuel temperatures during the experiment were then calculated by thermal analysis using the temperature measured in the graphite holder.

A helium-neon gas mixture flowed between the graphite fuel holder and the primary containment wall, providing active temperature control. By adjusting the relative concentration of the two gases, the thermal conductivity of the sweep gas was varied to control the radial heat flow to the HFIR cooling water. The flow rate and gas mixture were adjusted for fine tuning of the fuel compact temperatures which were monitored by the thermocouples in the graphite holder. The gas tubing was also monitored for radioactivity. In each case, 15 feet of the sweep gas tube was coiled around a radiation detector. In NPR-1, this system consisted of two ionization chambers. In NPR-2, two Geiger-Müller (GM) monitors were used. This system is sensitive enough to discern single particle failures by the burst of activity associated with such events. Samples of the sweep gas were also collected periodically and analyzed off line for their fission gas content. 


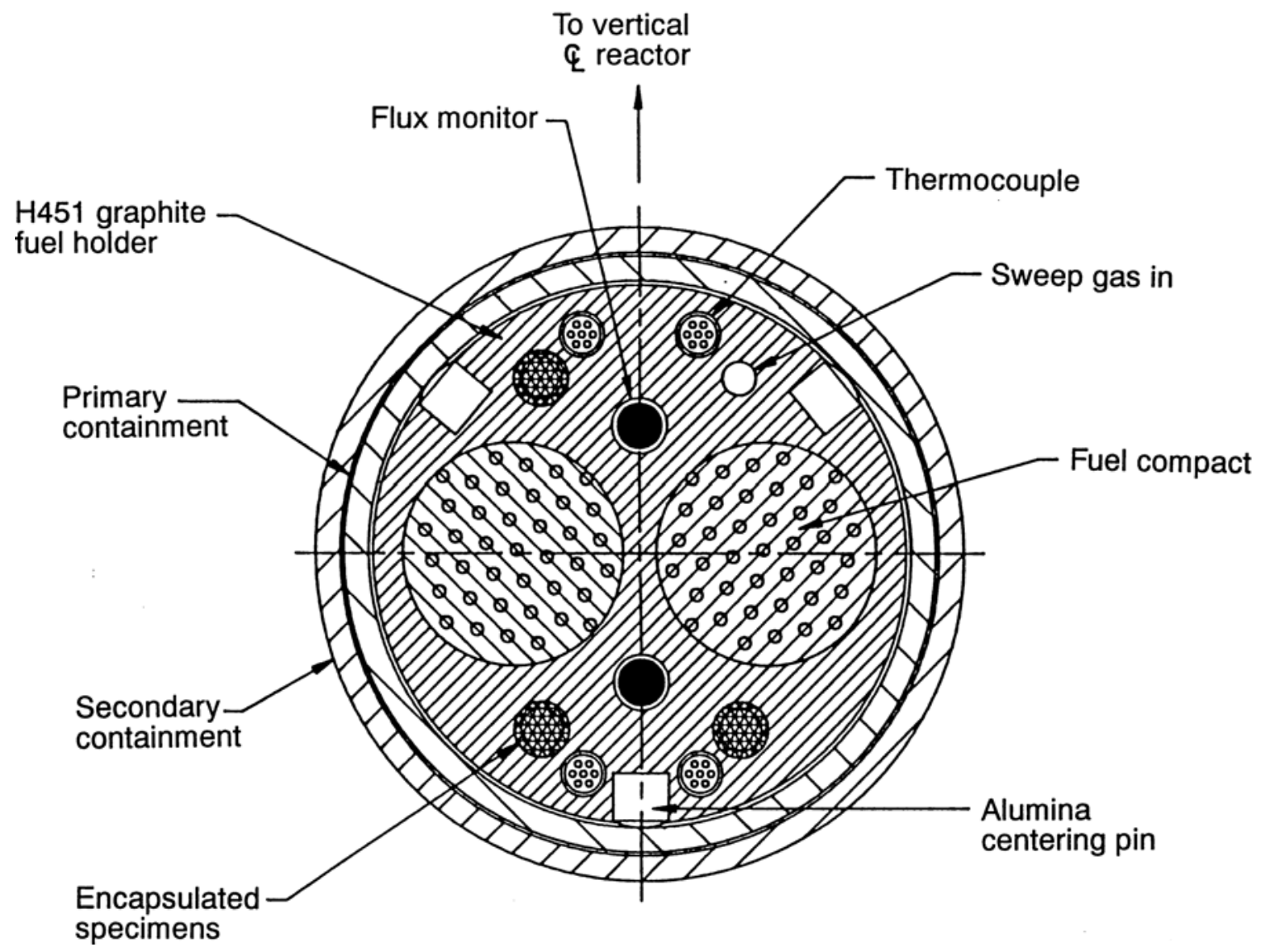

Figure 4-7. A schematic cross section of the NPR-1/2 irradiation capsule, showing the fuel compacts, thermocouple bundles, flux monitors and encapsulated specimen cavities and the sweep gas feed. The gas returns through the gap between the graphite and the Inconel-718 primary containment. The HFIR colling water is in contact with the outer wall of the secondary containment. 


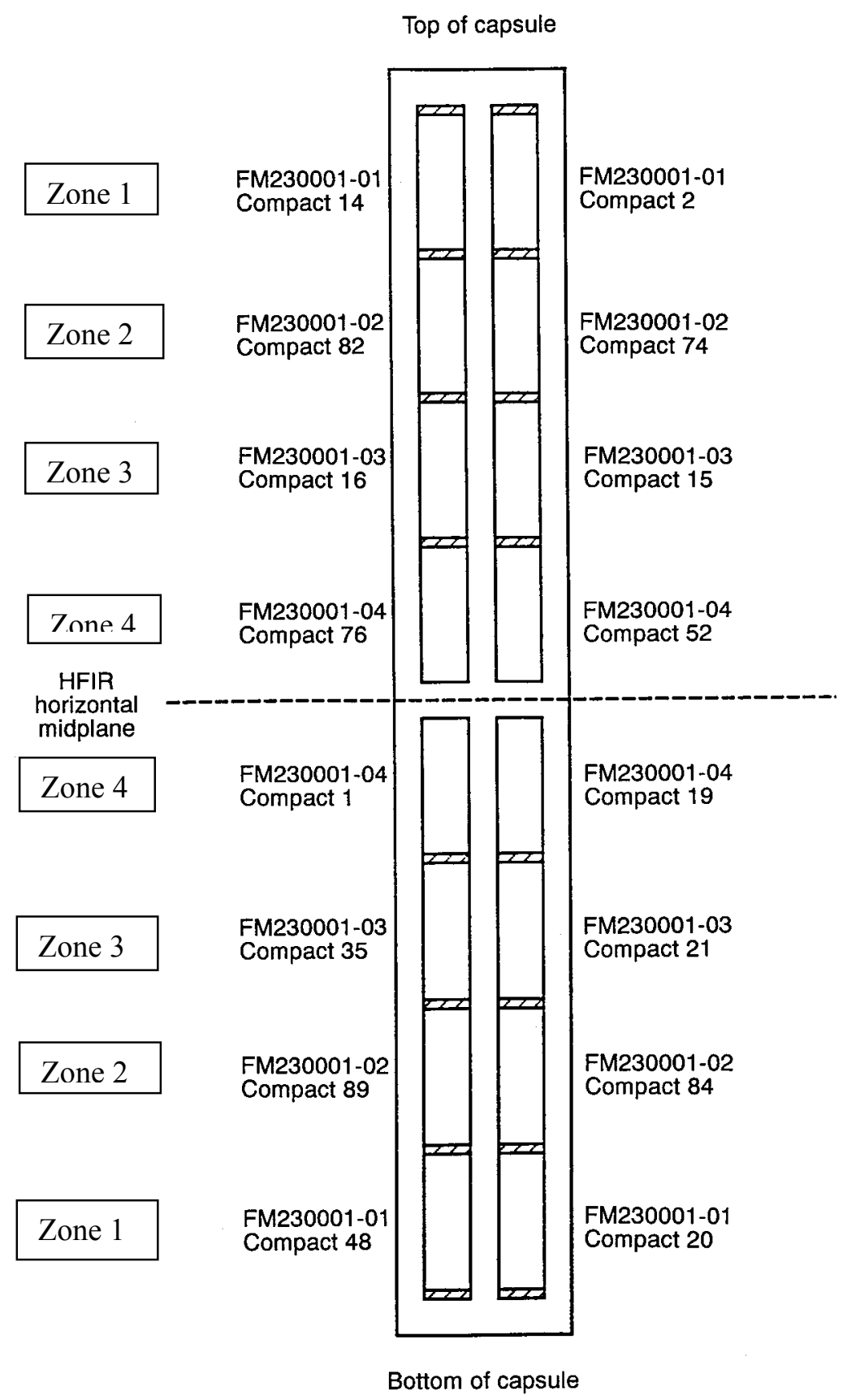

Figure 4-8. NPR-1 Fuel compact loading scheme. 
Irradiation on NPR-1 capsule began July 25, 1991, and was completed on May 29, 1992, at a peak fluence of $3.7 \times 10^{25} \mathrm{n} / \mathrm{m}^{2}$. The calculated capsule average temperature is plotted as a function of time in Figure 4-9. The calculated temperatures ranged from 727 to $1027^{\circ} \mathrm{C}$. Temperatures remained fairly constant over the first three cycles. However, there was a gradual decrease in temperatures during the last three cycles as the uranium was depleted from the compacts. Figure 4-10 is a plot of the fast fluence and Figure 4-11 is a plot of the burnup in the four zones of the NPR-1 capsule. The results indicate that most of the compacts achieved very high burnup and fluence during the irradiation. Two positions within the HFIR were used causing most of the burnup to be attained in the first three cycles before significant amounts of fast fluence were accumulated. In the last five cycles, the fuel saw a high fast fluence and a lower burnup rate.

Figure 4-12a is a plot of the ${ }^{85 \mathrm{~m}} \mathrm{Kr} \mathrm{R} / \mathrm{B}$ during the NPR-1 experiment. The R/B remained low $\left(\sim 10^{-8}\right)$ during the first 120 full power days. However, on January 2, 1992, at a peak fluence of $1.7 \times 10^{25} \mathrm{n} / \mathrm{m}^{2}$, the R/B increased to $1.7 \times 10^{-7}$ indicating particle failure. The peak burnup and temperature at the time of the first particle failure were $72 \% \mathrm{FIMA}$ and $1123^{\circ} \mathrm{C}$, respectively. The ${ }^{85 \mathrm{~m}} \mathrm{Kr} \mathrm{R} / \mathrm{B}$ continued to increase during the irradiation and reached a final value of $\sim 3 \times 10^{-4}$ at the end of the experiment. Based on these results and activity spikes recorded by the ionization chamber, 526 particles were estimated to have failed.

Irradiation of the NPR-2 capsule began August 28, 1991, and was completed on May 29, 1992, at a peak fluence of $3.7 \times 10^{25} \mathrm{n} / \mathrm{m}^{2}$. The calculated capsule average temperature is plotted as a function of time in Figure 4-13. The calculated temperatures ranged from 597 to $897^{\circ} \mathrm{C}$. Figure 4-14 is a plot of the fast fluence and Figure 4-15 is a plot of the burnup in the four zones of the NPR-2 capsule. As in the case of NPR-1, the results indicate that most of the compacts achieved high fluence during the irradiation. Most of the burnup was attained before the significant amounts of fast fluence were accumulated. 


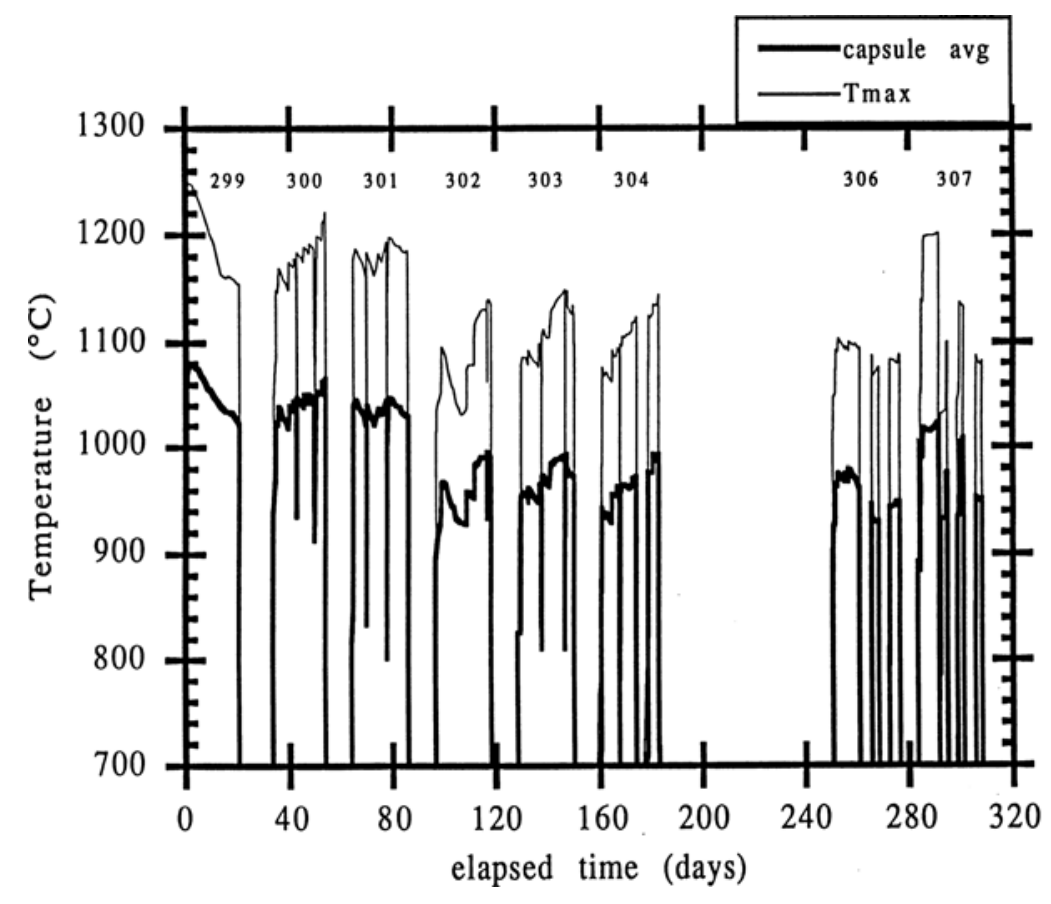

Figure 4-9. NPR-1 capsule averaged fuel compact temperature and the maximum local fuel compact temperature as a function of irradiation time.

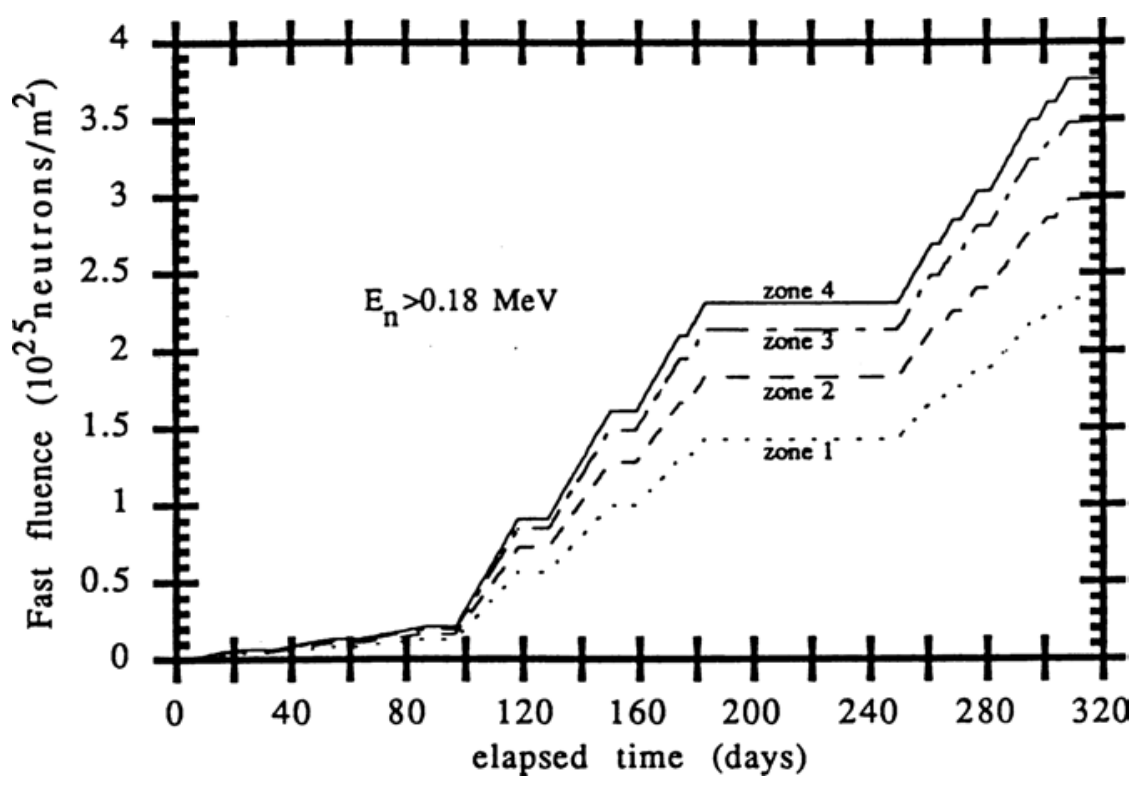

Figure 4-10. Calculated fast fluence as a function of irradiation time for the NPR-1 test. 


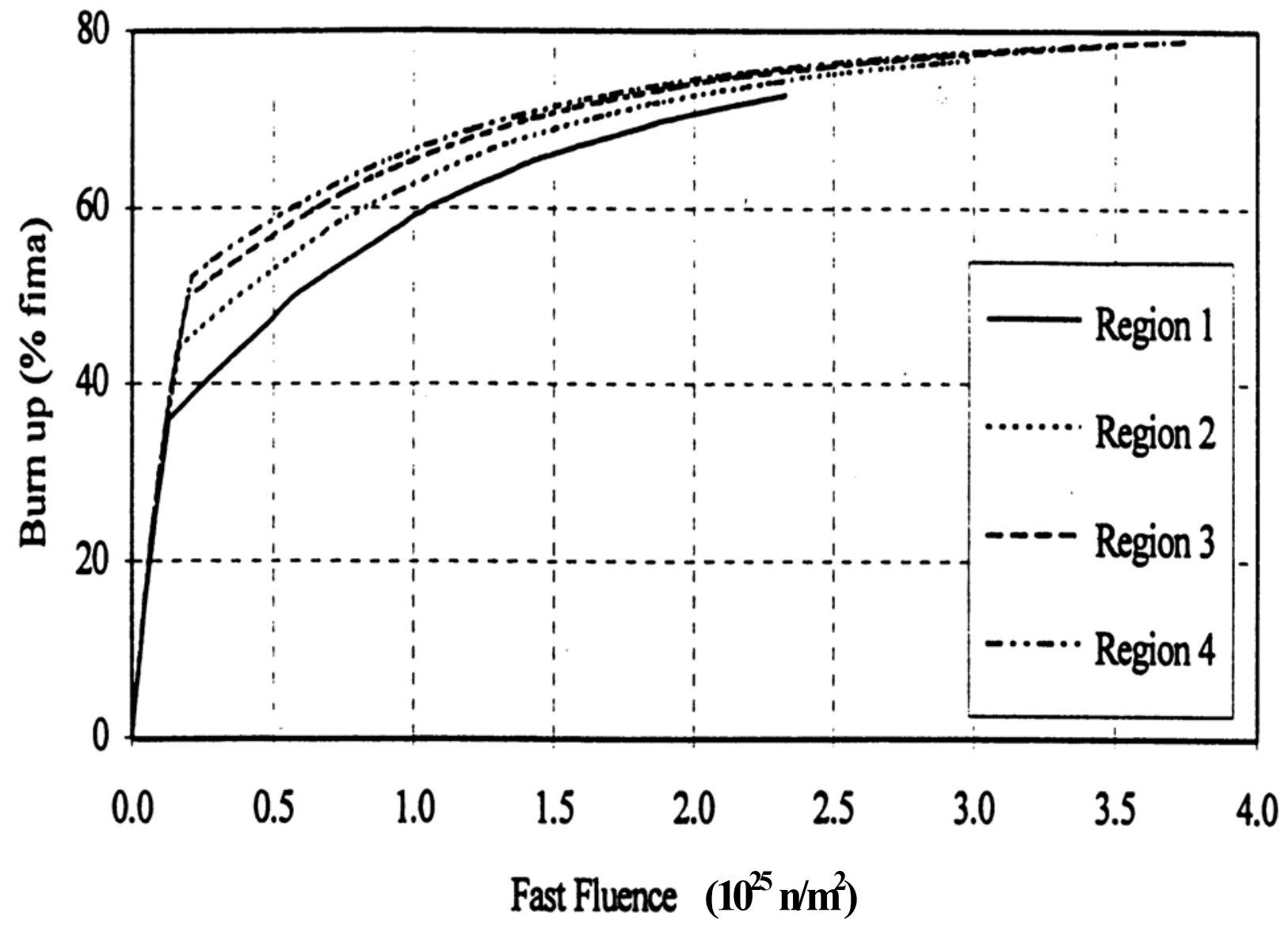

Figure 4-11. NPR 1 capsule fast neutron fluence versus burnup (\%FIMA). 


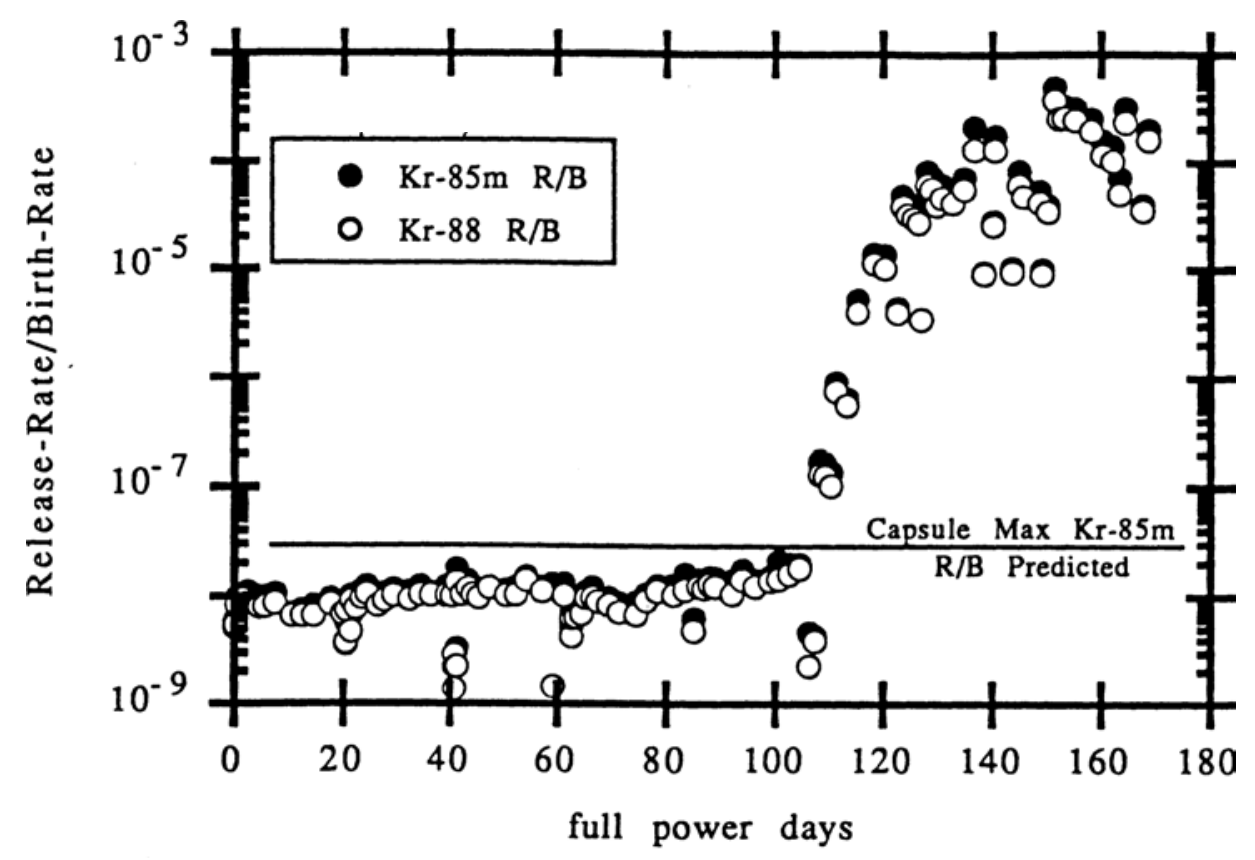

a.

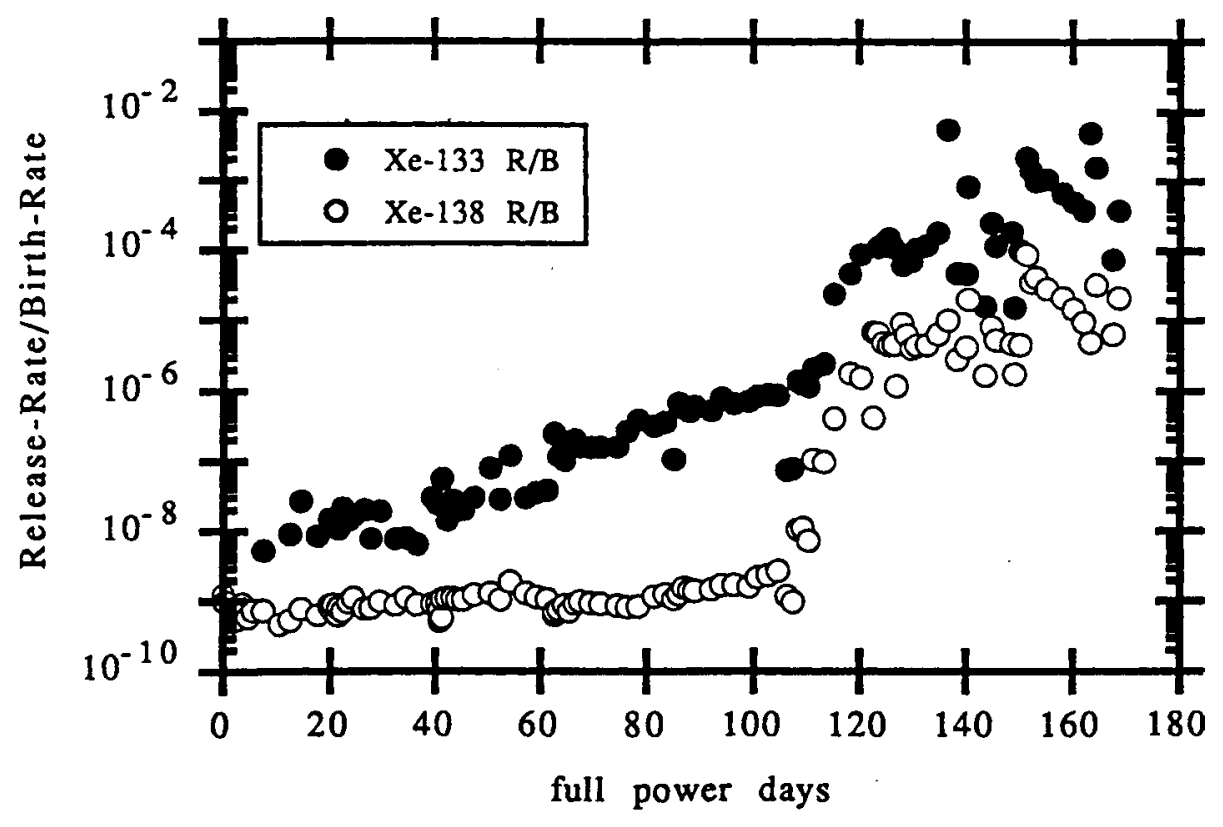

b.

Figure 4-12. a. NPR-1 calculated R/B ratios as a function of full power days for ${ }^{85 \mathrm{~m}} \mathrm{Kr}$ and ${ }^{88} \mathrm{Kr}$. b. NPR-1 calculated R/B ratios as a function of full power days for ${ }^{133} \mathrm{Xe}$ and ${ }^{138} \mathrm{Xe}$. 


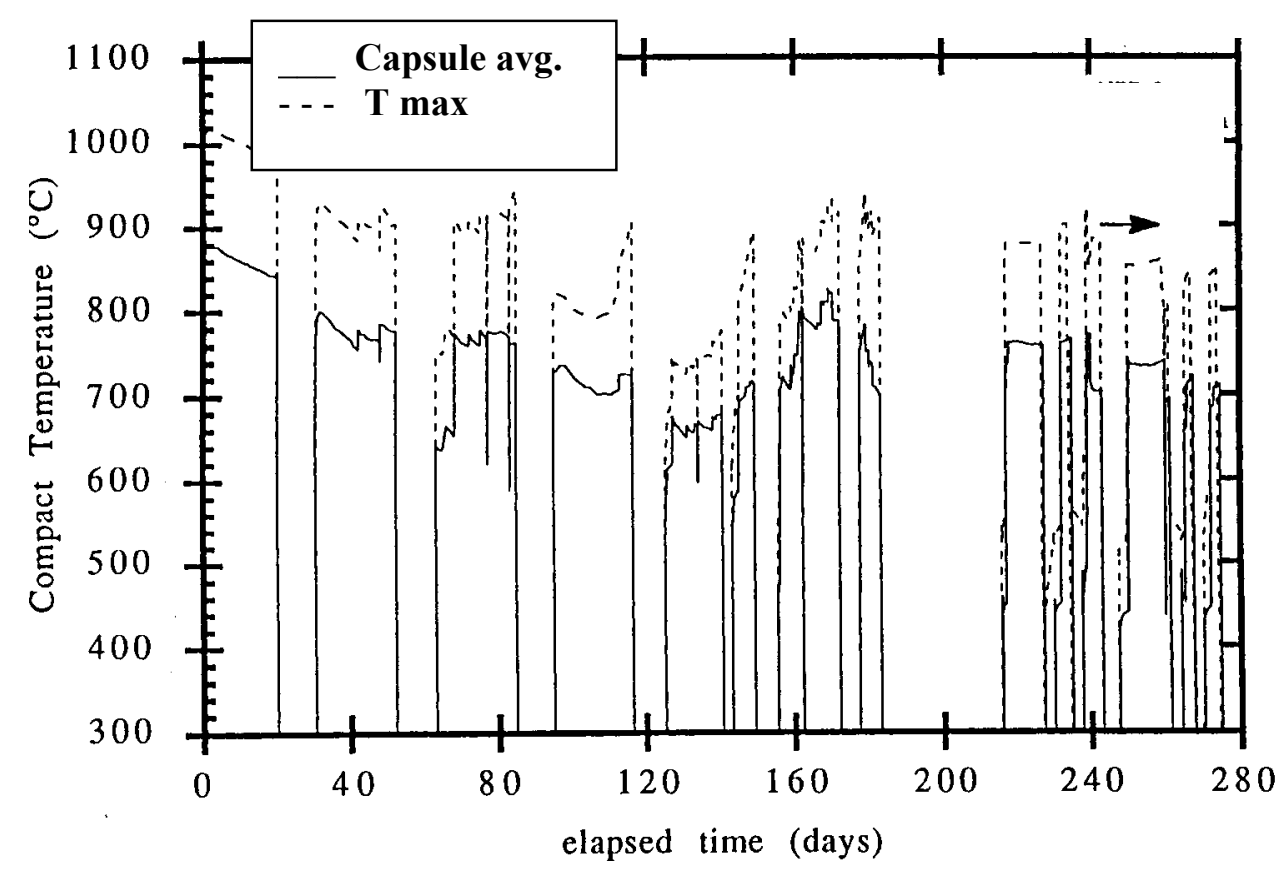

Figure 4-13. NPR-2 capsule averaged fuel compact temperature and the maximum local fuel compact temperature as a function of irradiation time.

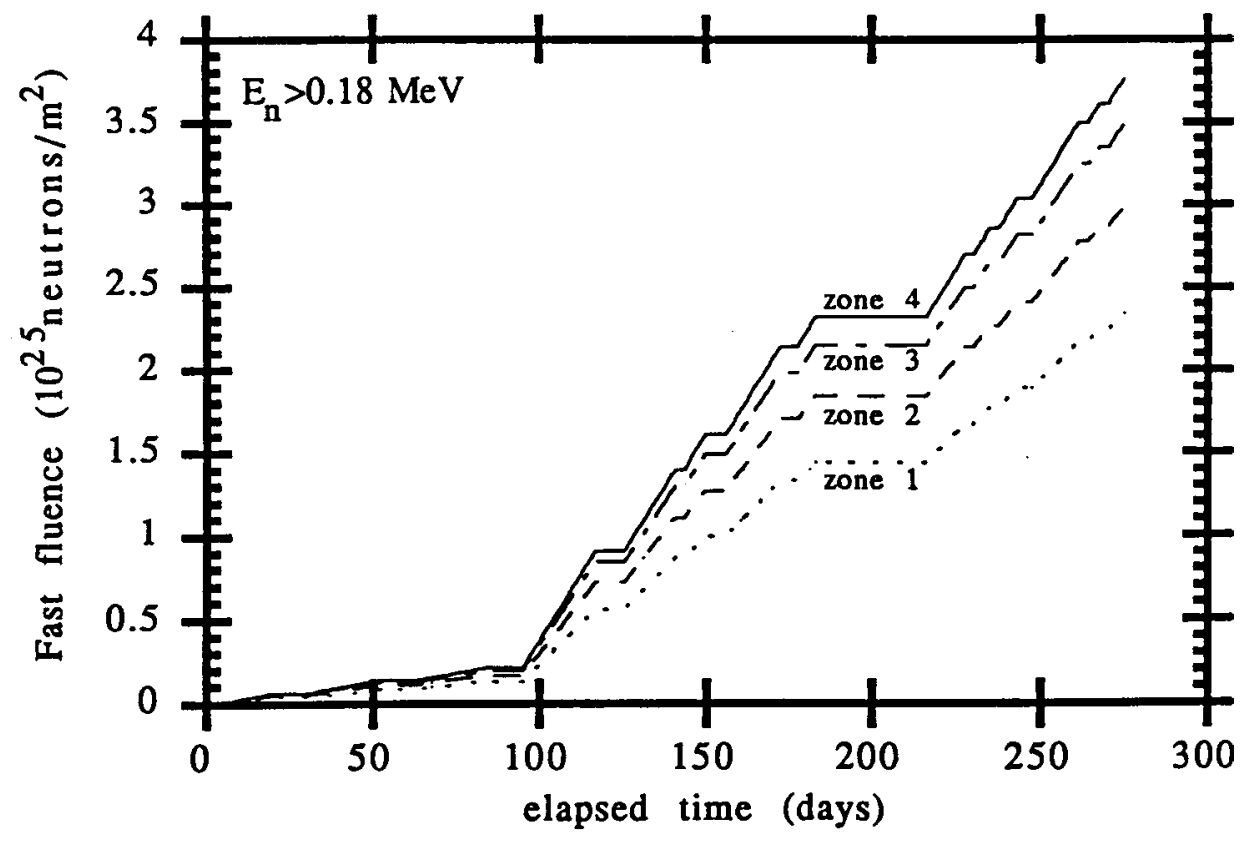

Figure 4-14. Calculated fast fluence as a function of irradiation time for the NPR-2 test. 


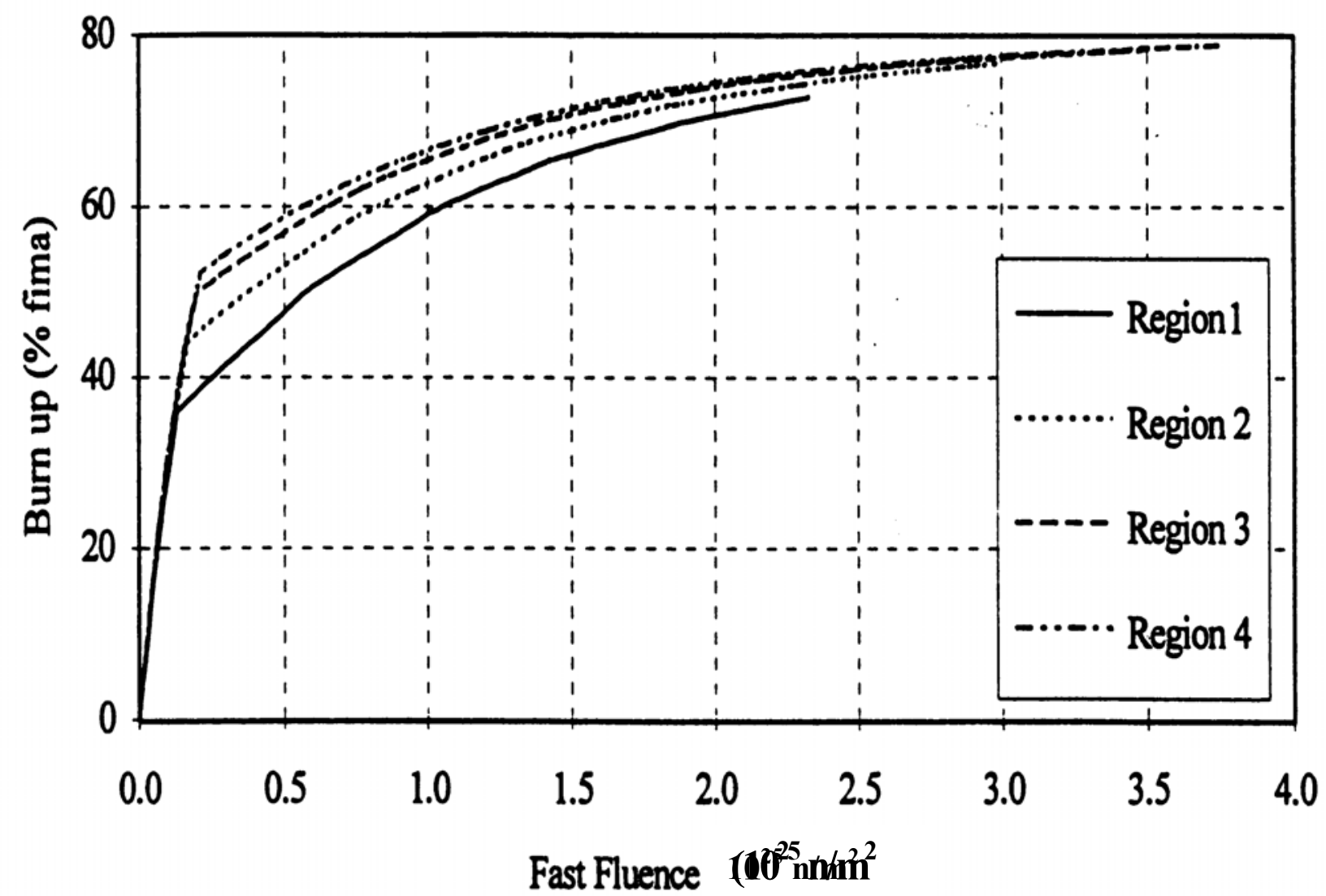

Figure 4-15. NPR 2 capsule fast neutron fluence versus burnup (\%FIMA)

Figure 4-16 is a plot of the ${ }^{85 \mathrm{~m}} \mathrm{Kr} \mathrm{R} / \mathrm{B}$ during the experiment. The R/B remained low $\left(<10^{-8}\right)$ during the first 120 full power days. However, on February 11, 1992, at a peak fluence of $2.0 \mathrm{x}$ $10^{25} \mathrm{n} / \mathrm{m}^{2}$, the R/B increased to $7 \times 10^{-7}$, indicating particle failure. The peak burnup and temperature at the time of particle failure were $75 \% \mathrm{FIMA}$ and $960^{\circ} \mathrm{C}$, respectively. The ${ }^{85 \mathrm{~m}} \mathrm{Kr}$ $\mathrm{R} / \mathrm{B}$ continued to increase during the irradiation and reached a final value of $\sim 6 \times 10^{-5}$ at the end of experiment. Based on these results and activity spikes recorded by the Geiger-Müller monitors, 135 particles were estimated to have failed. 


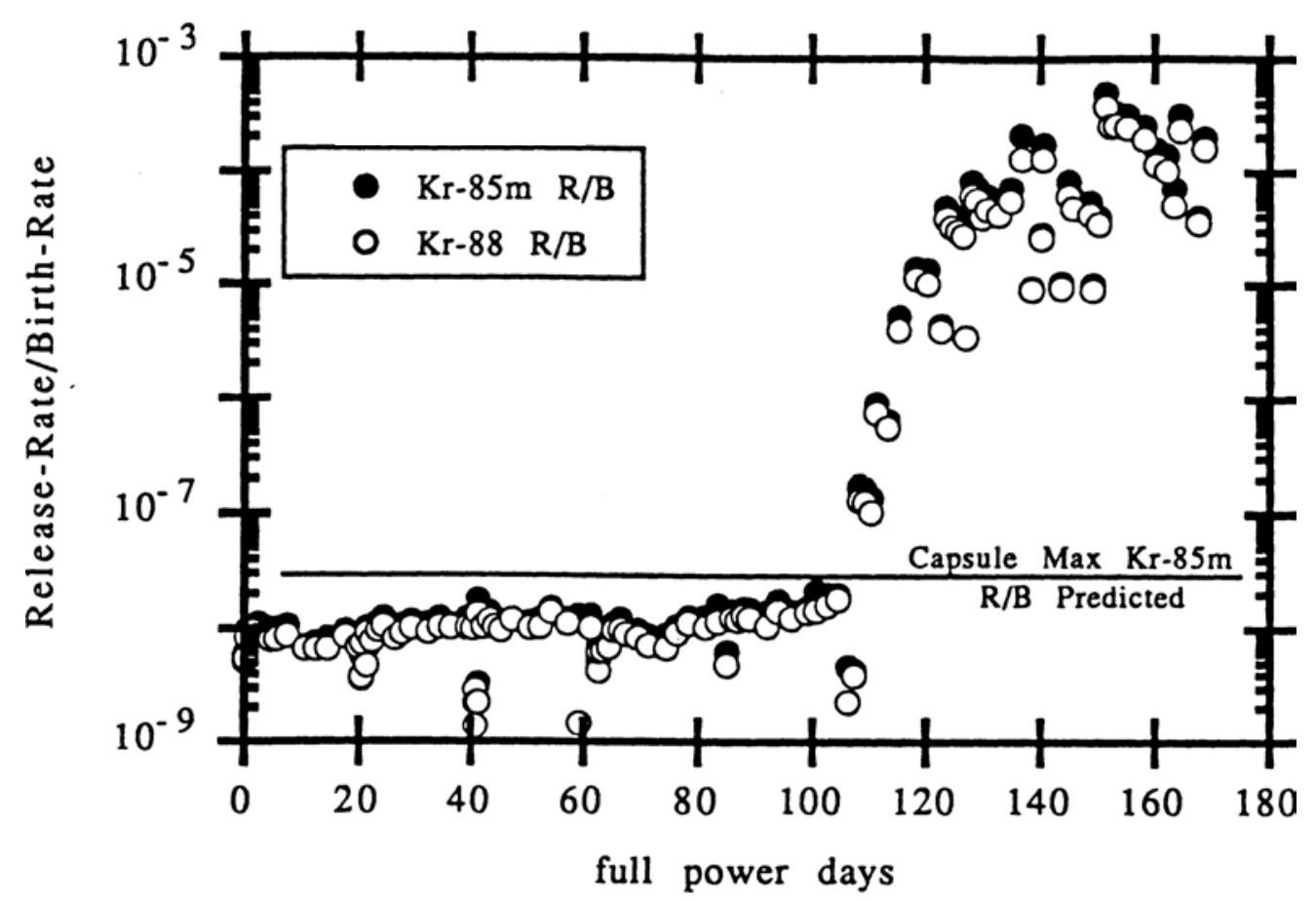

a.

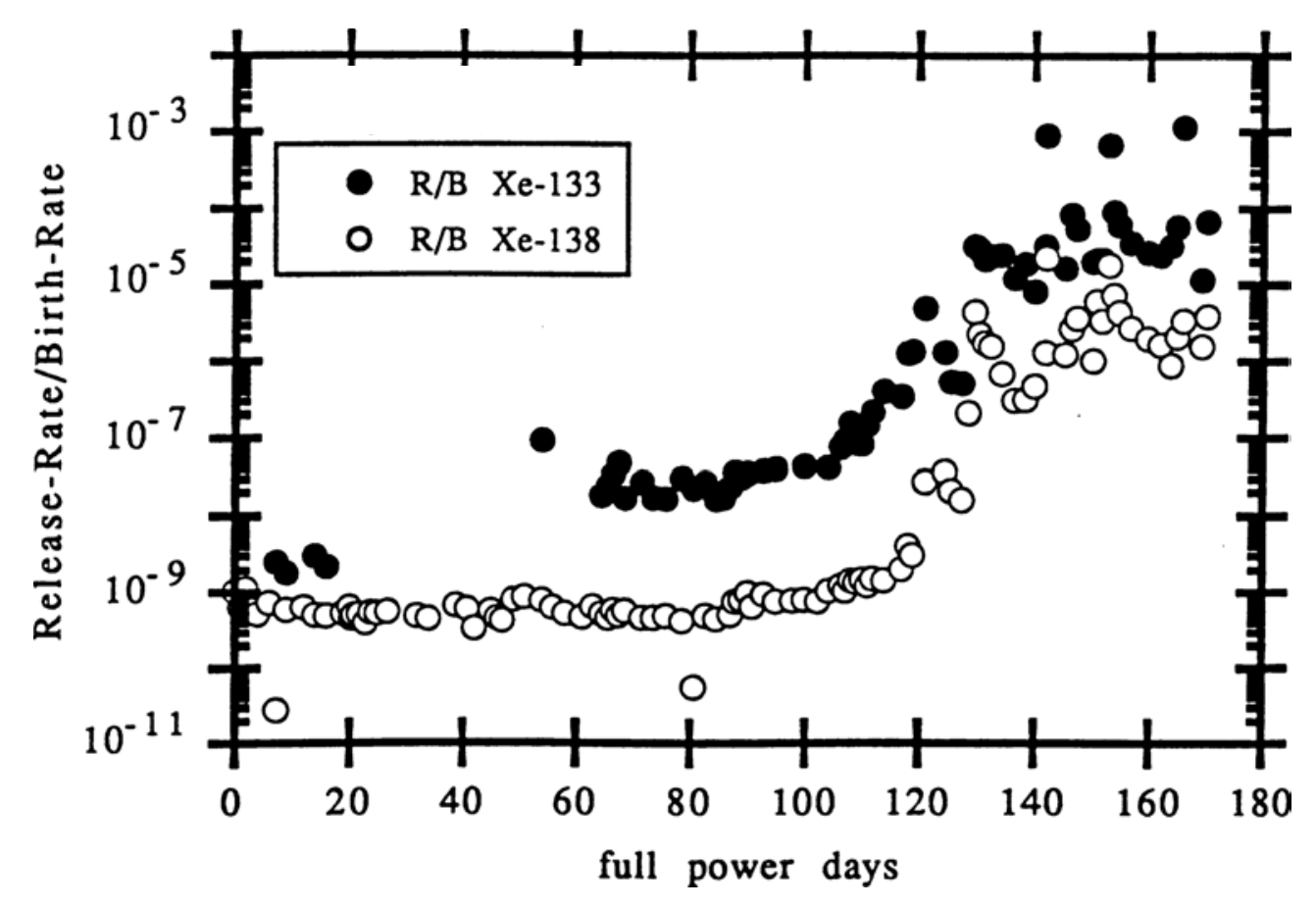

b.

Figure 4-16. a. NPR-2 calculated R/B ratios as a function of full power days for ${ }^{85 \mathrm{~m}} \mathrm{Kr}$ and ${ }^{88} \mathrm{Kr}$. b. NPR-2 calculated R/B ratios as a function of full power days for ${ }^{133} \mathrm{Xe}$ and ${ }^{138} \mathrm{Xe}$. 


\subsection{Comparison with Previous Gas Reactor Irradiations}

The three NP-MHTGR fuel irradiation capsules initially performed with very low gas release, in the range of $10^{-9}$ to $10^{-8} 85 \mathrm{~m} \mathrm{Kr}$ R/B. Prior U.S. capsules containing TRISO fuel typically exhibited $10^{-7}$ to $10^{-5}{ }^{85 \mathrm{~m}} \mathrm{Kr} \mathrm{R} / \mathrm{B}$, as illustrated in Figure 4-17. The HRB-21 capsule initially ran with ${ }^{85 \mathrm{~m}} \mathrm{Kr}$ $\mathrm{R} / \mathrm{B}$ of approximately $1.5 \times 10^{-8}$. Within the first month of irradiation (approximately $3 \% \mathrm{FIMA}$ and $0.5 \times 10^{25}$ fluence), however, the HRB-21 capsule containing NE-MHTGR fuel began having fuel failures. At the capsule EOL $\left(3.5 \times 10^{25} \mathrm{n} / \mathrm{m}^{2}\right.$ fluence), HRB-21 reached an ${ }^{85 \mathrm{~m}} \mathrm{Kr} \mathrm{R} / \mathrm{B}$ of approximately $2 \times 10^{-4}$.

As illustrated in Figure 4-18, other older, U.S. capsules began irradiation with an ${ }^{85 \mathrm{~m}} \mathrm{R} / \mathrm{B}$ of about $10^{-6} 85 \mathrm{~m} \mathrm{Kr} \mathrm{R} / \mathrm{B}$ and ended at about $5 \times 10^{-4}$. Thus, the previous capsules ended at about the same $\mathrm{R} / \mathrm{B}$, but began with significantly larger exposed uranium fractions. The NP-MHTGR capsules performed with no particle failures until relatively high burnups: 47\%FIMA for NPR-1A, 72\%FIMA for NPR-1, and 75\%FIMA for NPR-2. Past capsules (SLS-2, HRB-21, R2-K13, etc.) failed much earlier in burnup, but contained low amounts of enriched uranium. The fast fluences for onset may have been similar, but the early failures are somewhat masked by high initial ${ }^{85 \mathrm{~m}} \mathrm{Kr}$ R/B. The EOL R/Bs for all the capsules are similar. Plotting these versus EOL conditions of burnup, fast fluence, and capsule peak temperatures indicate no observable dependence except for a slight dependence on temperature. This dependence may be explained solely by the R/B behavior of a single particle with an exposed kernel versus temperature. It appears, therefore, that the root causes of TRISO particle failures in U.S. capsules had never been adequately addressed. We believe, however, that the performance of the NP-MHTGR capsules presents strong evidence for a feasible NPR reactor, because the core conditions are well enveloped by the irradiation conditions for the capsules. Feasible core fuel management options could further increase the margin of the core operating envelope by reducing peak fuel temperature, fluences, and burnups closer to the average values for these parameters. 


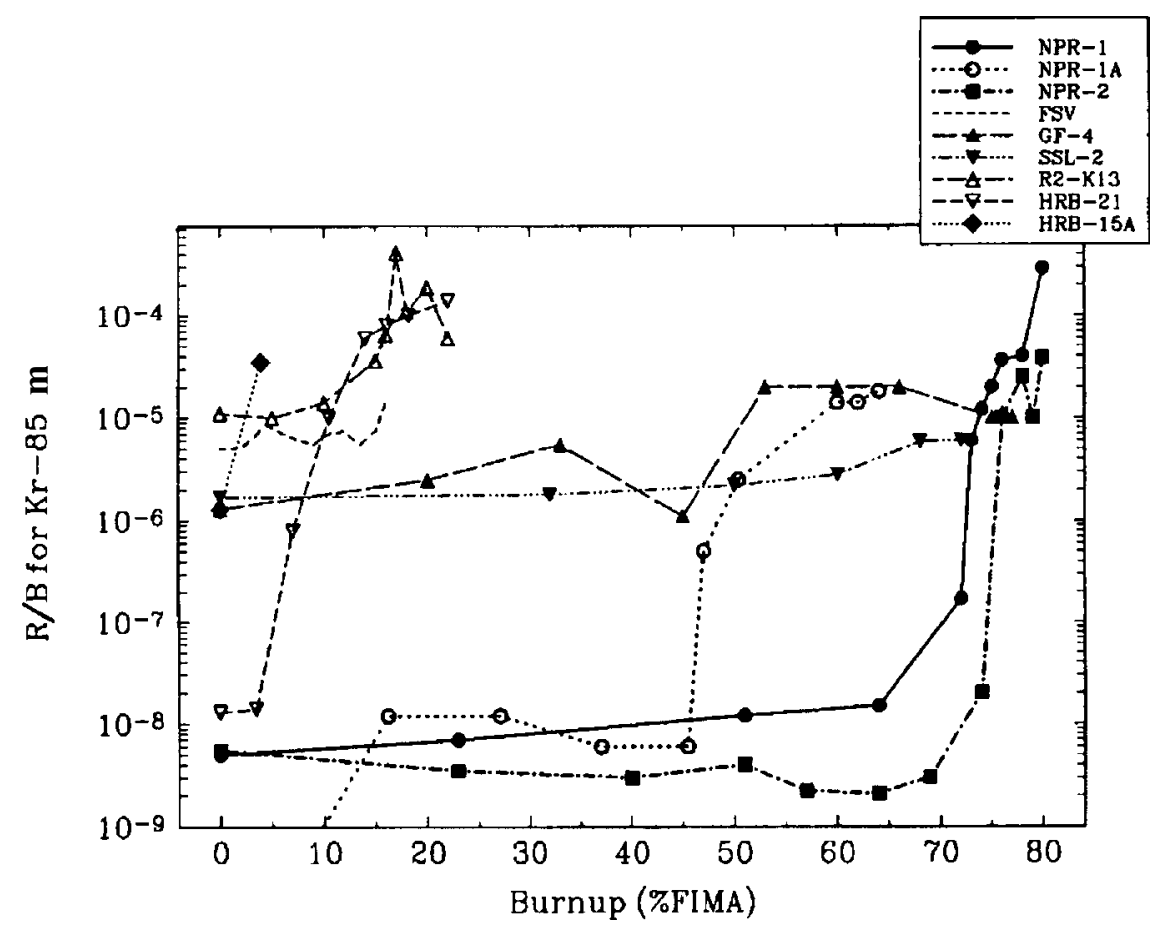

Figure 4-17. ${ }^{85 \mathrm{~m}} \mathrm{Kr} \mathrm{R} / \mathrm{B}$ versus burnup for various U.S. irradiations.

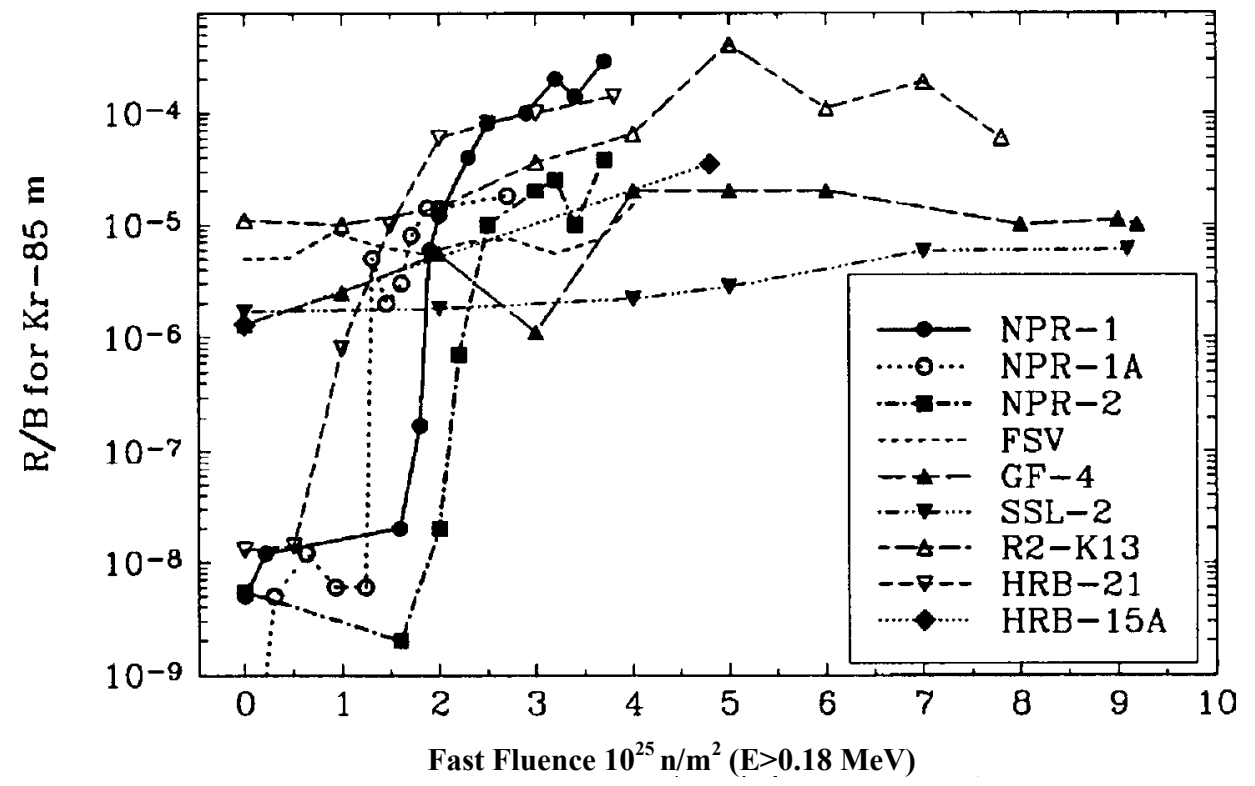

Figure 4-18. ${ }^{85 \mathrm{~m}} \mathrm{Kr} \mathrm{R} / \mathrm{B}$ versus fast fluence for various U.S. irradiations. 


\section{POSTIRRADIATION EXAMINATION}

As part of the NP-MHTGR Fuel Development Program (McCardell, 1992), a comprehensive postirradiation examination of the three irradiation capsules was planned to characterize the fuel performance and fission product behavior. The results were to be used to improve and validate models of fuel performance and fission product transport under normal operating and accident conditions. However, given the much higher than expected fuel failures evident from measurements of fission gas release during all three irradiations, it was decided to concentrate on examinations that would determine the cause(s) of fuel particle failure rather than investigate the fuel response to accident conditions. Examinations of both unirradiated fuel and irradiated test articles were used to determine the cause(s) of failure.

A variety of examination techniques were used to obtain information on the failure fraction of fuel particles in individual compacts and on the nature of the failures. The fraction of exposed kernels (failure of all protective coatings: $\mathrm{IPyC}, \mathrm{SiC}, \mathrm{OPyC}, \mathrm{PPyC}$ ) was measured by R/B as a result of reactivating compacts in a TRIGA reactor and by a leach-burn-leach (LBL) procedure carried out on one compact. The fraction of particles with $\mathrm{SiC}$ failure was measured by (a) radioisotope inventory of individual particles in the irradiated microsphere gamma analyzer apparatus after compact deconsolidation, (b) the initial leaching steps before burning of the LBL procedure, and (c) examination by optical microscopy of metallographic cross sections of compacts. These measurement techniques and their results are discussed in the following paragraphs, as are observations of kernel and coating layer conditions by metallography and fission product migration in fuel particles by scanning electron microscopy, which relate to $\mathrm{SiC}$ failure mechanisms.

\subsection{Fuel Characterization}

Initial irradiation testing of NP-MHTGR test fuel resulted in less than expected in-reactor performance. To obtain additional data for postirradiation examinations and to obtain more detailed information on fuel quality, a series of characterization tests was performed on fuel sample material. Characterization analyses centered around the kernel, the silicon carbide, and methods of accurately predicting the expected fission product release from the particles. 


\section{Kernel Characterization}

Because the fuel kernel chemistry was critical to management of fission products, the phases and phase distribution of fuel kernels were studied. Both oxygen and carbon-to-uranium ratios were determined during fabrication. The values, however, were obtained from dissolution and chemical analysis of samples of particles. A method was developed for kernel characterization that involved a quantitative phase distribution analysis of individual kernels. The individual particle analysis revealed that the fabrication analysis work was correct but the distribution had a tail primarily on the high carbide side. The high carbide phase distribution variants resulted from adherence of fuel to graphite container walls during sintering. A potential solution to the problem was to sinter particles using a specially developed $\mathrm{NbO}_{2}$ furnace liner, for which the particles have no affinity.

\section{Silicon Carbide Characterization}

The microstructure and strength of several different batches of SiC were studied extensively to determine if the NP-MHTGR SiC was inferior to the SiC used on other fuels manufactured at different times or by different vendors.

Optical ceramography and scanning electron microscopy (SEM) were used to thoroughly characterize as-manufactured fuel particle quality. NP-MHTGR SiC was determined to have a larger columnar grain structure than other SiC samples. In some cases, single grains extended nearly through the coating. The evaluation found evidence of lenticular voids and flaws in the $\mathrm{SiC}$ (called gold spots because of their appearance) that slightly decreased the structural strength of the SiC. The gold spot formation was determined to be the result of fuel particles leaving the reaction zone of the furnace during coating and contacting furnace surfaces to get contaminated with $\mathrm{SiC}$ ash, which was then sealed in the coating when the particle re-entered the reaction zone. Other fuels did not exhibit the gold spot defects. Contamination of the NP-MHTGR SiC was also observed in this study. The contamination, generally on the surface of the coating, was from chromium and nickel, presumably from sampling and handling equipment. Most of the other fuels tested also exhibited metallic contamination on the exterior surface of the coating.

$\mathrm{SiC}$ strength testing was performed with equipment to apply point source and dimple (distributed) compressive loads on the unsupported coated particle (Lessing, 1993). Finite element analysis 
revealed that point source loading put a small portion of the inner $\mathrm{SiC}$ surface under maximum tensile stress. The dimple loading tests stressed a large volume of the $\mathrm{SiC}$ with very high tensile loads. Sample sizes of 500 particles were tested for each fuel. Tests were performed both on the complete particles and with outer pyrocarbons burned away. Failure statistics on each group of 500 particles were analyzed using the traditional Weibull methodology.

It was found that dimple loaded specimens provided much lower strength than point source loaded particles, probably because of the higher stress distribution over a larger portion of the coating with the dimple loading. The coating strength was found to be determined by the type and size of flaws present in the coating rather than by the base material properties. Lowest strength particles were those with large flaws or cracks in the coating. Metallic inclusions (primarily $\mathrm{Cr}$ and $\mathrm{Ni}$ ) in the $\mathrm{SiC}$ also accounted for low strength. Gold spot particles were tested as a group, but did not show a large decrease in measured strength. Flaws associated with the gold spots however, appear to contribute to a low strength tail to the strength distribution. No deterioration in strength appeared to occur in the particles as a result of compacting, and some apparent healing or blunting of stress concentrators apparently occurs as a result of the compacting heat treatment operations. SiC manufactured by adding successive coatings without intermediate fuel removal and sampling was found to have the least coating contamination. The strength of the SiC in the PTF fuel was not significantly different than other particle type fuels.

\section{Fission Product Release Prediction}

Operation of a New Production Reactor will depend upon being able to accurately predict the life of the fuel and how it will perform during reactor service. The methods specified to predict such performance of the test fuel were inadequate. Alternate methods, including cesium release, methylene iodide intrusion, and mercury intrusion were evaluated to determine if they could accurately predict the performance actually obtained with the fuel.

Cesium release was expected to be a quality baseline for the fuel. At high temperatures $\left(1600^{\circ} \mathrm{C}\right)$, cesium is released essentially immediately through pyrocarbon but is still retained by high quality SiC. Cesium release testing of PTF particles and comparison with other similar particles show that the PTF particles had defect fractions approximately an order of magnitude higher than indicated in standard fuel quality tests. The as-fabricated defect fraction, however, was not adequate to explain the fuel's in-reactor performance. The best $\mathrm{SiC}$ tested was about 3 
times more retentive of cesium than the test fuel. Testing shows that cesium release was impractical in terms of time and irradiation required as a defect measurement tool. More importantly, it was shown that the test could not adequately identify fuel that would be expected to fail in reactor service because the in-service failures were not caused by initially defective SiC.

Mercury intrusion was tested by burning back and etching SiC coated particles and inserting them in a $\mathrm{Hg}$ penetrometer installed in a porosimeter, then pressurizing them for 30 minutes. After pressurization and slow pressure dissipation, the particles were removed and all external $\mathrm{Hg}$ was cleaned from their surfaces. Radiography was used to obtain evidence of Hg intrusion into the particle. Tests were performed at different pressures to determine whether any pressure-related differences affected test capability. The Hg intrusion test was found to be effective at identifying failed particles, but it was also responsible for breaking some particles, especially at higher intrusion pressures. Failures were found both from the initial pressurization and as a result of the pressurized $\mathrm{Hg}$ inside the particles after removal of external pressure. Radiographs were found difficult to interpret where small quantities of $\mathrm{Hg}$ were noted, and it could not be discerned whether contamination was internal or external.

Methylene iodide intrusion testing was performed by preparing particles as in the $\mathrm{Hg}$ intrusion test, followed by immersion in liquid $\mathrm{CH}_{2} \mathrm{I}_{2}$ for 16 hours at $0.69 \mathrm{MPa}$ (100psig). Sample particles were then surface cleaned and rapidly heated to $900^{\circ} \mathrm{C}$ to break down defective particles that were holding the iodide. A standard burn leach test was then used to ensure identification of the particles that had failed as a result of internal iodide expansion. The test was also highly effective in identifying failed particles. However, the fuel particles that had the highest quality according to cesium release tests results tended to fail at a very high rate with the iodide test.

Sample preparation for the methylene iodide test was shown to have a significant effect on the results obtained. The burn back of the particles was performed at $750^{\circ} \mathrm{C}$ for 144 hours. It is thought that very small defects in the high quality $\mathrm{SiC}$ allowed oxygen to pass through the $\mathrm{SiC}$, burning out a cavity for the iodide and resulting in particle failure on heating. This indicates that the burn leach test would also be more effective if more aggressive burnback is used in sample preparation.

Both methylene iodide and $\mathrm{Hg}$ intrusion tests could be correlated with burn leach test results for all but particles determined to have high quality using the Cesium release test. None of the tests, 
however, provided a good correlation with cesium release test results. The methylene iodide test showed promise as a manufacturing QC tool with the capability of finding defects as small as 13 nm.

\subsection{Exploratory Process Development}

Some process exploration was performed to determine the relationship between process parameters used for deposition of coatings and relative changes in product quality resulting from variations in process parameters. Such testing was limited by both time and funding because of the closeout of the NP-MHTGR program.

A statistical test program was devised that used a central composite experimental design to test ten settings of two variables. The ten tests were divided into two series. The first series included four scoping runs at the boundaries of the process feasibility field and a central point based on previous experience. The second set used one point to replicate the central point and four others to obtain more information around the optimum calculated from the first series. This test program was executed on the IPyC coating to study the effect of the coating gas to total gas ratio (CGR) and the total gas velocity to minimum fluidization ratio $\left(\mathrm{U} / \mathrm{U}_{\mathrm{mf}}\right)$ on $\mathrm{QC}$ characteristics of the coating. By statistically testing two variables simultaneously, both the effects and the interrelationships between the variables and coating quality were determined. The effects of the variables on coating density, microporosity, isotropy, and $\mathrm{HCl}$ gas permeability were determined for the test fuel. Contour plots were developed that showed the effect of the coating variables on each fuel coating property by mathematically evaluating coating variables in comparison with the measured coating properties. By comparing plots developed for key properties, an optimum coating process and reasonable coating process limits could be selected for future coating efforts.

The test shows that the CGR has a strong effect on the permeability of the coating, but that the $\mathrm{U} / \mathrm{U}_{\mathrm{mf}}$ has very little effect on any of the examined quality parameters. The test sequence defined an optimum process for depositing the IPyC coating and demonstrated that even highly experienced technical personnel could not predict the process requirements for an optimum coating. Review of several historical fuels show that the processes used in several cases were marginal at best for providing the desired pyrocarbon attributes. Exploratory type testing would be required to optimize other coatings prior to putting the particle fuel into production. 


\subsection{Irradiated Exposed Kernel Fraction}

Eight of the 16 compacts from each of the NPR-1 and NPR-2 capsules and all 20 of the compacts from capsule NPR-1A were given a standard fission gas release test in the TRIGA Mark 1 Reactor Facility at General Atomics. In this test, fission gas release was measured under irradiation for 30 minutes while the compact was held at $1100^{\circ} \mathrm{C}$. The fraction of exposed kernels in each compact was obtained by dividing the measured R/B values by the R/B for an exposed kernel (varied from 0.030 to 0.043 , depending on the irradiation exposure of the compact) under the conditions of the TRIGA R/B testing.

The eight compacts tested from each of the capsules (NPR-1 and NPR-2) were from the bottom half of these capsules, which were symmetrically located about the axial mid plane of the HFIR reactor with respect to the compacts in the top half of the capsules. Symmetry of burnup and fast fluence between compacts in the top and bottom halves of the capsule was assumed to lead to symmetry in TRIGA R/B values used to calculate the capsule average exposed kernel fraction. The capsule average values of exposed kernel fraction are compared with values based on end-oflife (EOL) in-pile R/B and counting radiation spikes (assumed to correspond to the release of fission gas upon particle failure) in the effluent coolant gas in Table 5-1. The ratios of exposed kernel fraction by TRIGA R/B to those based on EOL R/B indicate that values derived from TRIGA R/B were higher by factors that increase with decreasing irradiation temperatures. Apparently, TRIGA R/B testing at $1100^{\circ} \mathrm{C}$ caused an enhanced fission gas release rate relative to the fission gas release rate at the end-of-life in the lower temperature irradiations. The agreement between values of exposed kernels derived from EOL R/B and radiation spikes is remarkably good.

In addition to the high temperature of the TRIGA testing relative to irradiation temperatures, uncertainties were encountered both in extrapolation of the 30 minute data to steady state R/B values and in the U-235 content of high burnup compacts, which affected the calculation of fission gas birth rate. These uncertainties severely limit the usefulness of the TRIGA R/B results and suggest the need for improvements in this technique. However, the plots of particle failure fractions in individual compacts in Figure 5-1 indicate that the exposed kernel fraction was a strong function of fast fluence, in agreement with the capsule R/B data from the irradiations. 
Table 5-1. Comparison of exposed kernel fraction derived from TRIGA R/B, EOL R/B, and radiation spikes in experiment off gas.

\begin{tabular}{|l|c|c|c|c|c|}
\hline \multirow{3}{*}{ Capsule } & \multicolumn{3}{|c|}{ Capsule average } & \multicolumn{2}{c|}{$\begin{array}{c}\text { EOL } \\
\text { RatioVol. Ave. }\end{array}$} \\
\cline { 2 - 6 } & \multicolumn{3}{|c|}{ Exposed kernel fraction } & & \\
\cline { 2 - 6 } & Spikes & EOL R/B* & TRIGA R/B & TRIGA/ EOL & Temp. $\left({ }^{\circ} \mathrm{C}\right)$ \\
\hline NPR-1A & 0.00064 & 0.00064 & 0.0026 & 4.1 & 977 \\
\hline NPR-1 & 0.0068 & 0.0025 & 0.104 & 4.2 & 974 \\
\hline NPR-2 & 0.0017 & 0.0011 & 0.090 & 82 & 753 \\
\hline
\end{tabular}

${ }^{*}$ Assumes ${ }^{85 \mathrm{~m}} \mathrm{Kr}$ R/B for a failed particle $=0.028$ for NPR-1A, 0.012 for NPR-1, and 0.054 for NPR-2 with EOL R/B for NPR-1A $=1.8 \times 10^{-5}$ EOL R/B for NPR-1 $=3 \times 10^{-4}$ EOL R/B for NPR-2 $=6 \times 10^{-5}$
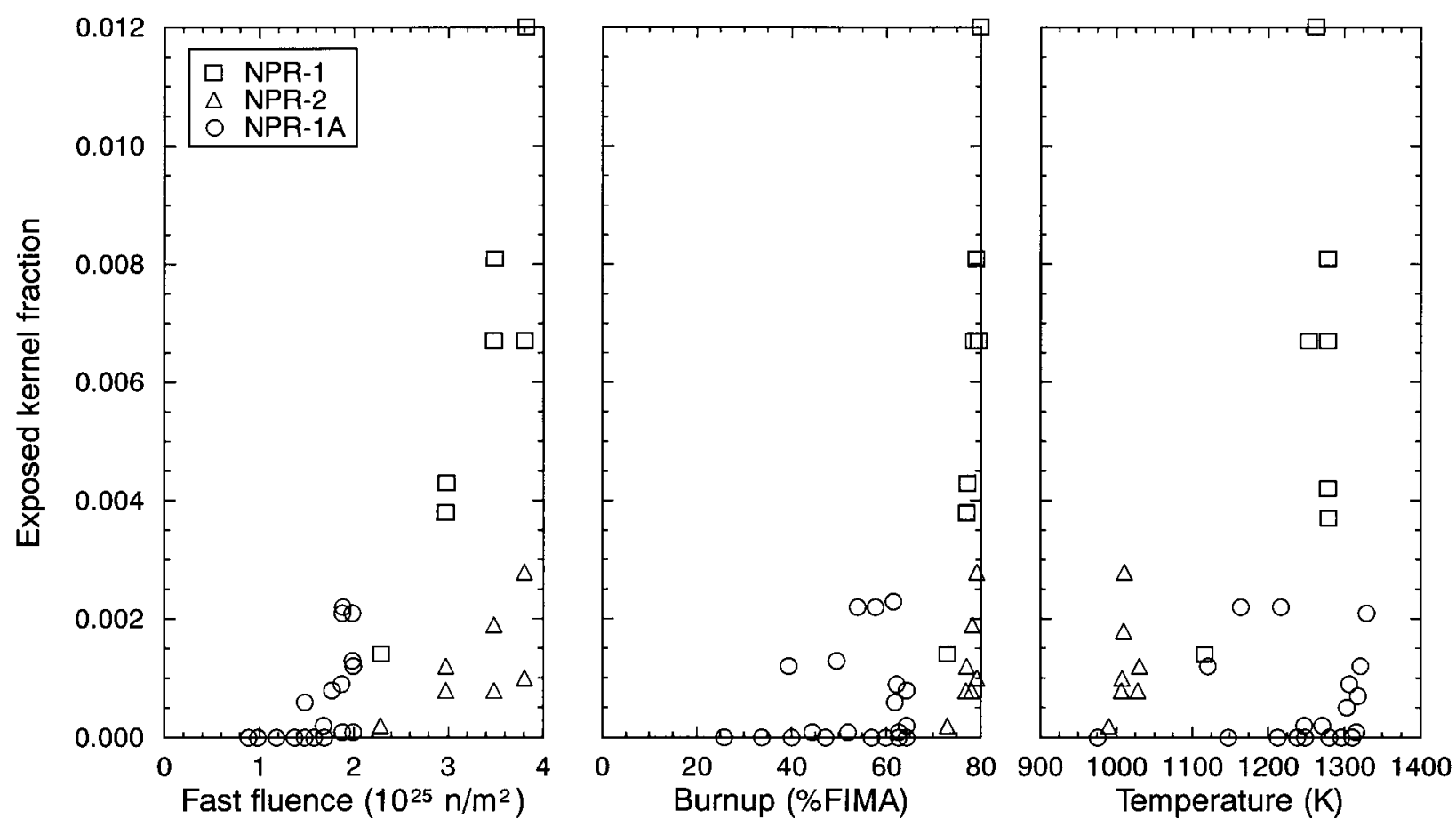

Figure 5-1. Exposed kernel fraction (from normalized TRIGA R/B) versus fast fluence, temperature and burnup. 
A leach-burn-leach (LBL) procedure was carried out on compact NPR-1 B6. It consisted of a 24hour leach in boiling concentrated nitric acid $(14 \mathrm{M})$, plus hydrofluoric acid $(.03 \mathrm{M})$ to dissolve kernels that had been exposed by the failure of all the coating layers. This was followed by a burn in air at $750^{\circ} \mathrm{C}$ for 48 hours to remove all compact matrix and PyC layers (including any intact IPyC beneath failed $\mathrm{SiC}$ ), and finally a 48-hour leach (under the same conditions as above) to dissolve any kernels exposed by the burn, providing a measure of the fraction of particles with failed SiC but intact IPyC layers. The ${ }^{95} \mathrm{Zr}$ and ${ }^{144} \mathrm{Ce}$ contents of the leach solutions were determined by radiochemical analysis. These fission products were expected to remain with the kernel and serve as a measure of the fraction of the kernels in the compact dissolved in the leach solutions. The results of these measurements are included in Table 5-2 and show reasonable agreement with results of $\mathrm{SiC}$ failure fraction based on other measurements. Although used to a very limited extent in this PIE, LBL showed promise as a method for determining exposed kernel fraction and $\mathrm{SiC}$ failure fraction in irradiated compacts, and is a candidate for continued development. 
Table 5-2. Particle Failure in NP-MHTGR fuel compacts. IMGA Met LBL*LBL**

\begin{tabular}{|c|c|c|c|c|c|c|}
\hline \multirow[t]{2}{*}{ Compact } & \multirow{2}{*}{$\begin{array}{c}\text { Fast } \\
\text { fluence } \\
\left(10^{25} \mathrm{n} / \mathrm{m}^{2}\right.\end{array}$} & \multirow{2}{*}{$\begin{array}{l}\text { Burnup } \\
\text { (\%FIMA) }\end{array}$} & \multicolumn{3}{|c|}{ SiC failure fraction } & \multirow{2}{*}{$\begin{array}{c}\begin{array}{c}\text { Exposed } \\
\text { kernel }\end{array} \\
\text { LBL }^{* *}\end{array}$} \\
\hline & & & IMGA & Met & LBL* & \\
\hline $\begin{array}{l}\text { NPR-1 } \\
\text { A5 } \\
\text { NPR-1 } \\
\text { B4 } \\
\text { NPR-1 } \\
\text { B5 } \\
\text { NPR-1 } \\
\text { B6 }\end{array}$ & $\begin{array}{l}3.7 \\
3.7 \\
3.7 \\
3.5\end{array}$ & $\begin{array}{l}79 \\
79 \\
79 \\
78\end{array}$ & $\begin{array}{r}0.038^{\mathrm{a}} \\
0.02^{\mathrm{b}}\end{array}$ & $0.03 / 0.006^{\mathrm{f}}$ & 0.014 & 0.013 \\
\hline $\begin{array}{l}\text { NPR-2 } \\
\text { A4 } \\
\text { NPR-2 } \\
\text { B4 }\end{array}$ & $\begin{array}{l}3.7 \\
3.7\end{array}$ & $\begin{array}{l}79 \\
79\end{array}$ & $0.002^{\mathrm{c}}$ & $0.06 / 0.03^{\mathrm{g}}$ & & \\
\hline $\begin{array}{l}\text { NPR-1 } \\
\text { A8 } \\
\text { NPR-1 } \\
\text { B8 }\end{array}$ & $\begin{array}{l}2.3 \\
2.3\end{array}$ & $\begin{array}{l}73 \\
73\end{array}$ & $0.002^{\mathrm{d}}$ & $0.00 / 0.00^{\mathrm{h}}$ & & \\
\hline $\begin{array}{l}\text { NPR-1 } \\
\text { A9 } \\
\text { NPR-1 } \\
\text { A1 }\end{array}$ & $\begin{array}{l}1.9 \\
1.9\end{array}$ & $\begin{array}{l}64 \\
62\end{array}$ & $0.002^{\mathrm{e}}$ & $0.06 / 0.01^{j}$ & & \\
\hline
\end{tabular}
a. 22 failures out of 582 particles examined
b. 19 failures out of 972 particles examined
c. 1 failure out of 424 particles examined
d. 1 failure out of 500 particles examined
e. 1 failure out of 450 particles examined
f. 1 failure out of 39 particles with kernels/ 1 failure out of 178 particles with or without kernels
g. 5 failures out of 84 particles with kernels/ 8 failures out of 287 particles with or without kernels
h. $\quad 0$ failures out of 53 particles with kernel/ 0 failures out of 260 particles with or without kernels
i. 1 failure out of 17 particles with kernel/ 1 failure out of 83 particles with or without kernels

LBL* Based on an average of fractions of ${ }^{95} \mathrm{Zr}$ and ${ }^{144} \mathrm{Ce}$ leached during a 24-hour leach before burn and 48-hour leach after burn.

$\mathrm{LBL}^{* *}$ Based on an average of fractions of ${ }^{95} \mathrm{Zr}$ and ${ }^{144} \mathrm{Ce}$ leached during a 24 -hour leach before burn. 


\subsection{Irradiated SiC failure fraction}

Compacts from the NPR-1 and NPR-2 capsules were deconsolidated by an electrochemical process, and compact NPR-1A 13 was deconsolidated by burning to obtain particles for IMGA (individual microsphere gamma analyzer) examination to determine the fraction of particles with failed SiC. The IMGA measured the content of gamma-emitting nuclides in individual particles. The ratio ${ }^{137} \mathrm{Cs} /{ }^{144} \mathrm{Ce}$ was used as a measure of $\mathrm{SiC}$ integrity. ${ }^{144} \mathrm{Ce}$ remained within exposed kernels, whereas ${ }^{137} \mathrm{Cs}$ could only be retained by an intact $\mathrm{SiC}$ layer. Values of $\mathrm{SiC}$ failure measured by IMGA are presented in Table 5-2. The values of 0.02 and 0.038 measured on the high fluence compacts NPR-1 B4 and B5 are in reasonable agreement with the value of 0.014 obtained from LBL for compact NPR-1 B6. Agreement between values of exposed kernel fraction and $\mathrm{SiC}$ failure fraction was expected, given the large fractional failure of the PyC layers discussed below.

Optical metallography of compact cross sections was used primarily to characterize the condition of the kernel and coating layers, to measure failure fractions of PyC layers, and to investigate $\mathrm{SiC}$ failure mechanism. When SiC failure fractions exceed 0.01 , metallography can also provide data on $\mathrm{SiC}$ failure fraction, since, frequently, the number of particles examined in cross sections of a compact is about 100. Two numbers are given in Table 5-2 for the SiC failure fraction determined by metallography. The first number resulted from the examination of particles in which the kernel was retained through the grinding and polishing process, the second includes all particles examined, with or without kernels. There appeared to be a tendency for metallography to overestimate $\mathrm{SiC}$ failure fraction relative to other methods, especially when using the relatively smaller number of observations based only on particles containing kernels.

The comparison of particle failure fractions in Table 5-2 points to the necessity of measuring a sufficient number of particles to obtain reasonable statistical significance in the results. Methods that use all the particles in a compact, such as TRIGA R/B and LBL, were attractive. In principle, IMGA could also be used to examine a large fraction or all the particles in a compact, but in practice, the handling of individual particles, even though automatic in the IMGA machine, was time consuming, resulting in a throughput of about 250 particles per day. 


\subsection{Irradiated Kernel and Coating Layer Conditions}

Metallography of cross-sectioned compacts is a powerful tool for observing the condition of the kernel and coating layers of the TRISO fuel particle. The technique required care in epoxying to retain fuel particles and in polishing to avoid producing artifacts and to reveal cracking, porosity, material interactions in layers, and photography to record the observations. Judgement is required in the selection of compacts on which to apply this time consuming, but essential, examination process.

Kernels were observed to contain large gas voids and to have undergone swelling at the high burnups in the NP-MHTGR irradiations (up to 79\%FIMA). Generally, the kernels retained a spherical shape and were contained in the densified buffer coating, as illustrated in Figure 5-2. Occasionally, the buffer cracked radially and the swelling kernel extruded through the crack to the IPyC layer, as shown in Figure 5-3. No chemical attack of the IPyC by the kernel or by fission products was observed.

Most often, shrinkage of the buffer led to the opening of an annular gap between the buffer and the IPyC, as in Figure 5-2. In only about $5 \%$ of the buffers did irradiation-induced densification of the buffer lead to the formation of radially oriented shrinkage cracks as in Figure 5-3. Radial cracks were observed in IPyC layers with increasing frequency as a function of fast fluence, occurring in up to $65 \%$ of the particles in a compact cross section at the highest exposure. The cause of these cracks was thought to be irradiation-induced shrinkage of the IPyC, which was thicker than the IPyC layers previously used (53 versus $35 \mu \mathrm{m}$ ) and less isotropic [Bacon anisotropy factor, optical $\left(\mathrm{BAF}_{\mathrm{o}}\right)=1.06 \mathrm{vs} .<1.04$ for optimal performance]. The IPyC had been made thicker to reduce the chemical interaction of kernels with corrosive gases during $\mathrm{SiC}$ coatings in the particle manufacturing process.

The cracks in the IPyC were observed not to propagate directly into the $\mathrm{SiC}$, although, whenever a radial crack was observed in the $\mathrm{SiC}$, it was located near a crack in the IPyC. A planar view of a spherical object could also explain why the cracks do not seem to align. Contact between the IPyC and SiC layers was maintained except in the neighborhood of the IPyC cracks, where irradiation shrinkage appeared to have caused the IPyC to pull away from the SiC toward the particle's center. These features are shown in the particle cross section in Figure 5-4. 
The only though-wall cracks in the $\mathrm{SiC}$ were observed to be radial in orientation, as shown in Figure 5-4. Some short circumferential cracks were observed on the inside surface of the $\mathrm{SiC}$ that did not penetrate a great distance into the layer, as illustrated in the cross section in Figure 5-5. Much longer circumferential cracks were observed in one low exposure compact cross section as shown in Figure 5-6. It is suspected that these cracks may have been induced by grinding and polishing during metallographic preparation of the compact cross section, as this type of cracking was not observed in compacts at higher irradiation exposures. In general, it is thought that cracks were not induced into the brittle SiC layer during metallographic mount preparation, as evidenced by stable crack patterns observed in successive grindings of the same mount and the absence of new cracks developing in successive grindings. Occasionally, evidence of porosity in the SiC was found, as illustrated in Figure 5-7. Such porosity was sometimes observed in the metallographic examination of particles that had been identified by IMGA to have lost cesium, but the principal characteristic that separated cesium-releasing particles from cesium-retaining particles was through-wall radial cracks in the $\mathrm{SiC}$ layer. Figure 5-8 shows an example of lenticular inclusion (gold spot) occasionally observed in the $\mathrm{SiC}$, but not associated with failure of the coating. Asphericity of particles was not observed to be associated with SiC failure, as many of the failures were in nearly spherical particles, and strongly aspherical particles generally did not fail. 


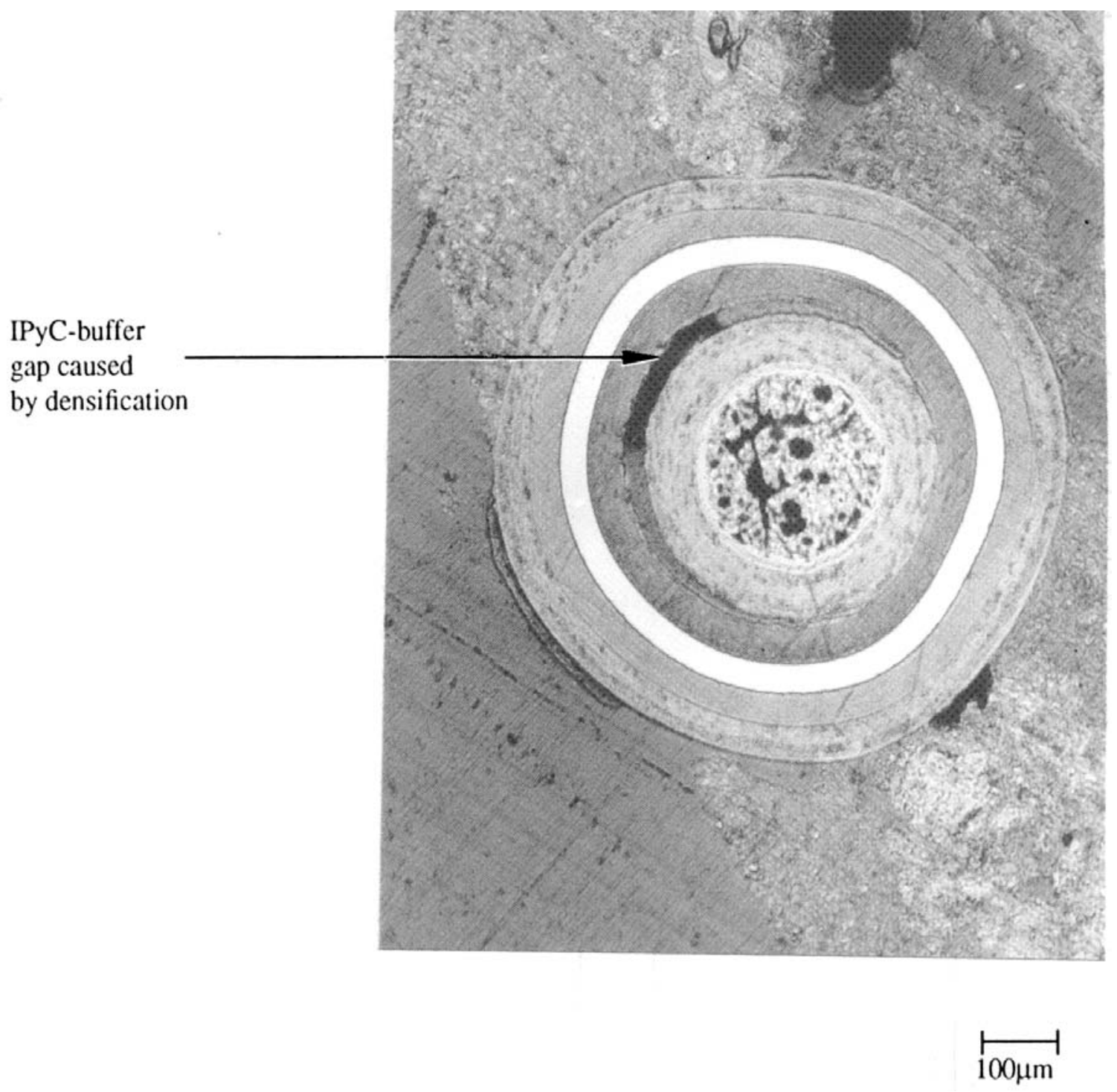

Figure 5-2. Irradiation-induced shrinkage of buffer caused a gap between the IPyC and buffer. Fission gas bubbles in the kernel indicate kernel swelling took place. $\left(3.7 \times 10^{25} \mathrm{n} / \mathrm{m}^{2}, 79 \% \mathrm{FIMA}\right.$, $\left.746^{\circ} \mathrm{C}\right)$. 


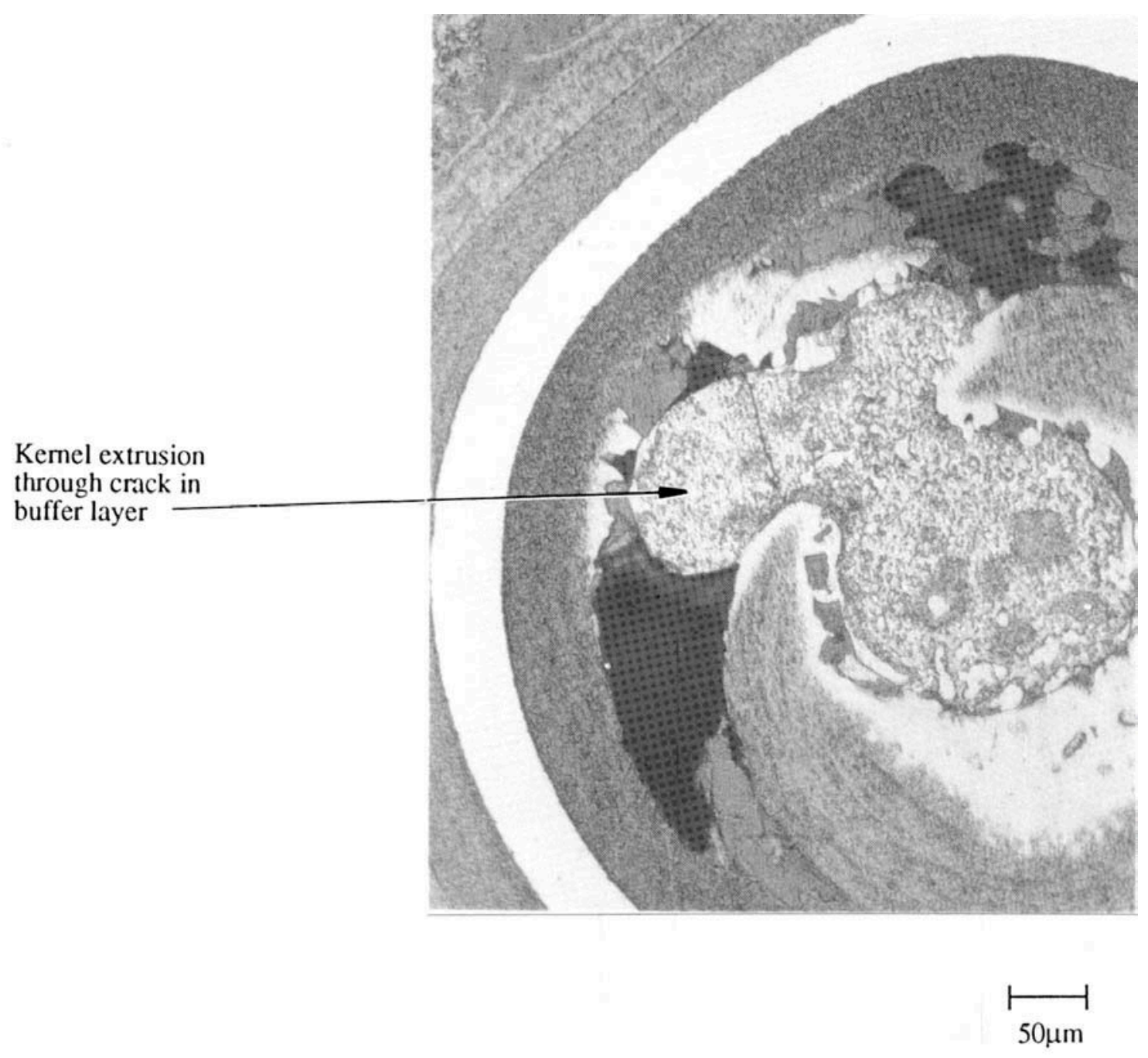

Figure 5-3. Kernel swelling through a radial crack in the buffer was effectively retained by IPyC. $\left(3.7 \times 10^{25} \mathrm{n} / \mathrm{m}^{2}, 79 \%\right.$ FIMA, $\left.987^{\circ} \mathrm{C}\right)$. 


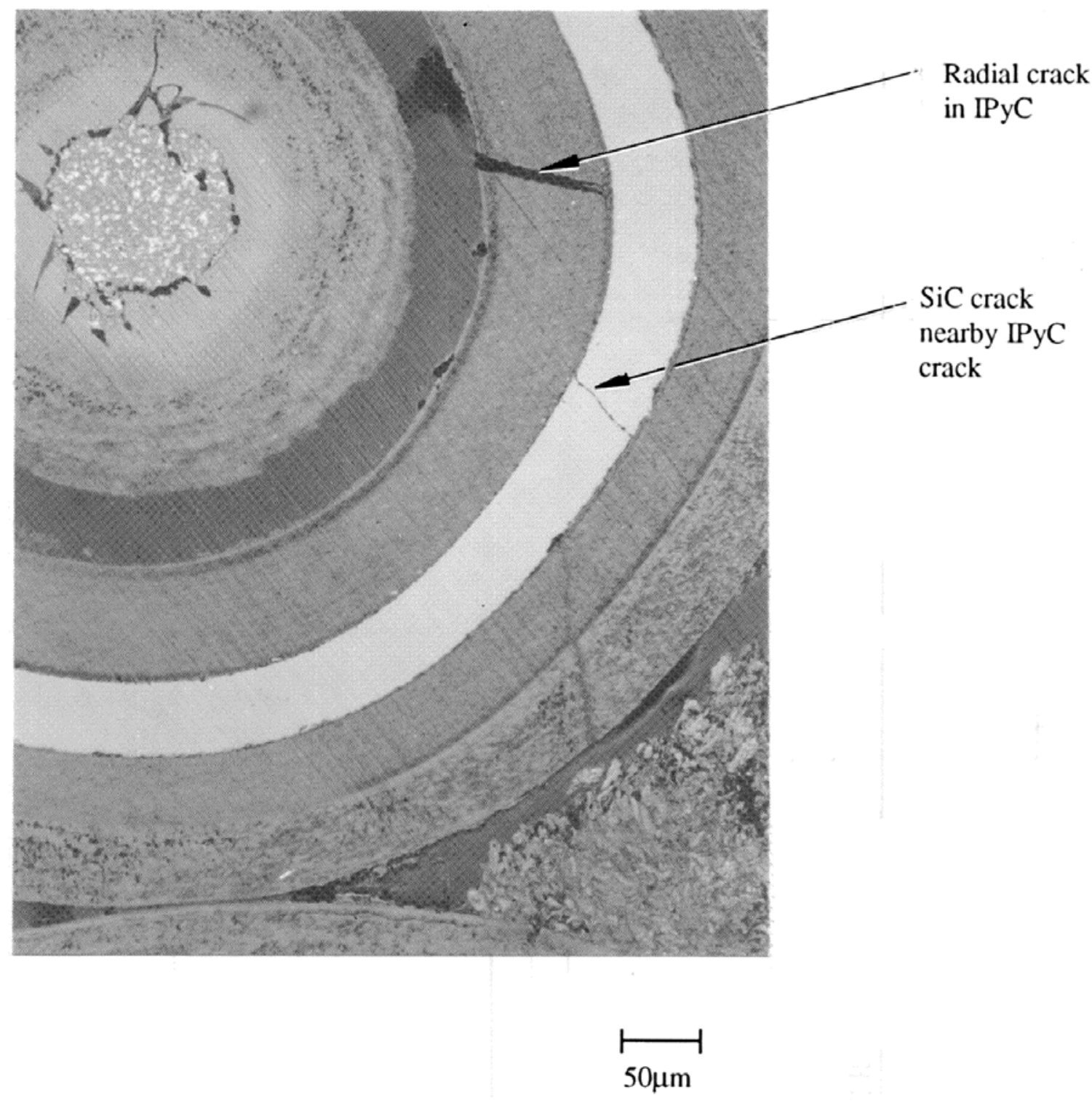

Figure 5-4. Radial cracks in the $\mathrm{SiC}$ were usually near a crack in the IPyC. The IPyC was generally in contact with the SiC except at the location of the crack in the IPyC. $\left(3.7 \times 10^{25} \mathrm{n} / \mathrm{m}^{2}\right.$, 79\%FIMA, $\left.746^{\circ} \mathrm{C}\right)$. 


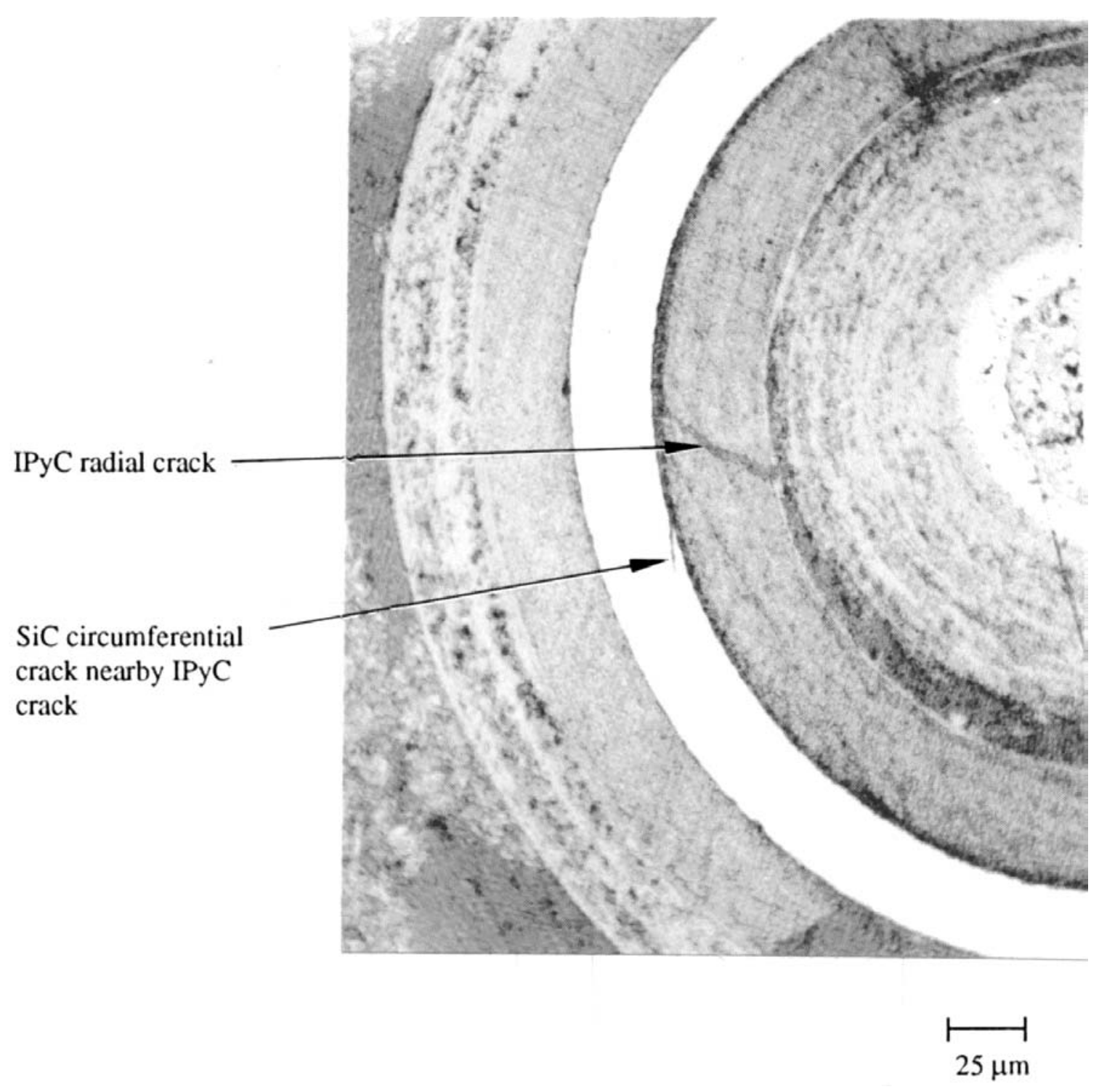

Figure 5-5. Small circumferential cracks on the inside surface of the $\mathrm{SiC}$ layer. $\left(3.7 \times 10^{25} \mathrm{n} / \mathrm{m}^{2}\right.$, $79 \%$ FIMA, $746^{\circ} \mathrm{C}$.) 


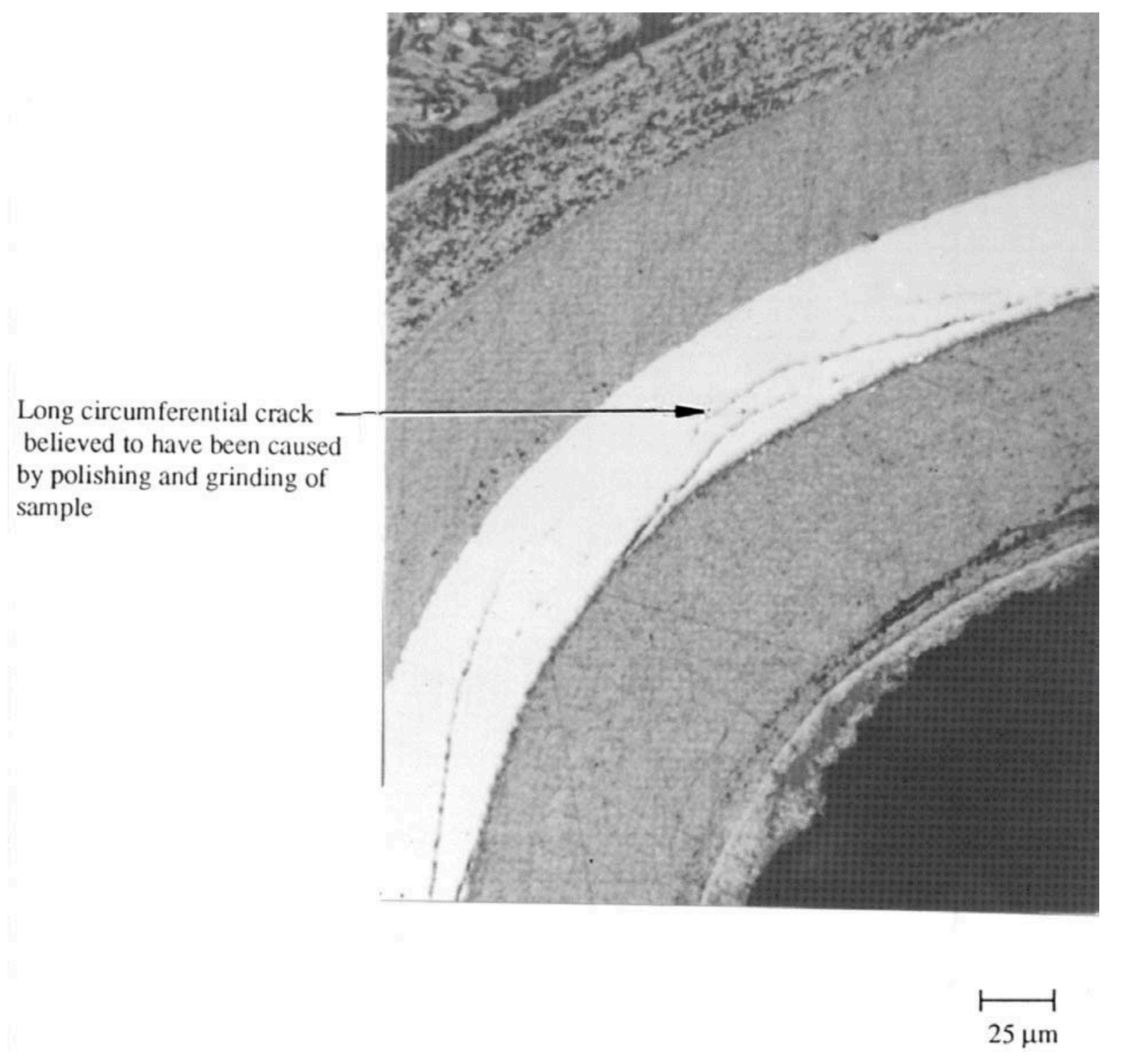

Figure 5-6. Large circumferential cracks in SiC. $\left(2.3 \times 10^{25} \mathrm{n} / \mathrm{m}^{2}, 73 \% \mathrm{FIMA}, 845^{\circ} \mathrm{C}\right.$.) 


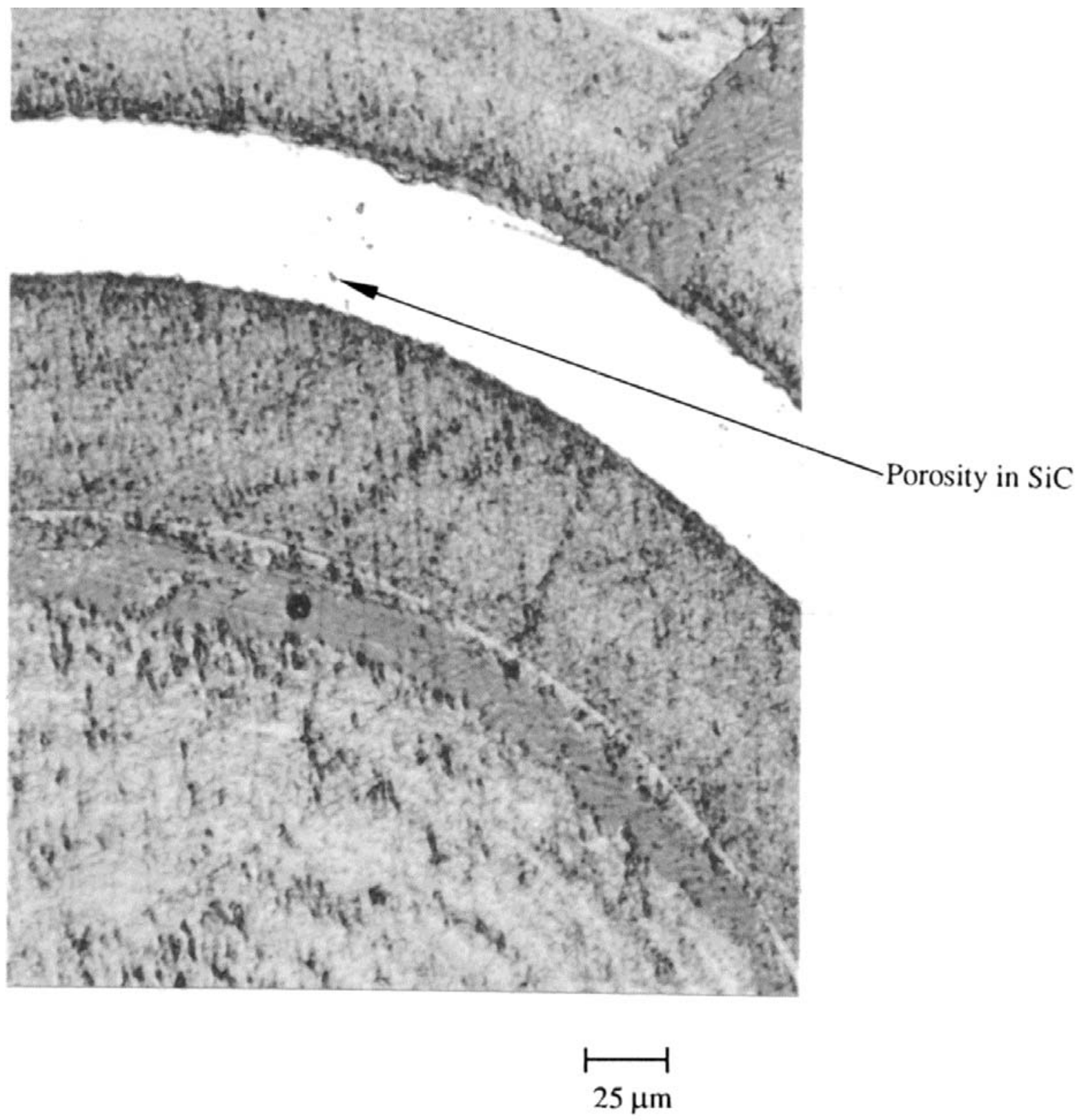

Figure 5-7. Porosity in SiC. $\left(3.7 \times 10^{25} \mathrm{n} / \mathrm{m}^{2}, 79 \%\right.$ FIMA, $806^{\circ} \mathrm{C}$.) 


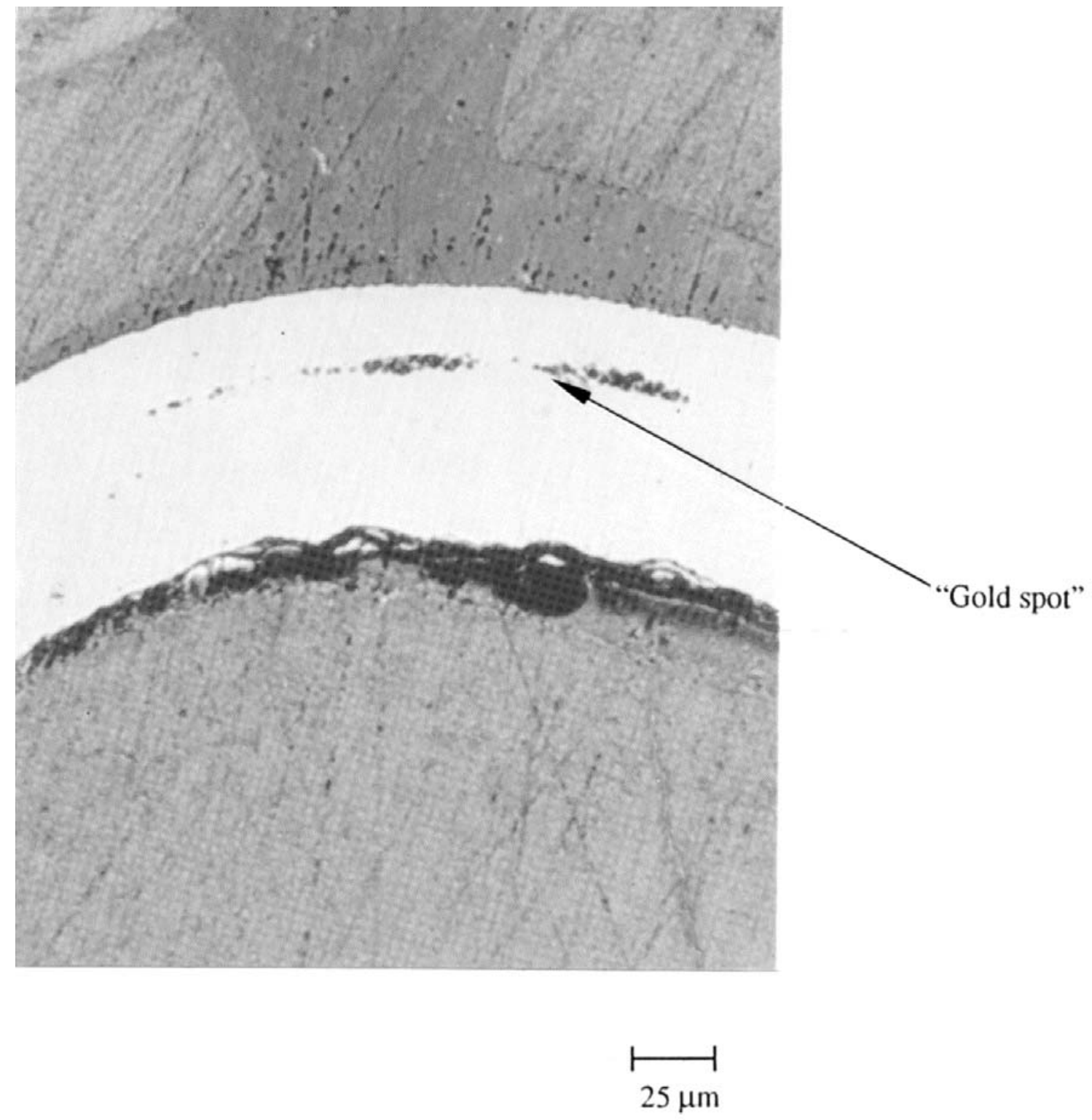

Figure 5-8. Lenticular flaws (gold spots) in SiC. $\left(3.7 \times 10^{25} \mathrm{n} / \mathrm{m}^{2}, 79 \% \mathrm{FIMA}, 987^{\circ} \mathrm{C}\right.$.) 
Coating layer failure statistics gathered from metallographic examinations of compact cross sections are presented in Table 5-3 as a function of neutron fast fluence. These data indicate that PPyC failures are uniformly very high (85 to $100 \%$ ) at fluences above $1.9 \times 10^{25} \mathrm{n} / \mathrm{m}^{2}$. Over this same range of fluence, OPyC failures were 47 to $90 \%$, IPyC failures were 9 to $65 \%$, and $\mathrm{SiC}$ failures were 0 to $3 \%$. The much higher failure rates of the PyC layers, compared with $\mathrm{SiC}$, suggest that the occurrence of failed SiC without failed IPyC or OPyC is unlikely (in fact, none were observed in metallography) and that measurements of the fraction of particles with exposed kernels and the fraction of particles with failed SiC should be nearly identical (in agreement with results in Table 5-2).

Table 5-3. Coating layer failures measured by metallography of compact cross sections.

\begin{tabular}{|c|c|c|c|c|c|}
\hline $\begin{array}{c}\text { Compact/ } \\
\text { segment }\end{array}$ & $\begin{array}{c}\text { Fast fluence } \\
\left(10^{25} \mathrm{n} / \mathrm{m}^{2}\right)\end{array}$ & $\begin{array}{c}\text { PPyC failure } \\
(\%)\end{array}$ & $\begin{array}{c}\text { OPyC failure } \\
(\%)\end{array}$ & $\begin{array}{c}\text { IPyC failure } \\
(\%)\end{array}$ & $\begin{array}{c}\text { SiC failure } \\
(\%)\end{array}$ \\
\hline NPR-1 A8/1 & 2.3 & 85 & 71 & 9 & 0 \\
NPR-1 A8/2 & 1.8 & 16 & 5 & 0 & 0 \\
NPR-1 A5 & 3.7 & 100 & 90 & 30 & 1 \\
NPR-2 A4 & 3.7 & 92 & 67 & 65 & 3 \\
NPR-1A 9 & 1.9 & 100 & 47 & 18 & 1 \\
\hline
\end{tabular}




\subsection{Fission Product Distribution}

Scanning electron microscopy was a useful, but time consuming tool for the investigation of the distribution of fission product elements throughout the irradiated fuel particle, including fission product chemical attack of SiC. Consequently, this technique was only applied to a few carefully selected particles.

The distribution of fission products through particle coating layers was measured by scanning electron microscope using energy dispersive and wavelength-despersive spectroscopy. Four individual fuel particles from high exposure (fast fluence of $3.7 \times 10^{25} \mathrm{n} / \mathrm{m}^{2}$ ) compacts from capsule NPR-1 were examined. Two of the particles had been determined by IMGA to be retentive of cesium and two were determined to be non-retentive. The particles were individually mounted and ground to remove most or all of the kernel, thereby reducing the radioactivity and allowing examination on an unshielded electron microscope.

Cesium, cerium, and barium were found outside the kernel in the buffer and IPyC in retentive particles, and perhaps, at a low level in the $\mathrm{SiC}$ of non-retentive particles. Although the majority of the cerium and barium remains in the kernel, the migration of these materials into the IPyC has been observed previously (Minato et al., 1994). Figure 5-9 shows the distribution of cesium, cerium, and barium in a non-retentive particle in which a small portion of the kernel remains. Palladium was occasionally observed to concentrate at the $\mathrm{IPyC} / \mathrm{SiC}$ interface, as is shown in a cross section of a retentive particle in Figure 5-10. In no case were fission products found to concentrate at defects in the $\mathrm{SiC}$, such as at gold spots or cracks. 


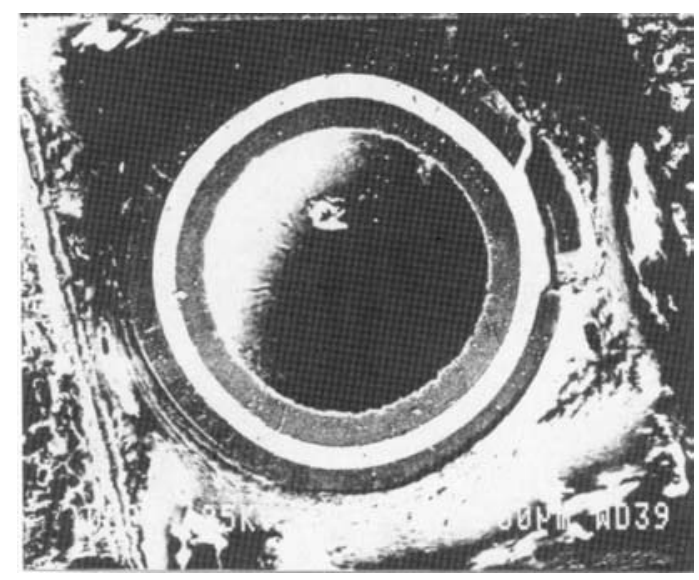

a.

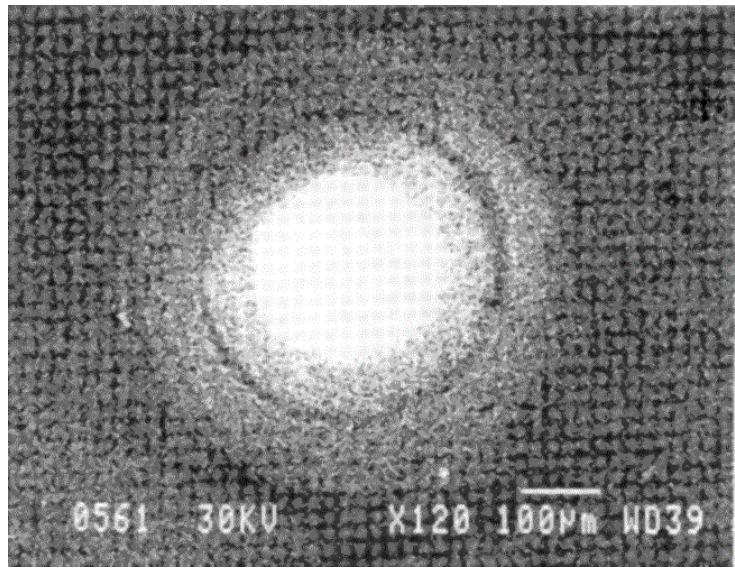

c.

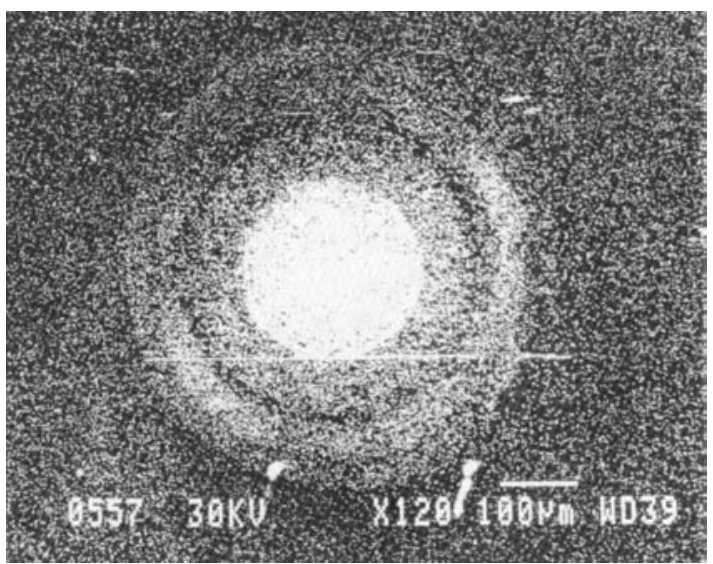

b.

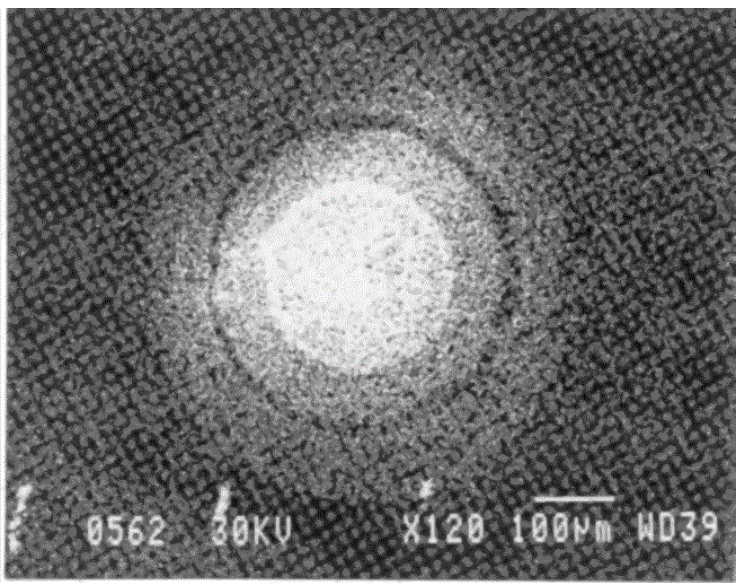

d.

Figure 5-9. a. Secondary electron image of a non retentive particle containing a portion of the fuel kernel $\left(3.7 \times 10^{25} \mathrm{n} / \mathrm{m}^{2}, 79 \%\right.$ FIMA, $\left.987^{\circ} \mathrm{C}\right)$. b. Cesium distribution in the kernel, buffer, $\mathrm{IPyC}$, and $\mathrm{SiC}$. c. Cerium distribution in the kernel, buffer, IPyC, and $\mathrm{SiC}$. d. Barium distribution in the kernel, buffer, IPyC, and SiC. 


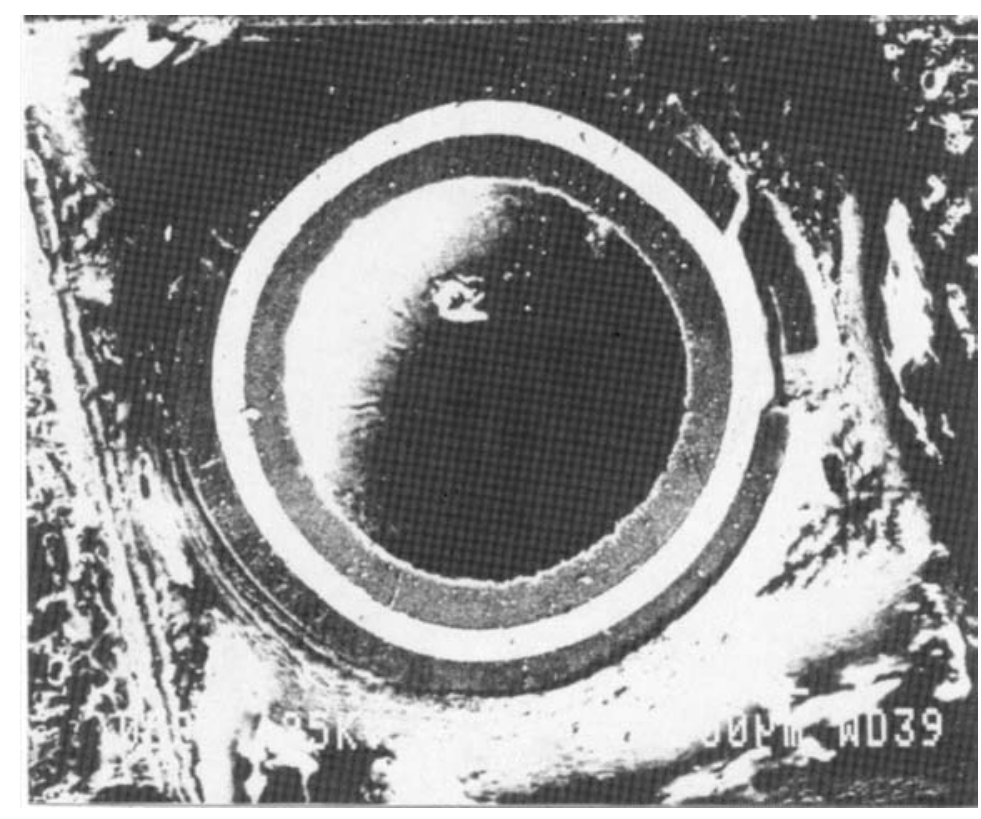

$\mathbf{a}$

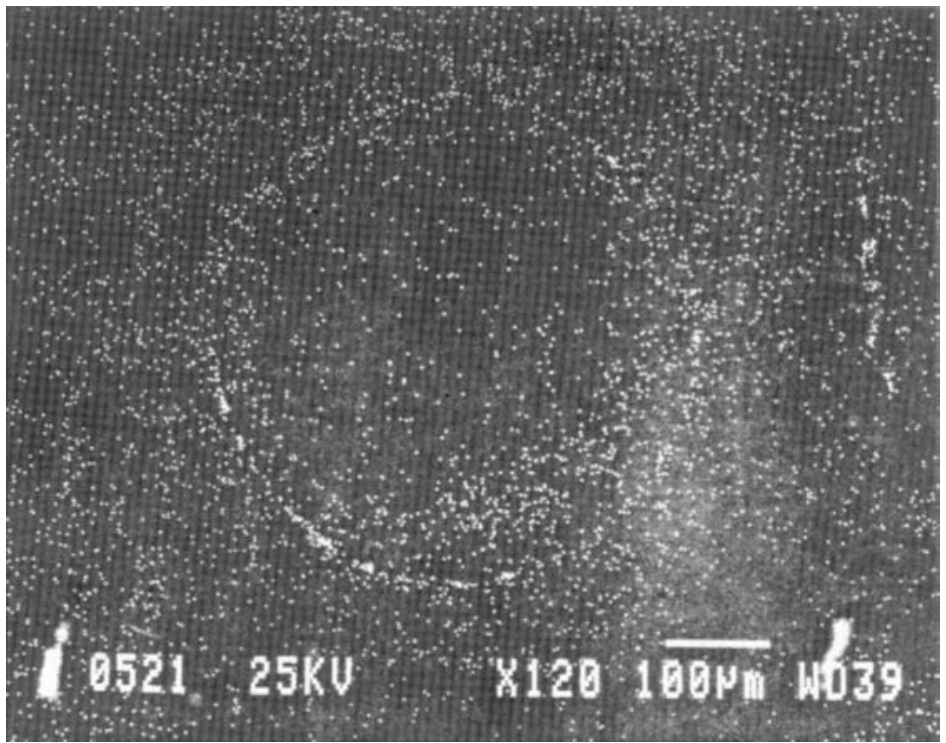

Figure 5-10. a. Secondary electron image of a retentive particle without kernel and buffer (3.7 $\mathrm{x} 10^{25} \mathrm{n} / \mathrm{m}^{2}, 79 \%$ FIMA, $987^{\circ} \mathrm{C}$ ). b. Palladium accumulation at the IPyC/ $\mathrm{SiC}$ interface 


\section{MOST PROBABLE CAUSES OF FUEL PARTICLE FAILURE}

Evidence from as-manufactured characterization, irradiation, and postirradiation examination data indicates that irradiation-induced changes in material properties of the pyrocarbons played a dominant role in the failure of fuel particles to retain fission gases. First, the as-manufactured particle characterization data indicate that the level of as-manufactured defects in the SiC prior to irradiation $\left(4 \times 10^{-4}\right)$ was two orders of magnitude too low to account for the level of particle failures (up to $4 \times 10^{-2}$ in high fluence compacts) inferred from in-reactor fission gas release and measured in the postirradiation examination. Introduction of percent level $\mathrm{SiC}$ defects during compact fabrication was unlikely, based on burn leach tests that detected only $3 \times 10^{-6}$ fraction at the compact stage and $2 \times 10^{-3}$ fraction measured postirradiation by IMGA in moderate fluence compacts. Second, the particle failures were a strong function of neutron fast fluence, as evidenced by the increase in in-reactor fission gas release with irradiation time. Third, IMGA data indicates cesium release from fuel particles was a function of both fast neutron fluence and irradiation temperature. Fourth, fission gas release data from postirradiation TRIGA testing indicate fuel particle failure strongly depended on fast neutron fluence and less strongly depended on irradiation temperature.

These observations are in accordance with the well-known behavior of pyrocarbons, i.e., pyrocarbons undergo dimensional changes with fast neutron fluence, sometimes leading to failure of coating layers, depending in starting density and isotropy (Kaae, 1975). In contrast, SiC is relatively stable under neutron irradiation (Price, 1977). The experimental evidence strongly implicates irradiation-induced changes in the pyrocarbon layers as having played a leading role in the NP-MHTGR fuel particle failures. Direct observation by metallography in the PIE confirmed the large-scale failure of pyrocarbon layers and the fluence dependence of these failures.

The PPyC is expected to shrink and fail early under irradiation and widespread PPyC failure (85 to $100 \%$ above a fluence of $1.9 \times 10^{25} \mathrm{n} / \mathrm{m}^{2}$ ) was measured by metallography. The OPyC is also expected to shrink under irradiation, but the extent of OPyC failure observed above $1.9 \times 10^{25}$ $\mathrm{n} / \mathrm{m}^{2}(47-90 \%)$ was unexpected and is mostly likely attributable to crack propagation from the PPyC. The inner seal coat between the PPyC and the OPyC was expected to separate the two layers and prevent crack propagation. However, the seal coat acted as a strong bond and facilitated crack propagation. 
The IPyC layer was thicker, denser, and more anisotropic than the OPyC layer and was constrained on its outer dimension by the SiC. These factors led to a calculation of $40 \%$ probability of IPyC failure at high fluence. IPyC failure was widespread (18 to 65\%) at fluences above $1.9 \times 10^{25} \mathrm{n} / \mathrm{m}^{2}$, but was less extensive than $\mathrm{OPyC}$ failure. IPyC failure was most likely a result of irradiation-induced shrinkage.

The irradiation-induced failures of the pyrocarbon layers suggest three possible SiC failure mechanisms for which evidence was found in the NP-MHTGR fuel irradiations. Two of these mechanisms are mechanical in nature and one is chemical/ mechanical. It must be acknowledged that the limited postirradiation examinations conducted on the NP-MHTGR fuel cannot eliminate the possibility that other, as yet identified, failure mechanisms could exist.

The most probable of the causes identified was mechanical failure of the $\mathrm{SiC}$ induced by the concentration of tensile stresses in the $\mathrm{SiC}$ in the vicinity of cracks in the IPyC, where an IPyC layer was apparently strongly bonded to the $\mathrm{SiC}$. In compact metallography IPyC failures were observed without $\mathrm{SiC}$ failures, but all through-wall cracks in the $\mathrm{SiC}$ were found to be in the vicinity of the IPyC cracks. Metallographic evidence could not determine the strength of the bond between the IPyC and the SiC, but only that contact existed. However, in crush strength tests on unirradiated fuel particles, it was observed that the IPyC layer (but not the OPyC layer) remained attached to the $\mathrm{SiC}$ layer after the particles had been broken.

Preliminary analyses show that large concentrations of tensile stresses are possible in the SiC adjacent to cracks in an IPyC layer, which is strongly bonded to the $\mathrm{SiC}$ layer. The analyses indicate that, because of the singularity at the crack tip, the magnitudes of the stresses and the failure probability calculated depend on the fineness of the finite element mesh. This preliminary evaluation concluded that fracture analysis is required to quantify the stresses around the crack tip and to assess the potential for crack propagation through the SiC coating. However, the preliminary analysis also indicates that the probability of SiC failure by this mechanism was five times greater when the $\mathrm{OPyC}$ had failed than when it was intact.

In addition to the most probable cause identified above, there are two additional mechanisms that could have contributed to the fuel particle failures found in the NP-MHTGR irradiations, one mechanical and one chemical/ mechanical. Crush-strength measurements of unirradiated NPMHTGR fuel particles (obtained from the burning of compacts) have produced some evidence of 
a population of weak $\mathrm{SiC}$ layers. Analyses indicate that the weak particles, making up the tail $(\sim 1 \%)$ of the distribution of particle strengths, could fail from fission product over pressure, given failure of both the OPyC and IPyC layers. However, no observed examples of multiple fracturing of $\mathrm{SiC}$ suggest that $\mathrm{SiC}$ bursting caused by over pressure was probably not a major failure mechanism in these irradiations.

The third mechanism was primarily chemical but also required the irradiation-induced failure of the IPyC layer. Some evidence of porosity in the $\mathrm{SiC}$ layer was observed in the postirradiation metallography of NP-MHTGR particles determined by IMGA to be deficient in cesium.

Analyses indicate that $\mathrm{CO}$ produced at high burnups (>75\%FIMA) in kernels whose initial composition was below the desired 15 mole percent of $\mathrm{UC}_{2}$ could cause corrosion of $\mathrm{SiC}$. This mechanism was limited by the fraction of particles having $\mathrm{UC}_{2}$ contents less than $15 \%$ (measured to be $1.5 \%$ ) that were also at high burnup and had fractured IPyC. Corrosion of SiC by CO has been found to exhibit strong local grain boundary attack and pitting of the SiC (Minato et al, 1991) rather than the minor porosity observed in the metallography of the NP-MHTGR fuel. These differences cast doubt on the likelihood of the CO corrosion mechanism as a contributor to $\mathrm{SiC}$ failure in the NP-MHTGR irradiations. 


\section{RECOMMENDATIONS FOR FUTURE MHTGR FUEL DEVELOPMENT}

The NP-MHTGR program demonstrates that fuel can be designed and fabricated to meet requirements for as-manufactured fuel quality that are much more stringent than those required of past HTGR fuel used successfully in U.S. reactors (300 times more stringent than the requirements for Fort St. Vrain fuel, despite there being a containment in the NP-MHTGR design). However, the design changes intended to meet these new as-manufactured quality requirements did not change fuel particle integrity under irradiation. The NP-MHTGR fuel, as tested, was capable of meeting all safety requirements for normal operations. Nonetheless, the goals of a passively safe and very clean NP-MHTGR led the program to pursue better fuel performance. The authors recommend further development in the following areas.

Future MHTGR fuel development should first set requirements for as-manufactured fuel quality and in-service fuel integrity under normal and accident conditions that meet safety requirements with reasonable margin, taking into account all the applicable safety features of the reactor design in addition to the fuel itself. Then, the development program should focus on designing, fabricating, and demonstrating the performance of fuel that maintains its required integrity during irradiation, while meeting acceptable as-manufactured quality requirements. For example, use of a containment should enable the relaxation of some of the requirements for as-manufactured fuel quality and in-service fuel performance, keeping in mind, however, requirements for maintainability and exposure to reactor personnel.

Measurement of the microstructural, impurity, and strength characteristics of SiC coatings in PTF and German fuel in the NP-MHTGR program revealed no difference that should lead to vastly different integrity of this layer under irradiation. It appears, therefore, that the $\mathrm{SiC}$ layer fabricated in the NP-MHTGR program was, in itself, capable of maintaining adequate integrity under irradiation. Decreasing the grain size of the $\mathrm{SiC}$ to be closer to that in the German $\mathrm{SiC}$ may be marginally beneficial in terms of reducing fission product diffusive release and improving strength. However, the principal recommendation is that future MHTGR fuel development programs should concentrate on other aspects of the fuel particle design to seek improved particle integrity under irradiation. 
The principal fuel particle failure mechanism, identified by the postirradiation examination of compacts irradiated in the NP-MHTGR program and subsequent stress analysis of the layers, was the cracking of $\mathrm{SiC}$, induced by shrinkage cracks in the IPyC, the OPyC having to a large extent, failed earlier. The failure of the $\mathrm{OPyC}$ was caused by crack propagation from the PPyC through its inner seal coat. Future MHTGR fuel development programs should eliminate the PPyC and its seal coats. The PPyC was a new feature of the NP-MHTGR fuel designed to reduce SiC breakage during compacting. This design change was successful in improving as-manufactured fuel quality, but caused increased OPyC failure under irradiation. The inner seal coat was supposed to prevent crack propagation from the PPyC to the $\mathrm{OPyC}$, but it did not perform this function. Future MHTGR fuel development programs will need to improve compacting conditions such as matrix chemistry and impurity control, as well as injection pressure and curing requirements to minimize particle damage during compacting.

The IPyC failed from excessive irradiation-induced shrinkage, probably caused by a higher degree of anisotropy, (associated with reduced permeability) and greater thickness designed to reduce uranium chemical reaction with corrosive gases during $\mathrm{SiC}$ coating. Again, the design change performed its function of improving as-manufactured fuel quality, but led to enhanced coating layer failure under irradiation. Stress analysis indicates that both the thicker IPyC and early OPyC failure increase the likelihood of $\mathrm{SiC}$ failure upon failure of the $\mathrm{IPyC}$, which was well bonded to the SiC. Future MHTGR fuel development should return to the customary $35 \mu \mathrm{m} \mathrm{IPyC}$ layer thickness used historically in the United States and Germany from the $50 \mu \mathrm{m}$ thickness used in the NP-MHTGR design. Additionally, future development in this area should seek to improve the isotropy of this layer, and also that of the $\mathrm{OPyC}$ layer to reduce the probability of failure of these layers under irradiation. Future programs will need to consider other means, such as reduced $\mathrm{SiC}$ coating temperature, to minimize reaction with uranium during $\mathrm{SiC}$ coating. Future fuel development programs should review the benefits and detriments associated with a strong bond between the IPyC and the SiC. It may not be easy to avoid strong bonding, and an experimental study in the Dragon Program (Voice, 1974) recommends strong bonding between these layers.

It appears that future MHTGR fuel development programs would benefit by considering the performance of the entire system of coating layers in the TRISO design with respect to particle integrity under irradiation. Stress analysis indicates that intact $\mathrm{PyC}$ layers provide a significant benefit to $\mathrm{SiC}$ integrity by maintaining compressive stresses on both the ID and OD surfaces of 
the $\mathrm{SiC}$. It is necessary for the $\mathrm{IPyC}$ to be bonded to the $\mathrm{SiC}$ to provide compressive stress on the inner surface of the $\mathrm{SiC}$. However, it is not necessary for the $\mathrm{OPyC}$ to be bonded to the $\mathrm{SiC}$ to maintain the $\mathrm{SiC}$ in compression. It is likely that more attention to the properties of PyC layers to resist failure by irradiation-induced shrinkage would result in improved fuel irradiation performance relative to that achieved in the NP-MHTGR program.

We recommend that mechanistic modeling studies be performed early in the re-design of the fuel particle to explore design alternatives, better understand fission product transport, and add confidence that the fuel will perform as required. It is likely that improvements to models of coating layer performance, including the mechanical properties of $\mathrm{PyC}$ layers as a function of fluence and irradiation temperature, will be required.

Whatever the design changes that may be investigated by future programs, we recommend, based on the exploratory process development portion of the NP-MHTGR program, that a statistically designed exploratory process improvement program be implemented to ensure the achievement of optimum coating conditions leading to the desired coating characteristics and reproducible results. SiC characterization, perhaps based on the methylene iodide work done by the NPMHTGR program, needs to be expanded so that fabrication process problems can be identified and coupled with irradiation performance.

Results from attempts to improve the methods for the measurement of SiC defects in asmanufactured fuel were not successful in the NP-MHTGR program. Furthermore, none of the methods was capable of predicting in-reactor particle failure. Future MHTGR fuel development programs should reconsider what properties of the fuel particles and compacts should be characterized by quality assurance measurements and whether the results of such measurements can reasonably be expected to predict in-reactor performance.

Design alternatives should be tested under irradiation, employing adequate postirradiation examination to identify early on the strengths and weaknesses of various approaches to fuel improvement, and to develop an understanding of the relationship between the measurable characteristics of the as-manufactured fuel and the irradiation behavior. Future irradiation capsules need to be based on statistical validation of performance models, at the least a factorial design to fully cover core conditions. 
A number of lessons were learned about the effectiveness of various techniques for examining irradiated MHTGR fuel during the postirradiation examination conducted under the NP-MHTGR program. It was discovered that TRIGA fission gas release measurements were a good indicator of the relative failure fraction of particles (bare kernels) from compact to compact within an irradiation capsule. The technique, however, produced absolute values that were high by a factor of 4 to 80 , relative to measurements of particle failure fraction from in-reactor fission gas release (both gamma spikes and noble gas R/B), irradiated microsphere gamma analysis (IMGA), leachburn-leach, and compact metallography. IMGA provided results on SiC failure fraction in reasonable agreement with results from optical metallography and leach-burn-leach. Optical metallography of compacts requires skillful and painstaking sample preparation and photo microscopy, but was essential in determining failure modes of particle coating layers. Scanning electron microscopy using energy dispersive spectrometry and wave length spectrometry is a useful tool for examining a limited number of fuel particle cross sections, especially failed particles, for evidence of fission product migration within coating layers and fission product or chemical attack on SiC.

There is a need to develop efficient techniques for postirradiation measurements of the fraction of exposed kernels and particles with failed SiC. Gas release measurements by reactivating short lived fission gases at elevated temperature (performed in a King furnace in a TRIGA reactor) is a sensitive and reasonably cost effective technique, but the absolute magnitude of the results are uncertain and the availability of reactor facilities capable of this measurement in the future is uncertain. Both the absolute magnitude of the results and the availability of a facility for activation of short-lived fission gases must be addressed if this technique is to be used in the future. IMGA provides a good measure of the fraction of particles with failed $\mathrm{SiC}$, but the technique is relatively slow and expensive. The leach-burn-leach technique shows promise for the measurement of both exposed kernels and failed SiC, but concerns about sensitivity of the technique (especially as fuel performance improves) and corrosion of SiC need to be addressed by future development.

Finally, core fuel management studies that reduce peak-to-average values for burnup, fluence, and temperature should be pursued. Preliminary studies indicate that a $100^{\circ} \mathrm{C}$ decrease in peak fuel temperature, and a $20 \%$ decrease in peak fluences are achievable without affecting core economics and average burnup. Further work in this area, coupled with a greater understanding of the fuel performance drivers, should reveal considerable performance margins. 


\section{REFERENCES}

Baldwin, C.A. et al., 1993, "The New Production Reactor Fuel Post Irradiation Examination Data Report for Capsules NPR 1, NPR 2, and NPR 1A”, ORNL/ M-2849.

Kaae, J.L., 1975, “Irradiation-Induced Microstructural Changes in Isotropic Pyrolytic Carbons, ” Journal of Nuclear Materials, Vol. 57, pp. 82.

Kovacs et al., 1985, "High Temperature Gas-Cooled Reactor Fuel Pressure Vessel Models," Nuclear Technology, Vol. 68.

Lessing, P.A., 1993, Strength Testing of NPR Fuel Particles: Final Report, Idaho National Engineering Laboratory, Report EGG-NPR-11014.

McCardell, R.K., et al., 1992, NP-MHTGR Fuel Development Program Plan, Idaho National Engineering Laboratory, Report EGG-NPR-8971 (Revision C)

Martinson, Z.R., et al., 1993, “Test NPR-1A Results Report”, EDF-NPR-MHTGR-0656.

Minato, K., et al., 1991. "Carbon Monoxide-Silicon Carbide Interaction in HTGR Fuel Particles," Journal of Material Sciences, Vol. 26, pp. 2379.

Minato, K., et al., 1994, "Fission Product Behavior in TRISO-Coated $\mathrm{UO}_{2}$ Fuel Particles", Journal Nuclear Material, Vol. 208, pp. 266.

Olander, D.R., 1976, Fundamental Aspects of Nuclear Reactor Fuel Elements, TID-26711-P1. Price, R. J., 1977, "Properties of SiC for Nuclear Fuel Particles Coating, Nuclear Technology," Vol. 35, pp. 320,

Voice, E.H., 1974, Results from Some Recent Fuel Coating Irradiations, “ Dragon Report DP-866 (February). 